\title{
IV. Der Ausschluß bedürftiger Juden aus der Öffentlichen Wohlfahrt
}

\section{Die zentrale Neuorientierung der Verfolgung (Herbst 1938 - Winter 1938/1939)}

\section{Die Gewaltaktionen und die jüdische Fürsorge}

Seit September 1938 ging die NS-Führung zu noch radikaleren antijüdischen Verfolgungsplänen über, da sie während der "Sudetenkrise" mit dem Ausbruch eines Krieges rechnete. Nun zielte man nicht mehr nur auf Beraubung und Vertreibung, sondern auf die totale Separierung der jüdischen Bevölkerung in der deutschen Gesellschaft. Über Arbeitszwang und Ghettoisierung diskutierte nicht nur die Sicherheitspolizei, sondern auch die Ministerialbürokratie. ${ }^{1}$ Bereits am 14. Oktober 1938 fand bei Ministerpräsident Göring eine erste große Konferenz zur Koordination von Judenverfolgung und Kriegsvorbereitung statt. Göring kündigte offen an, die „Judenfrage“ jetzt mit allen Mitteln lösen zu wollen. Er erklärte allerdings zugleich, keinerlei Devisen zur Finanzierung einer Massenemigration bereitstellen zu wollen. Damit war der einzige legale Weg einer raschen Vertreibung versperrt. Wenn die Austreibungspolitik scheitere, schlußfolgerte Göring lapidar, müsse man eben "Ghettos in den einzelnen Großstädten“ einrichten.?

Mit der Preisgabe der „Sudetengebiete“ durch die Westmächte war Deutschland Anfang Oktober 1938 im internationalen Kräfteverhältnis zwar noch einmal gestärkt, ein Krieg aber nur kurzzeitig abgewendet worden. Bis zu der für das kommende Frühjahr geplanten Annexion des tschechischen Reststaates sollten nach dem Willen der NS-Führung die Juden aus dem deutschen Herrschaftsbereich vertrieben sein. Nicht nur ideologische Befürchtungen vor einem neuen Dolchsto $\beta^{3}$ und das absehbare Ende der bisherigen Vertreibungspolitik mit der Sperrung aller Grenzen im Kriegsfall, sondern auch konkrete Sozialanalysen beförderten diese Überlegungen. In einem internen Lagebericht hatte das SD-Judenreferat eingeschätzt, daß aufgrund der aus den neuen Verfolgungsmaßnahmen resultierenden Finanzschwäche der Jüdischen Gemeinden es „bald in einigen Gebieten des Reiches fast unmöglich wird, die Fürsorgeunterstützten weiter zu unterhalten. Das bedeute für die Zukunft eine Zunahme des jüdischen Proletariats und eine enorme Belastung der öffentlichen Fürsorge, wenn nicht die beschäfti-

\footnotetext{
Ausführlicher dazu Gruner, NS-Judenverfolgung und die Kommunen, S. 102-103.

IMT, Bd. XXVII, Dok. PS-1301, S. 160-164: Besprechung bei Göring am 14. 10. 1938.

Sowohl das Ende jeder Migration schien gefährlich als auch das Verbleiben hunderttausender Juden, die die „innere Front" schwächen würden; Pätzold, Verfolgung, S. 144; Burrin, Hitler und die Juden, S. 35.
} 
gungslosen Juden durch die Auswanderung aus dem Reichsgebiet entfernt werden können". ${ }^{4}$

Einziger Ausweg aus der selbstgeschaffenen Situation schien die Anwendung von Gewalt. Diese Option nahm Hitler, hierin offensichtlich von Goebbels und der Sicherheitspolizei unterstützt, nun in radikalem Stil wahr. Mit einer Massenrazzia in den deutschen Städten verhaftete man Ende Oktober 17000 Juden polnischer Staatsangehörigkeit und deportierte sie unter Zurücklassung ihres Eigentums an die polnische Grenze. ${ }^{5}$ Hitler erkundigte sich genauestens bei der Sicherheitspolizei über den „Erfolg“ der Gewaltaktion, d.h. die Zahl der „Abgeschobenen “. ${ }^{6}$ Oft mußten jüdische Wohlfahrtsstellen während der Aktion helfend eingreifen, ob durch Notversorgung der Abzutransportierenden wie in Hannover ${ }^{7}$ oder durch die spätere Unterbringung der wegen der geschlossenen Grenze Zurückkehrenden. In Frankfurt am Main brachten jüdische Stellen die unerwarteten Rückkehrer, deren Wohnungen längst versiegelt waren, in Massenquartieren wie Schulen und Heimen unter und versorgten sie mit Lebensmitteln und medizinischer Hilfe. ${ }^{8}$

Das Attentat auf einen deutschen Botschaftsangestellten in Paris genügte wenige Tage später, um mit Terror nun gegen sämtliche Juden im Großdeutschen Reich vorzugehen. Hitler entschied am Abend des 9. November 1938 in München persönlich, daß diese jetzt „den Volkszorn zu verspüren bekommen“, und auf welche Weise dieser organisiert werden sollte. Dauerte das Pogrom ${ }^{9}$, die Zerstörungen und Morde, "nur" eine Nacht und einen Tag, so verhaftete auf Anweisung Hitlers die Polizei noch eine Woche später allerorten jüdische Männer, insgesamt wohl über 30000, und brachte sie in Konzentrationslager, um ihre Emigration zu erzwingen. ${ }^{10}$

Seit den Novembertagen wurden die Geschicke der Jüdischen Gemeinden im Reich von der lokalen Gestapo strenger als je zuvor kontrolliert, zum Teil auch direkt gesteuert. ${ }^{11}$ Das Pogrom hatte zudem die soziale Infrastruktur jüdischer

4 YV Jerusalem, 051/OSOBI, Nr. 47 (500-3-317), unfol.: Lagebericht des SD-Judenreferats für August vom 8. 9. 1938, S. 9.

5 Zur Einschätzung der meist nur nebenbei erwähnten Razzia vgl. Herbert, Ulrich: Best. Biographische Studien über Radikalismus, Weltanschauung und Vernunft 1903-1989, 2. durchges. Aufl., Bonn 1996, S. 217-218.

6 BA, ZwA Dahlwitz-Hoppegarten, ZA 1, Nr. 7358, A.3, unfol.: FS Gestapo NürnbergFürth (Dr. Heigl) an IdS München vom 8. 11. 1938.

7 Vgl. Gruner, Berichte, S. 307.

8 Vgl. Dokumente Frankfurter Juden, VI 25, S. 295: Ralph Bergel „Die Jüdische Wohlfahrtspflege 1933-1939“ (1961).

9 Zum Pogrom vgl. Pehle, Walter H. (Hrsg.), Der Judenpogrom 1938, Frankfurt am Main 1988; Pätzold, Kurt/Runge, Irene: Pogromnacht 1938, Berlin 1988; Obst, Dieter: „Reichs-

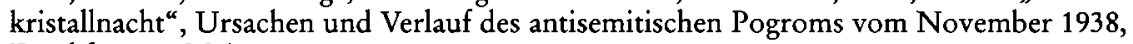
Frankfurt am Main u. a. 1991.

$10 \mathrm{Zu}$ den direkten Anweisungen Hitlers vgl. Goebbels, Joseph: Die Tagebücher von Joseph Goebbels. Im Auftrag des Instituts für Zeitgeschichte und mit Unterstützung des Staatlichen Archivdienstes Rußlands, hrsg. von Elke Fröhlich, München 1998, Bd. 6, S. 180: Eintrag vom 10.11. 1938. Zur enormen Bedeutung der Massenverhaftungen vgl. Herbert, Best, S. 219.

11 In Hamburg löste die Gestapo im November 1938 das Repräsentantenkollegium auf, 
Einrichtungen weitgehend lahmgelegt. An vielen Orten konnte die jüdische Wohlfahrtspflege den Hilfsbedürftigen oder Entlassenen nicht mehr helfen, da Mittel und Räumlichkeiten von den Behörden beschlagnahmt, Gemeindezentren, Kleiderkammern und Wohlfahrtsküchen zerstört, Sachen, Lebensmittel, Gelder geraubt und Gemeindeangestellte sowie das Fürsorgepersonal in Konzentrationslager verschleppt worden waren. ${ }^{12}$ In Frankfurt am Main konfiszierte die lokale NSDAP das Haus Königswarterstraße, das die Jüdische Wohlfahrtspflege, die Jüdische Notstandsküche, die Jüdische Winterhilfe und die Beratungsstelle für Wirtschaftshilfe beherbergte. Die Arbeit dieser Stellen endete damit auf einen Schlag. Die Frankfurter NSV „übernahm“ das Kleiderdepot der Jüdischen Winterhilfe. Die Gestapo beschlagnahmte Kleider- und Wäschelager der jüdischen Fürsorgestellen, die Konten des Jüdischen Krankenhauses sowie mit Hilfe der lokalen Handelskammer die Lebensmittel der Jüdischen Winterhilfe. ${ }^{13}$ Noch im Monat November entschied die Kommune, daß für eine Überbrückungsphase das städtische Fürsorgeamt die jüdischen Einrichtungen, d.h. Heime und Fürsorgestellen, stellvertretend leiten werde. Sowohl die örtliche NSV als auch die Gestapo votierten für dieses Verfahren. Um einen Überblick über die Mittel der jüdischen Wohlfahrt zu erhalten, erklärte sich die Gestapo sogar bereit, den Geschäftsführer Dr. Bergel vorzeitig aus dem KZ zu entlassen. Die Gestapo regte außerdem an, daß das Fürsorgeamt einen Kommissar zur Überwachung der jüdischen Wohlfahrt bestellen solle. Im Zuge dieser lokalen Vereinbarungen gab die NSV das von ihr geraubte Vermögen an die jüdische Wohlfahrt zurück. Deren Rechnungsführung sollte künftig zusätzlich von einem städtischen Finanzbeamten kontrolliert werden. ${ }^{14}$ Auf Anraten des Städtischen Fürsorgeamtes ließen die Parteistellen jetzt zu, daß die jüdische Wohlfahrtspflege ihre Arbeit wieder aufnahm. Sie erhielt jedoch ihr Haus nicht zurück, sondern mußte im Gebäude der jüdischen Volksschule unterkommen. ${ }^{15}$

Für ganz Württemberg sowie für die Städte Darmstadt und Göttingen ist nachzuweisen, daß konfiszierte Vermögen, Räume oder Vorräte nach den Pogromtagen nicht wieder freigegeben, sondern der NSV überlassen wurden. ${ }^{16}$ In München, wo man während des Pogroms Altersheime beschlagnahmt und geplündert

setzte die Gemeindeverfassung außer Kraft und bestellte Dr. Max Plaut zum Leiter eines neugebildeten Jüdischen Religionsverbandes und zum Vorstand aller jüdischen Organisationen in Hamburg; StA Hamburg, 522-1, Nr. 991 a, Bl. 33: Bericht über Arbeit der Religionsgemeinde Ende 1938 bis Ende 1940 (ca. Mai 1941).

12 Zu Württemberg: Sauer, Verfolgung, Teil II, S. 134-138, Dok. Nr. 375-377. Zur Pfalz: Düwell, Kurt: Die Rheingebiete in der Judenpolitik des Nationalsozialismus vor 1942, Bonn 1968, S. 155.

13 Dokumente Frankfurter Juden, VI 25, S. 296: Ralph Bergel „Die Jüdische Wohlfahrtspflege 1933-1939“ (1961) sowie ebenda, VI 46, S. 323-328: Bericht des Rechnungsprüfungsamtes vom 23.6. 1939. Vgl. zu folgendem: Kingreen, Raubzüge, S. $26-27$.

14 Ebenda, VI 42, S. 319-320: Protokoll Sitzung Fürsorgeamt und OB vom 21. 11. 1938.

15 Ebenda, VI 25, S. 295-296: Ralph Bergel „Die Jüdische Wohlfahrtspflege 1933-1939“ (1961).

16 Zu Darmstadt: CAHJP Jerusalem, Darmstadt III, Nr. 145, unfol.: Jüd. Notstandsküche an IKG Darmstadt am 15.5.1939. Zu Göttingen: StadtA Göttingen, Sozialamt, Acc. Nr. 407/77, Nr. 47/1, unfol.: Aktennotizen vom 7. 12. 1938 und 16. 2. 1939. 
hatte, gab die Stadt diese erst im Frühsommer 1939 an die Israelitische Kultusgemeinde zurück. ${ }^{17}$ Auch wenn also nach einiger Zeit Einrichtungen wieder notdürftig hergerichtet oder Ersatzstellen installiert worden waren, reichten Mittel und Kapazitäten der jüdischen Wohlfahrt meist nicht, alle mittlerweile in Not Geratenen zu versorgen.

Die Öffentliche Fürsorge war also gezwungen, jüdische Arme zu unterstützen, und das, obwohl man eigentlich darauf hinarbeitete, sich dieser Pflicht zu entledigen. Das Bezirksamt Bad Neustadt an der Saale wies in einem Bericht an seinen Regierungspräsidenten darauf hin, daß „die wenig wohlhabenden Juden in Oberelsbach durch die Vernichtungsaktion und durch den Wegfall jeder Verdienstmöglichkeit bereits in eine solche Notlage geraten seien, daß die Ortsfürsorge zum wiederholten Eingreifen gezwungen gewesen $\operatorname{sei}^{\text {" }} .18$

\section{Spontane Maßnabmen städtischer Woblfabrtsämter}

Das Novemberpogrom 1938 verstanden dessenungeachtet viele Wohlfahrtsämter als Signal, die deutschen Juden nicht mehr an der staatlichen Fürsorge partizipieren zu lassen. In Berlin hatte am 14. November der Bezirk Wedding im Landeswohlfahrtsamt auf die „baldige Herbeiführung einer Entscheidung“" gedrängt, ob an jüdische Arme künftig noch gezahlt werden solle. ${ }^{19}$ Das Wohlfahrtsamt Freiburg im Breisgau schrieb am 17. November an seinen Oberbürgermeister: „Die neueste Judengesetzgebung dieser Tage räumt den Juden eine staatsrechtliche Stellung ein, die eine ganz erhebliche Beschränkung ihrer bürgerlichen Rechte bedeutet und ihnen auch nicht mehr die Rechte zubilligt, die Ausländer im Reich genießen. Es kann daher künftig nicht mehr verantwortet werden, daß Juden fürsorgerechtlich gleich behandelt werden wie deutsche Volksgenossen und besser behandelt werden wie Ausländer." Das Amt beantragte, Juden in der Versorgung Ausländern gleichzustellen, d.h. sie aus der Gehobenen Fürsorge auszuschließen und sie nur noch in der Allgemeinen Fürsorge zur unterstützen. Darüber hinaus schloß man „Erziehung und Erwerbsbefähigung im Sinne des $\$ 6$ der Reichsgrundsätze" vom notwendigen Lebensbedarf aus und verlangte, daß Juden „vor dem Eintreten der öffentlichen Fürsorge sämtliche Eigenmittel (Einkommen- und Vermögen) in vollem Umfang einzusetzen" haben. Auch kleine Vermögen sollten also zuerst restlos aufgebraucht und Zuwendungen Dritter auf öffentliche Leistungen angerechnet werden. ${ }^{20}$ In Nürnberg handelte man bereits. Dort stellte das

17 Hanke, Juden in München, S. 269.

18 Monatsbericht des Regierungspräsidenten von Unterfranken vom 9. 12. 1938, in: Bayern in der NS-Zeit, Bd. 1, München u.a. 1977, S. 475.

19 LA Berlin, Rep. 203, Acc. 867, Nr. 5100, Bl. 1: Vfg. Wohlfahrtsamt Berlin-Wedding vom 14. 11. und Vermerk vom 15. 11. 1938.

20 Der Oberbürgermeister gab erst am 26. 11., also nach Erscheinen der VO über die Fürsorge dem Wohlfahrtsamt grünes Licht. In Freiburg zählte die städtische Wohlfahrt Ende Oktober 193820 jüdische Parteien (39 Personen); StadtA Freiburg i. Br., C4 XVII/6, Nr. 6, unfol.: Wohlfahrtsamt an OB Freiburg am 17. 11. 1938; ebenda: Vfg. OB für Wohlfahrtsamt vom 26. 11. 1938. 
Wohlfahrtsamt am 16. November 1938 die Betreuung von Juden ein und verwies sie an die freie jüdische Wohlfahrtspflege. ${ }^{21}$

In München hatte sich Ratsherr und Amtsdirektor Ortner schon vor dem Pogrom, am 3. November 1938, sämtliche Akten „der noch in Betreuung stehenden Nichtarier“ aller Fürsorgezweige vorlegen lassen. ${ }^{22}$ Nur zwei Tage nach den Exzessen, am 12. November, fand eine Sitzung im dortigen Wohlfahrtsamt über die „Befürsorgung der Juden“ statt. Das Dezernat 6 der Stadtverwaltung München hatte im „Anschluß an die Ereignisse [...] vorsorglich die Einstellung jeder Unterstützung für die Juden bis auf weiteres verfügt und vorgeschrieben, daß etwaige Anträge an das Büro des Amtsdirektors“ zu richten seien, wo „schon zuvor eine Zusammenfassung aller Fürsorgeakten von Juden zwecks schärfster Überwachung nach einheitlichen Grundsätzen erfolgt“ sei. Auf einer zweiten Besprechung am 14. November 1938 wollten die Fürsorgebeamten diskutieren, ob „jede Bar- und Sachunterstützung weiterhin generell gesperrt" bleiben könne. Doch diese Entscheidung habe letztlich allein die Reichsregierung zu treffen, allerdings erwarte man rasche "gesetzliche Maßnahmen“. Bis dahin plante das Wohlfahrtsamt München, zunächst sämtliche Sonderleistungen einzustellen, außer wenn diese aus Gesundheitsgründen vom Arzt als notwendig erachtet würden oder der Ersparung öffentlicher Ausgaben, z. B. bei der Krankenhausbehandlung, dienten. Alle Bezüge der Gehobenen Fürsorge würden gesperrt, da eine entsprechende Reichsregelung erwartet werde. Juden sollten in München künftig als „asozial im Sinne des $\$ 13^{*}$ der Reichsfürsorgegrundsätze behandelt werden, also Leistungen nur unter den Richtsätzen der Allgemeinen Fürsorge erhalten. Nach ihrer Absegnung durch den Oberbürgermeister sei zu erwägen, die Vorschläge wegen ihrer überregionalen Bedeutung dem Bayerischen Staatsministerium zur Genehmigung vorzulegen, weil mit ihnen „der kommenden reichsgesetzlichen Regelung vorgegriffen wird, wenn auch sicherlich nur in voller Übereinstimmung mit dem gesunden Volksempfinden“. Dem Ministerium sei auch die Frage zu unterbreiten, ob die reichs- und landesgesetzlich vorgeschriebenen Mietbeihilfen bei jüdischen Bedürftigen künftig wegfallen könnten. Auch hier sei ein zentrales Plazet notwendig, da "die dadurch entstehende Obdachlosigkeit der Juden besondere Maßnahmen erfordern würde", denn die vorhandenen Notunterkünfte benötige man für die „obdachlosen arischen Volksgenossen“.23 Alle Vorhaben wurden zunächst vom Wohlfahrtsamt beschlossen, dann von Oberbürgermeister Fiehler in einer Ratssitzung am 15. November bestätigt: In München stufte man also jetzt jüdische Arme als "asozial“ ein, alle Sonderleistungen fielen damit weg. ${ }^{24}$

Die Deklassierung jüdischer Wohlfahrtsempfänger bildete lediglich ein Element eines ganzen Maßnahmenkataloges, den man in diesen Tagen in der Münchner Kommunalverwaltung entwickelte. Zu diesem Zweck hatte OB Fiehler noch

21 YV Jerusalem, M1DN, Nr. 162, Bl. 34: DGT Bayern an BFV München-Stadt am 12. 1. 1939; vgl. BA, R 36, Nr. 902, unfol.: Protokoll 6. Tagung der Süddt. Arbeitsgemeinschaft für Wohlfahrtspflege am 27, 1. 1939 in Bad Dürkheim, S. 3.

22 YV Jerusalem, M1DN, Nr. 168, Bl. 157: Vfg. Stadt München/Dez. 6 vom 3. 11. 1938.

${ }^{23}$ Ebenda, Bl. 164-165: Vermerk Stadt München/Dez. 6-3 vom 14. 11. 1938.

24 Ebenda, Bl. 167: Vermerk Stadt München/Dez. 6-1 vom 15. 11. 1938. 
am selben Tag ein Rundschreiben an seine Stadtverwaltung gerichtet: „Die Ausschaltung der Juden aus dem öffentlichen Leben, insbesondere auf dem wirtschaftlichen und kulturellen Sektor, wirft für die kommunale Verwaltung eine ganze Menge von Fragen und Zweifeln auf. Es muß zum Beispiel Klarheit geschaffen werden über die Behandlung der Juden in der Fürsorge, ihre Aufnahme in städtische Krankenhäuser, ihre Zulassung zur Markthalle, die Behandlung auf schulischem Gebiet. An sich sind nach $\$ 17$ DGO die Einwohner und damit auch die Juden berechtigt, die öffentlichen Einrichtungen zu benutzen. Es muß also bis zur Schaffung einer reichseinheitlichen Regelung ein Übergangszustand gefunden werden, der sich möglichst an die endgültige Regelung anpaßt. Ich gedenke beim Staatsministerium des Innern, entsprechende Weisung einzuholen. Es ist deshalb notwendig, daß mir auf dem schnellsten Wege alle Schwierigkeiten, Zweifelsfragen und besonderen Verhältnisse mitgeteilt werden, die die Behandlung von Juden hinsichtlich der gemeindlichen Einrichtungen jeder Art betreffen. ${ }^{\text {"25 }}$

Das Wohlfahrtsamt München stoppte dann aber am 17. November 1938 per Verfügung plötzlich die Ausgabe sämtlicher Leistungen an Juden. Offensichtlich war man über die konkretisierten Pläne der zentralen Ebene unterrichtet, Juden per Reichsverordnung aus der Öffentlichen Fürsorge auszuschließen. Bislang noch betreute jüdische Fürsorgeempfänger mußten sich jetzt beim Amt einfinden, um ihre Familien und Vermögensverhältnisse kontrollieren zu lassen. Falls eine Versorgung überhaupt künftig noch in Betracht kam, wurde nun nach folgenden Prinzipien verfahren: 1. Gehobene Fürsorge sei ausgeschlossen, 2. Mietbeihilfen würden nicht mehr gewährt und 3. sämtliche Einkommen auch der in Haushaltsgemeinschaft Lebenden würden voll angerechnet. ${ }^{26}$ Die neue Politik traf in München 250 arme Juden in Offener Fürsorge, 17 Juden, die ganz oder teilweise auf städtische Kosten in jüdischen Heimen, sowie acht oder neun geisteskranke Juden, die auf Kosten des Landesfürsorgeverbandes in öffentlichen „Irrenanstalten “ untergebracht waren. Über das Büro des Oberbürgermeisters leitete man die neuen Regelungen an die Bayerische Staatsregierung weiter; ergänzt um einen Vorschlag zur verschärften Anrechnung von Familieneinkommen ohne Freibeträge sowie um Fragen zur Anwendung der Familienunterstützung, zur Einbeziehung ausländischer Juden und zur Behandlung alter bzw. pflegebedürftiger Juden, die nicht mehr in städtische Anstalten aufgenommen werden sollten. ${ }^{27}$

Solche lokalen Vorgriffe geschahen nicht allein angesichts der allgemein veränderten Verfolgungssituation nach dem Pogrom, denn die lokalen Wohlfahrtsverbände zeigten sich über das zentrale Vorhaben, Juden aus der Öffentlichen Fürsorge auszuschließen, gut informiert. Schon Anfang November 1938 hatten beispielsweise die Fürsorgebehörden im Rheinland von den konkretisierten Plänen erfahren. Auf einer Tagung der Rheinischen Arbeitsgemeinschaft für Wohlfahrtspflege des Deutschen Gemeindetages klärte man fast 30 Vertretern von Städten,

25 Ebenda, Nr. 111 B, Bl. 150: Rundvfg. OB Fiehler vom 15. 11. 1938.

26 Ebenda, Nr. 109, Bl. 150: Rundschreiben Dezernat 6 vom 17. 11. 1938. Sowie Erklärung zum Dezernatsschreiben vom 17. 11. 1938 zit. bei Hanke, Juden in München, S. 266.

27 YV Jerusalem, M1DN, Nr. 168, Bl. 160-163: Vermerk Dez. 6-3 für OB Fiehler vom 18. 11.1938. 
Gemeinden und preußischen Landesregierungen nicht nur über die geplante sozialrassistische Neuordnung der Versorgungsklassen durch die „Würzburger Richtlinien" des Gemeindetages auf, sondern informierte sie, daß zudem spezielle gesetzliche Regelungen für Juden kurz bevorständen. ${ }^{28}$ Die seit Sommer im Reichsinnenministerium vorbereitete antijüdische Fürsorgeverordnung sollte aber erst nach dem Pogrom erscheinen und damit zum Bestandteil einer umfassenden Neuorientierung der Verfolgungspolitik werden.

\section{Zur Neuausrichtung der zentralen antijüdischen Politik}

Mit den Gewaltaktionen vom Oktober und November 1938 gelang es der NSFührung nicht, den selbstgeknüpften, gordischen Knoten ihrer Verfolgungspolitik zu zerschlagen. Trotz einer nochmaligen Forcierung der Emigration blieben Hunderttausende verarmte Juden im „Großdeutschen Reich “ zurück. Abgesehen von der Gewaltaktion ohne Beispiel, lag die Bedeutung des Novemberpogroms in einer bisher wenig untersuchten fundamentalen Neuorientierung der "Judenverfolgung "29: Unter der Leitung Görings sollte im Auftrag Hitlers eine staatliche Strategie entworfen werden, die einerseits die Vertreibung bis zu einem Krieg noch einmal forcierte, andererseits die potentiell Zurückbleibenden von der deutschen Gesellschaft isolierte. Auf mehreren Konferenzen im Laufe der dem Pogrom folgenden Tage und Wochen diskutierte und koordinierte die NS-Führung die von Ministerien und der SS seit dem Sommer entworfenen, teilweise differierenden Verfolgungskonzeptionen. ${ }^{30}$

Auf der ersten Tagung, der sogenannten Ministerkonferenz bei Göring im Reichsluftfahrtministerium, verständigte sich die bis auf Hitler und Heß vollzählig anwesende NS-Führung am 12. November 1938 erstmals grob über eine Neuorientierung. Statt Goebbels mit seinem Vorschlag zur Separierung der Juden im Ausbildungs-, Freizeit- und Kultursektor, welcher auf der Berliner Denkschrift vom Frühjahr basierte, oder Göring, der vor allem an der Ausschaltung auf wirtschaftlichem Gebiet und Vermögensenteignung interessiert war, setzte sich Heydrich mit einem viel umfassenderen Konzept in der Strategiedebatte durch. Unter

${ }^{28}$ An der Sitzung nahmen neben 17 Vertretern von Städten und Landkreisen auch Abgesandte der preußischen Regierungen in Düsseldorf und Köln, des Koblenzer Oberpräsidenten sowie der NSV teil, insgesamt fast 30 Personen; NW-HStA Düsseldorf, RW 53, Nr. 66, unfol.: Sitzung der Rhein. ArbG für Wohlfahrtspflege am 8.11. 1938 in Krefeld, S. $1-5$.

29 Vgl. Gruner, Denkschrift, S. 313. Ulrich Herbert, der den Wandel ähnlich stark charakterisiert, betont dabei den Sieg der strategischen Linie von Sicherheitspolizei und SD; Herbert, Best, S. 224. Auch Michael Wildt spricht von einer Wende, reduziert dies aber auf das SD-Konzept der forcierten Vertreibung; Judenpolitik des SD, S. 54-60. Bisher galten das Novemberpogrom und die nachfolgenden Beschlüsse in der Forschung zwar als Radikalisierung ohne Beispiel, aber meist eher als letzter Versuch der radikalen Antisemiten, sich durchzusetzen; Kershaw, Ian: Der NS-Staat. Geschichtsinterpretationen und Kontroversen im Überblick, Reinbek bei Hamburg 1995, S. 173. Einige Historiker betonten als Ziel die dem Pogrom folgende Verdrängung aus der Wirtschaft; z. B. Krausnick, Helmut: Anatomie des SS-Staates, 6. Aufl., München 1994, S. 578.

30 Zum folgenden vgl. Gruner, NS-Judenverfolgung und die Kommunen, S. 106-111. 
Beibehaltung des Ziels der raschen Vertreibung verknüpfte er das Wiener Verfahren, durch geraubtes Vermögen reicher Juden die Mittellosen aus dem Land zu schaffen, mit einer systematischen Politik gegenüber den zurückbleibenden, infolge der vorbereiteten Maßnahmen künftig dauerhaft pauperisierten Juden. Auf diese Gruppe, so Heydrich, habe man verstärkt die Aufmerksamkeit zu richten: "Ich muß also in Deutschland solche Maßnahmen treffen, daß sie auf der einen Seite den Juden isolieren, damit er nicht in den normalen Lebenskreis des Deutschen tritt." Auf der anderen Seite müsse gleichzeitig ein Minimum an Betätigung zur Selbstversorgung zugelassen werden. 31

Grundsätzlich galt also seit November 1938 eine Doppelstrategie: Forcierung der Emigration mit allen Mitteln und zwangsweise Reorganisation des Lebens der zurückbleibenden Juden in separaten Strukturen. Noch auf der Konferenz beschlossen die Anwesenden, in Zukunft alle jüdischen Firmen und Geschäfte zu „arisieren“ sowie ein Gewerbeverbot für Juden und eine Kontributionszahlung von einer Milliarde Reichsmark zu verhängen. Das neue Verfolgungsprogramm beinhaltete aber keineswegs, die Juden lediglich in öffentlichen Bereichen von der "NS-Gesellschaft" zu isolieren, wie es viele Kommunen in der letzten Zeit zunehmend praktiziert hatten. Die neue Strategie zielte vielmehr darauf, ihr Leben abgesondert neu zu organisieren: Das betraf Wohnen, Ausbildung, Erwerb, Kultur, Eigentum und soziale Versorgung. Zwangsarbeit und Ghettoisierung integrierte man jetzt in das Konzept. $\mathrm{Da}$ Göring inzwischen als zentrale Instanz für die Koordinierung der Verfolgungsmaßnahmen fungierte, sprach die Sicherheitspolizei mit ihm persönlich noch im November ab, eine Zwangsorganisation für die Juden im Reich zu gründen. Dieser „Reichsvereinigung der Juden“ sollte zuerst die Bildung eines jüdischen Fürsorgesystems, bald auch eines separaten Schulwesens übertragen werden. Nur auf der Basis dieser Entscheidungen konnte bereits bis Ende November der Ausschluß der deutschen Juden aus dem öffentlichen Schulund Wohlfahrtswesen dekretiert werden. Anfang Dezember erschienen dann die angekündigten Verordnungen zur Zwangsarisierung, zur Zwangsverwaltung des Vermögens und zum vollständigen Gewerbeverbot. Damit verurteilte der NSStaat die Mehrheit der deutschen Juden zwangsweise zur Beschäftigungslosigkeit, die vielen Mittellosen unter ihnen zur Abhängigkeit von der Wohlfahrt. ${ }^{32}$

Über die Ergebnisse der Konferenz und den Stand ihrer Umsetzung hatte Göring derweil Hitler berichtet. Auf dessen Befehl hin informierte er am 6. Dezember 1938 auf einer zweiten Tagung im Reichsluftfahrtministerium die Gauleiter,

31 IMT, Bd. XXVIII, Dok. PS-1816, S. 499-540: Stenographische Niederschrift von der Besprechung über die Judenfrage unter Vorsitz von Feldmarschall Göring im RLM am 12. 11. 1938.

32 Gruner, NS-Judenverfolgung und die Kommunen, S. 108-109. Die in der Literatur nach den Daten der Volkszählung oft angegebene Zahl von noch 16 Prozent jüdischer Erwerbstätiger ist im Mai 1939 nicht als Rest der ehemals Berufstätigen zuverstehen, sondern zeigt den Umfang einer strikt überwachten „Beschäftigung “: In dieser Zahl sind neben den wenigen zugelassenen „Krankenbehandlern", „Rechtskonsulenten“ und Handwerkern auch die Angestellten jüdischer Einrichtungen enthalten. Den größten Teil aber machten die inzwischen zu Tausenden von der Arbeitsverwaltung zum Zwangseinsatz herangezogenen Juden aus; Gruner, Geschlossener Arbeitseinsatz, S. 92. 
Oberpräsidenten und Reichsstatthalter über die neuen konzeptionellen Überlegungen zur Judenverfolgung, insbesondere über die Auffassungen Hitlers. ${ }^{33}$ Einleitend betonte Göring, daß unter seiner Leitung alle Maßnahmen im Rahmen des abgesteckten staatlichen Konzepts, mit dem abgesprochenen Instrumentarium und auf Hitlers Geheiß mit Rücksicht auf das Ausland möglichst unauffällig, ,auf dem Dienstwege" und ohne begleitende Pressepropaganda praktiziert werden sollten. Das oberste Ziel sei für Hitler weiterhin ${ }^{34}$, „die Juden so rasch und so effektiv wie möglich ins Ausland abzuschieben ". Nach innen sollte die antijüdische Politik hingegen schrittweise gestaltet werden, damit „der Jude immer noch etwas zu verlieren" habe. Hitler wolle deshalb auf die Kennzeichnung und die totale Isolierung der Juden zunächst verzichten. Ihre Konzentration in speziellen Wohngebieten und ihre Zwangsarbeit ließen sich ebenfalls "nur im Zuge einer Gesamtlösung " schrittweise realisieren. Bis dahin, so wies Göring an, könnten aber immer Teilschritte von den Gauen und Bezirken gegangen werden. Wie so oft seit 1933 wollte Hitler also durch die erprobte Taktik informeller Methoden auf lokaler Ebene die Verfolgung forcieren. Hinsichtlich der erwerbslosen und verarmten Juden stellte Göring die Anwesenden vor die hypothetische Alternative, entweder die jüdische Bevölkerung unbeschäftigt zu lassen, was ihre Sozialversorgung durch den NS-Staat bedeuten würde, oder sämtliche Juden zu Zwangsarbeitszwecken zu verhaften, was technisch nicht realisierbar sei. Man könne aber Erwerbs- und Vermögenslose „in gewisse Arbeiterformationen“ zusammenfassen. Die Hauptschwierigkeit für die nächste Zeit hieß, den neuen gemeinsamen Nenner über die Judenpolitik in praktische Politik umzumünzen, in Görings Worten: „Sie sehen immer wieder, daß die Judenfrage eine Lösung erfordert, die nur geschaffen werden kann, wenn alle am gleichen Strang ziehen." Effektivität sollte dabei durch eine strikte Aufgabenteilung erzielt werden, natürlich unter zentraler Aufsicht Görings: „Die Arisierungsverordnungen, die Verordnungen zur Regelung der Fürsorge der hilfsbedürftigen Juden und die Bestimmungen für die Auswanderung bekommen Sie alle noch in die Hand, besonders die Stellen, die das durchzuführen haben; die anderen Stellen dürfen sich nicht darum kümmern. “35

Am 16. Dezember 1938 fand eine weitere Koordinierungssitzung auf Reichsund Länderebene zur "Judenfrage" statt. ${ }^{36}$ Vor Ministern, Reichsstatthaltern,

33 Besprechung Görings „über die Judenfrage“ mit den Gauleitern, Oberpräsidenten und Reichsstatthaltern am 6. 12. 1938 im RLM; Abdruck bei Heim, Susanne/Aly, Götz: Staatliche Ordnung und „organische Lösung". Die Rede Hermann Görings „über die Judenfrage“ vom 6. Dezember 1938, in: Jahrbuch für Antisemitismusforschung, 2 (1993), S. 382-383.

34 Hitler hatte zwar die zwangsweise Massenemigration nach Übersee als Variante noch nicht aufgegeben, doch fehlten dafür trotz Verhandlungen sowohl die Zustimmung des Auslandes als auch die notwendige Finanzierung; vgl. Hitler-Gespräche mit ausländischen Diplomaten Ende 1938/Anfang 1939; ref. bei Friedlaender, Saul: Nazi Germany and the Jews, Vol. 1: The Years of Persecution, 1933-1939, New York 1997, S. 310.

35 Besprechung Görings am 6.12.1938, Abdruck bei Heim/Aly, Staatliche Ordnung und "organische Lösung“, S. 389-390.

36 Anwesend waren Reichsstatthalter und Regierungspräsidenten, Vertreter aus der „Ostmark" und dem Sudetengebiet, aber auch Wirtschafts- und Finanzminister des Reiches 
Gauleitern und SS-Gruppenführer Heydrich referierte Reichsinnenminister Frick im Auftrag Görings einerseits über den mittlerweile erreichten Stand in der Vertreibungspolitik, andererseits über die geplante Politik gegenüber den im Reich zurückbleibenden Juden. Zum zweiten Komplex verkündete Frick, daß den Juden in den nächsten Tagen der Mieterschutz entzogen werde. „Solange sie noch in Deutschland leben“, sei geplant, sie "in gewissen Straßen zusammenzulegen, ohne dabei ein Ghetto zu schaffen". Da durch die neuen Maßnahmen Juden in großer Zahl hilfsbedürftig geworden und jetzt auf die Fürsorgemittel des NS-Staates angewiesen seien, sprach Frick auch ihre Wohlfahrtsversorgung an: „Es ist zunächst die Jüdische Wohlfahrtshilfe in Anspruch zu nehmen. Darum darf diese und ihre Geschäftsstellen auch nicht behindert werden, wie es an vielen Orten geschehen ist. Wir brauchen diese jüdischen Wohlfahrtsstellen, insbesondere zur Auswanderung. Wenn die jüdischen Wohlfahrtsstellen nicht helfen können, muß die öffentliche Fürsorge eintreten. In Zweifelsfällen ist die Entscheidung des Ministeriums einzuholen." Es sei außerdem daran gedacht, die beschäftigungslosen Juden in besonderen "Arbeitskolonnen " zusammenzufassen. ${ }^{37}$

Nur vier Tage später, am 20. Dezember 1938, ordnete die Reichsanstalt für Arbeitsvermittlung und Arbeitslosenversicherung den „Geschlossenen Arbeitseinsatz" erwerbsloser Juden an, da der NS-Staat "kein Interesse" daran habe, arbeitsfähige Juden "aus öffentlichen Mitteln ohne Gegenleistung zu unterstützen“.38 Etwas später folgte eine Anordnung zur Installation eines separaten jüdischen Kulturwesens. ${ }^{39}$ Das Vorhaben, den Mieterschutz für Juden vollständig aufzuheben und sie in "Judenhäusern" zu konzentrieren, war in einem Gesetzentwurf ebenfalls in der ersten Hälfte Dezember 1938 fixiert worden. ${ }^{40}$ Doch Hitler entschied kurzfristig, den Mieterschutz noch nicht abzuschaffen, sondern „nur“ zu lockern, um eine Massenobdachlosigkeit zu vermeiden. ${ }^{41}$ Nur wegen dieser Änderung erschien das Gesetz über die Wohnkonzentration der Juden erst Ende April 1939.42

und der Länder sowie u. a. Reichsminister Lammers und eine Reihe von Gauleitern; NWHStA Düsseldorf, Reg. Aachen, Nr. 20116, unfol.: RMdI-Schnellbrief vom 13.12. 1938 mit Änderung der Tagesordnung der Konferenz zur Judenfrage am 16.12. 1938 sowie „Niederschrift über die Sitzung im RMdI am 16.12. 1938 in Angelegenheit der Judenfrage“, in: BNSGSP, Bd. 9: Bevölkerungsstruktur und Massenmord, Berlin 1991, S. 15, Dok. Nr. 1, S. 15-21.

37 Ebenda, S. 18-19. Vgl. BA, R 18, Nr. 5519, Bl. 299-305: Notiz RMdI/Adjudantur (Referentenentwurf für die Rede Fricks am 16.12.1938) vom 15.12. 1938. Auszug in: Pätzold, Verfolgung, S. 204, Dok. Nr. 164.

38 Zit. nach Gruner, Geschlossener Arbeitseinsatz, S. 67.

39 AO zur Gründung eines „Jüdischen Kulturbundes“; JNBl., Berliner Ausgabe, Nr. 11 vom 30. 12. 1938, S. 1 .

40 ÖStA/AdR Wien, Bürckel-Materie, Nr. 2330/1/1, unfol.: Begründung zu Gesetzentwurf (1. Hälfte Dezember 1938), S. 1-2.

41 Ebenda: Vermerk Bürckel/Stab vom 5. 1. 1939. Die Entscheidung findet sich auch in einer Hitler-Weisung vom 24. 12. 1938; IMT, Bd. XXV, S. 131-132: Göring Schnellbrief vom 28. 12.1938 mit Hitler-Weisung; vgl. auch Sauer, Verfolgung, Teil II, Nr. 339, S. 83-84: Hitler-Weisung vom 24. 12. 1938.

42 „Gesetz über Mietverhältnisse mit Juden “ vom 30. 4. 1939; RGB1., 1939 I, S. 864. 
Weit über eine gesellschaftliche Trennung hinausgehend, ging es dem NS-Staat demnach um eine systematische Reorganisation aller Lebensbereiche der jüdischen Bevölkerung. Dieses historisch wohl einmalige Verfolgungskonzept zur Schaffung einer „Zwangsgemeinschaft ${ }^{\text {" } 43}$ richtete sich am Ende des Jahres 1938 gegen ca. 320000 Juden, 150000 Männer und 170000 Frauen. Viele von ihnen waren nach Jahren der Verfolgung stark verarmt, viele standen in hohem Alter. ${ }^{44} \mathrm{Ge}-$ rade deswegen kam der antijüdischen Politik auf dem Gebiet der Fürsorge eine besondere Bedeutung zu.

\section{Die antijüdische Fürsorgeverordnung und weitere zentrale Regelungen}

Ein Element des neuen Verfolgungsprogramms bildete die Separierung der Juden im Wohlfahrtswesen. Trotz der krisenhaften Situation der Jüdischen Gemeinden, die bis dahin mit ihren Wohlfahrtseinrichtungen nur subsidiär flankierende Funktionen für jüdische Bedürftige zu erfüllen brauchten, sollten jene künftig allein alle armen Juden versorgen. Dank des seit Sommer 1938 zirkulierenden Entwurfes konnten Reichsinnenminister Frick, Reichsarbeitsminister Seldte und der Reichsminister der Finanzen Graf Schwerin von Krosigk schion am 19. November 1938 die „Verordnung über die öffentliche Fürsorge für Juden“ gemeinsam erlassen. Mit der Verordnung hob der NS-Staat erstmals aus rassistischen Gründen die aus der Weimarer Republik stammende gesetzliche Fürsorgepflicht gegenüber einer Gruppe deutscher Staatsbürger auf. Die Verordnung schloß Juden aus der Versorgung durch die Öffentliche Wohlfahrt aus und verwies sie auf die Wohlfahrtsmittel jüdischer Institutionen. Die Maximen sollten laut Artikel 1 der Verordnung als Zusatzparagraph 35 a) in die Reichsfürsorgeverordnung eingefügt werden: Öffentliche Leistungen gewähre man Juden künftig nur im äußersten Notfall, wenn eine Versorgung durch jüdische Institutionen vor Ort unmöglich sei. Dann aber müsse von der zuständigen Fürsorgebehörde die Hilfsbedürftigkeit der Juden strengstens geprüft werden. Selbst Kleinvermögen sollten angerechnet werden. Diese Bestimmung machte es jüdischen Armen künftig unmöglich, Rücklagen für Passage- oder Vorzeigegelder zu bilden, und schloß damit eine Emigration weitgehend aus. Laut Verordnung erhielten im Falle einer Versorgung

43 Erstmals zu diesem Verfolgungskonzept: Gruner, Geschlossener Arbeitseinsatz, S. 58-62 und 334-335; ders., NS-Judenverfolgung und die Kommunen, S. 106-111. Die bisher für diese Phase von der Forschung benutzten Begriffe wie Kasernierung, Ghettoisierung, soziale Deklassierung oder bürgerlicher Tod treffen immer nur Teilbereiche, nie das komplexe Konzept dieser Politik. Auch das Ghettoisierungsmodell von Hilberg „1. Unterbindung der sozialen Kontakte zwischen Juden und Deutschen, 2. Wohnungsbeschränkungen, 3. Reglementierungen der Bewegungsfreiheit, 4. Kennzeichnungsmaßnahmen, 5. Bildung eines jüdischen Verwaltungsapparates" greift nicht nur wegen des Fehlens von Zwangsarbeit zu kurz; Hilberg, Vernichtung, Bd. 1, S. 165.

44 Mitte Dezember 1938 schätzte man in der Reichsvertretung die Zahl der über Sechzigjährigen auf ein Drittel (96500) der jüdischen Einwohner; fast die Hälfte waren es, wenn man die über Fünfzigjährigen hinzuzählte. Juden im Alter zwischen 17 und 50 Jahren gab es noch rund 126000, davon 59000 Männer und 67500 Frauen; LBI/A New York, Reichsvertretung AR 221, Folder Statistics, unfol.: Anlage zu Brief RV (Cora Berliner) an Julius Seligsohn, New York, vom 5. 1. 1939. 
jüdische Arme künftig nicht einmal mehr den für Nichtjuden vorgeschriebenen "notwendigen Lebensbedarf“ gestellt, sondern lediglich „Unterkunft, Nahrung, Kleidung, Krankenpflege, Hilfe für Gebrechliche sowie für Schwangere und Wöchnerinnen Hebammenhilfe und, soweit erforderlich, ärztliche Hilfe". Selbst bei diesen Mindest-„Leistungen“ bestand für Juden künftig kein Anspruch auf die üblichen lokalen Richtsätze. In der Verordnung wurde auch festgeschrieben, daß das Gesetz über Kleinrentnerhilfe von 1934 (bzw. dessen Ergänzungsverordnung von 1937) nicht mehr für Juden galt. ${ }^{45}$ Allein von der Wirkung dieser Klausel sollen 20000 jüdische Sozialrentner und ca. 3000 jüdische Kleinrentner betroffen gewesen sein. ${ }^{46}$ Von der diskriminierenden Verordnung, die am 1. Januar 1939 in Kraft trat ${ }^{47}$, blieben nur schwerkriegsbeschädigte Juden nach Abs. 3 der Reichsgrundsätze vorerst teilweise ausgenommen. ${ }^{48}$ Das galt nur für die Person der Schwerbeschädigten, auf Anweisung des Reichsarbeitsministeriums nicht aber für deren Hinterbliebene. ${ }^{49}$ Juden waren so von allen privilegierten Versorgungskategorien, wie Sozialrentner- oder Kriegshinterbliebenenfürsorge, abgeschnitten.

Parallel diskutierten die Beamten im Reichsinnenministerium neue Richtlinien für die jüdischen Stiftungen. Bisher waren sie in mehrfachen Verhandlungen mit dem Stellvertreter des Führers davon ausgegangen, daß „rein jüdische Stiftungen“ aufrechtzuerhalten seien. Allerdings, so hieß es in einem Entwurf, sei der Stiftungszweck dahingehend zu ändern, daß aus den Stiftungsmitteln vor allem die Emigration von Juden gefördert werde. Inzwischen, so berichtete der Beauftragte der Stadt Frankfurt am Main aus Berlin seinem Oberbürgermeister, werde aber daran gedacht, „rein jüdische Stiftungen als jüdisches Vermögen mit Fürsorgecharakter zu erhalten, um die öffentliche Fürsorge gemäß dem zuletzt ergangenen Erlaß zu entlasten" ". ${ }^{50}$ Ein deutliches Indiz für die rasche Strategieänderung der NS-Führung nach dem Pogrom sowie für die Erkenntnis, daß eine schnelle und vollständige Vertreibung kaum noch zu realisieren sei.

Der Bezirksfürsorgeverband München wandte sich nach Erscheinen der antijüdischen Fürsorge-Verordnung sofort an den Deutschen Gemeindetag. Man wollte geklärt wissen, wie denn die Fürsorge für ,jüdische versippte Personen “ zu gestalten sei. Außerdem beabsichtige München, Juden die reichsgesetzliche Mietbeihilfe, die seit 30. März 1938 die früheren Mietzinssteuernachlässe ersetzte, mit dem Argument zu versagen, daß diese den Fürsorgeverbänden übertragene Son-

45 RGBl., 1938 I, S. 1649. Vgl. generell Gerl, Bruno: Leitfaden des geltenden Fürsorgerechts, Berlin 1941, S. 44 sowie Sauer, Verfolgung, Teil II, S. 132, Dok. Nr. 374: Württ. Gemeindezeitung vom 15.12. 1938.

46 Sachße/Tennstedt, Armenfürsorge, Bd. 3, S. 183.

47 RGBl., 1938 I, S. 1649. Am 21. 12. 1938 wurde die Fürsorge-VO für Juden noch einmal geringfügig korrigiert; RGBl., 1938 I, S. 1850.

$48 \$ 18$ bis 32 der Reichsgrundsätze kamen weiter zur Anwendung; RGBl., 1938 I, S. 1649.

49 BA, NS 25, Nr. 503, Bl. 178: RArbM/Abt. II an Sächs. Minister für Arbeit und Wirtschaft am 23.1. 1939 (Abschrift).

50 Dokumente Frankfurter Juden, III 65, S. 118-119: Beauftragter Frankfurt/M. an OB am 12. 12.1938. 
derleistung bisher ohne strenge Nachprüfung der Hilfsbedürftigkeit, wie es die neue Verordnung vorschreibe, gewährt worden sei. ${ }^{51}$

Rasch komplettierten weitere Reichsbestimmungen die antijüdische FürsorgeVerordnung. Am 12. Dezember 1938 schlossen das Reichsinnenministerium und das Reichsarbeitsministerium Juden gemeinsam von der neuen, vorteilhaften Regel aus, daß verbesserte Rentenleistungen, wie z. B. die Erhöhung des Invalidengeldes, von der Öffentlichen Fürsorge nicht mehr angerechnet zu werden brauchten. ${ }^{52}$ Am 15. Dezember übermittelten beide Ministerien dem Reichsfinanzministerium einen Verordnungsentwurf zur Verlängerung der Mietbeihilfe mit der Bemerkung, daß sich hier die Gelegenheit biete, „die Juden von den Vergünstigungen der Mietbeihilfen auszuschließen ". ${ }^{53}$ Schon einen Tag später informierte Ministerialrat Ruppert den Deutschen Gemeindetag, daß eine Verordnung über Mietbeihilfen in Vorbereitung sei, die Juden ausschließe. ${ }^{54}$ Der Deutsche Gemeindetag zögerte nicht, diese Information sogleich über seine Landesdienststellen zu verbreiten. ${ }^{55}$ Dem Vorschlag über die Neuregelung der Mietbeihilfen stimmten sowohl das Reichs- wie auch das Preußische Finanzministerium kommentarlos am 21. Dezember zu. ${ }^{56}$ Durch die am 31. Dezember 1938 herausgegebene "Zweite Verordnung über Mietbeihilfen" wurden bedürftige Juden dann von der Gewährung der Kreismietbeihilfen ausgeschlossen. ${ }^{57}$

In der Wohlfahrtspraxis wirkte sich das auf die Betroffenen in Berlin wie folgt aus: Ottilie Reich, alleinerziehende Mutter zweier unehelicher Kinder, verdiente $30 \mathrm{RM}$ wöchentlich. Sie hatte bisher ergänzend dazu $11 \mathrm{RM}$ Zuschuß von der städtischen Fürsorge sowie eine monatliche Mietbeihilfe (13,30 RM) erhalten. Sie schrieb verzweifelt an den Vormund ihrer unehelichen Kinder in der Jüdischen Gemeinde Berlin, „wie es ja Ihnen Herr Dr. bekannt ist, fällt der [Mietzuschlag] für uns Juden weg. Ich weiß nicht, was werden soll, entweder [...] Sie helfen mir weiter oder der Junge muß nach Schönhausen [Berlin-Niederschönhausen - ein Jüdisches Kinderheim, W.G.] untergebracht werden, daß ich mir selbst Arbeit suche und meine Verhältnisse gebessert werden. Wie Sie ja wissen [...], ist der Vater des Kindes im Lager, die Verantwortung kann ich nicht auf mich nehmen, das Kind verhungern zu lassen, ich selbst habe getan, was in meinen Kräften stand, jetzt kann ich nicht mehr weiter. ${ }^{\text {5 }} 8$

51 YV Jerusalem, M1DN, Nr. 168, Bl. 173: BFV München an DGT-Dienststelle Bayern am 2. 12.1938.

52 Galt nicht für schwerkriegsbeschädigte Juden; BA, 39.01, Nr. 6258, Bl. 182: Gemeinsamer Runderlaß des RArbM und des RMdI vom 12.12. 1938.

53 BA, 21.01, B 9382, unfol: Schnellbrief RMdI/RArbM am 15. 12.1938.

54 DGT-Vermerk vom 16. 12. 1938; nach Adam, Judenpolitik, S. 220.

55 YV Jerusalem, M1DN, Nr. 168, Bl. 194: DGT-Landesdienststelle Bayern an BFV München am 19.12.1938.

56 BA, 21.01, B 9382, unfol.: Antworten des RFM und des Preuß. MdF vom 21. 12. 1938.

57 Stadt- und Landkreise waren wegen Wegfall der Landesbestimmungen über Stundung und Niederschlagung der Gebäudeentschuldungssteuer verpflichtet, solche Mietbeihilfen zu zahlen; RGBl., 1938 I, S. 2017.

58 CJA Berlin, 75 A Be 2, Nr. 424, Bl. 27: Reich an Lamm am 8. 1. 1939. Vgl. Schüler-Springorum, „Elend und Furcht", S. 625. 
Als der Sächsische Innenminister sich nach Erlaß der Mietbeihilfenverordnung beim Reichsinnenministerium erkundigte, ob nichtdeutschen Juden solche Leistungen weiter bewilligt werden könnten, erhielt er negativen Bescheid: „Die Mietbeihilfe ist keine Leistung der öffentlichen Fürsorge [...]. Deshalb können Juden eine Mietbeihilfe auch dann nicht erhalten, wenn sie einem Staat angehören, mit dem Deutschland über die fürsorgerechtliche Behandlung seiner Angehörigen ein Abkommen geschlossen hat. ${ }^{\text {59 }}$ Das Reichsinnenministerium bezog mit seiner Auskunft vom 25. Januar 1939 also alle ausländischen Juden in die Ausgrenzung ein, was der Deutsche Gemeindetag wenig später über seinen „Nachrichtendienst" verbreitete, welcher der internen Information der Kommunen diente. ${ }^{60}$

Schon am 29. Dezember 1938 hatte der Badische Minister des Innern, offenbar infolge eines Antrages des Landeskommissärs in Mannheim, die Bezirksfürsorgeverbände seines Landes angewiesen, daß aufgrund der neuen Fürsorge-Verordnung Juden auch von den „Maßnahmen der Reichsregierung zur Fettversorgung der minderbemittelten Bevölkerung ab 1. Januar 1939" auszuschließen seien.61 Das Reichsarbeitsministerium gab einen entsprechenden zentralen Erlaß, gemeinsam mit dem Reichsministerium für Ernährung und Landwirtschaft, erst Mitte Februar 1939 heraus. ${ }^{62}$

Über die Details der neuen Fürsorge-Verordnung waren die Badischen Wohlfahrtsdezernenten am 19. Dezember 1938 in Karlsruhe auf einer Sitzung des Deutschen Gemeindetages informiert worden. Sie erfuhren aber zugleich, daß deren Bestimmungen nur einen ersten Schritt bedeuteten: „Oberregierungsrat Duntze vom [Badischen] MdI führt[e] aus, daß beabsichtigt sei, bis zum Frühjahr 1939 eine Reorganisation der freien jüdischen Wohlfahrtspflege unter staatlicher Aufsicht durchzuführen. Es sei zu erwarten, daß alsdann sämtliche Juden aus der öffentlichen Fürsorge ausscheiden können und ausschließlich [...] nach den vom Staat aufzustellenden Richtlinien von der jüdischen Wohlfahrtspflege betreut werden. Zur Finanzierung und Sicherstellung des Aufwands der jüdischen Wohlfahrtspflege sei in Aussicht genommen, eine Haftungsgemeinschaft des gesamten jüdischen Vermögens in Deutschland zu schaffen. ${ }^{~} 63$

59 BA, NS 25, Nr. 503, Bl. 83: RMdI an Sächs. MdI am 25. 1. 1939 (Abschrift für HA Kommunalpolitik).

60 Nachrichtendienst des DGT, Nr. 4 vom 11. 2. 1939, S. 44. Der „Nachrichtendienst“ diente dem Dienstgebrauch der Gemeinden. Die Weiterverbreitung des Inhalts war verboten. Er wurde seit 1935 auch den NSDAP-Gauleitern für Kommunalpolitik zur vertraulichen Information, nicht aber zum Zwecke des Abdruckes in Zeitschriften oder Mitteilungsblättern übergeben; BA, R 2 Research, O. 211, Bl. 311-316: Geschäftsführ. DGT-Präs. (i.V. Zeitler) an Gauamtsleiter für Kommunalpolitik Kurmark (Janetzke) am 17. 4. 1935.

61 Fettverbilligungsscheine erhielten u.a. Arbeitslosenunterstützungs-, Krankengeld- oder Fürsorgeempfänger sowie kinderreiche Familien in wirtschaftlichen Notlagen, Sozialrentner und Personen mit geringen Einkommen; StA Freiburg i.Br., Landeskommisär Konstanz, P. Nr. 3110, unfol.: MdI-Runderlaß vom 29.12. 1938.

62 Erlaß vom 16. 2. 1939; abgedruckt in: Dienstblatt der Stadt Berlin, 1939 Teil VII, S. 99, Nr. 99: Vfg. des Landeswohlfahrtsamtes Berlin vom 20.3.1939.

${ }^{63}$ StadtA Freiburg i. Br., C4 XVII/7, Nr. 6, unfol.: Niederschrift zur Fürsorge-DezernentenBesprechung in Karlsruhe am 19.12.1938, S. 2. 


\section{Neue Instrumente zur Erfassung, Kontrolle und Separierung}

In einem Schnellbrief verständigte Göring die anderen Reichsminister am 28. Dezember 1938 über letzte Weisungen Hitlers zur geplanten antijüdischen Politik. Um die Pauperisierung der Juden noch steuern zu können, ordnete Hitler an, daß Pensionen jüdischer Beamter vorerst nicht versagt, sondern „nur “ gekürzt, und jüdische Fürsorgeeinrichtungen nicht „arisiert “ werden dürften. Für die antijüdischen Maßnahmen müsse der Kreis der Betroffenen, speziell der Status von Juden in „Mischehen“, exakt abgesteckt werden. Gegen kinderlose Paare, in denen der Ehemann jüdisch und die Ehefrau „deutschblütig“ sei, seien alle Verfolgungsmaßnahmen anzuwenden, „als ob es sich um reine Juden“ handele. ${ }^{64}$ Mit dieser Klarstellung von höchster Stelle erledigten sich zunächst auch Fragen städtischer Wohlfahrtsämter, z.B. in München, wie die „jüdisch Versippten“ in der Fürsorge zu behandeln wären.

Zur Durchsetzung der antijüdischen Fürsorge-Verordnung wurde darüber hinaus sowohl auf zentraler wie auf lokaler Ebene ein Spezialinstrumentarium geschaffen. Reichsarbeits- und Reichsinnenministerium beauftragten regionale Fürsorgeverbände und kommunale Wohlfahrtsämter, jüdische Wohlfahrtsempfänger ab Januar 1939 in ganz Deutschland statistisch gesondert zu erfassen. ${ }^{65}$ In den Meldungen zum „Schnelldienst der Reichsfürsorgestatistik“, die die Kommunen und Bezirksfürsorgeverbände seit dem Ende der zwanziger Jahre vierteljährlich an das Statistische Reichsamt lieferten, mußten sie nun Juden extra auflisten. ${ }^{66}$ Sie hatten diese in drei Sparten gesplittet aufzuführen: 1. schwerkriegsbeschädigte deutsche Juden, die noch den Vorteil der Gleichstellung in einigen Bereichen genossen, 2. alle sonstigen Juden deutscher Staatsangehörigkeit, und 3. Juden nichtdeutscher Staatsangehörigkeit. Schon die Reduzierung auf nur drei Kategorien zeigt plastisch, wie infolge der neuen Verordnung bei jüdischen Armen die unterschiedlichen Fürsorgeklassen (Wohlfahrtserwerbslose, Sozialrentner oder Bezieher Gehobener Fürsorge) auf dem niedrigst möglichen Niveau zusammengefaßt wurden. Kommunen und Gemeinden registrierten aber nicht nur vom Staat abhängige, arme Juden, sondern berechneten extra auch die Kosten der für diese aufgewendeten Leistungen. ${ }^{67}$

Schon ab Beginn des Jahres 1939 konnte das Statistische Reichsamt die lokalen Resultate auswerten. In den vervielfältigten Ergebnissen des Schnelldienstes der Reichsfürsorgestatistik tauchen bereits in der Ausgabe für das erste Quartal 1939

64 Sauer, Verfolgung, Teil II, Nr. 339, S. 83-84: Göring Schnellbrief vom 28. 12.1938 mit Hitler-Weisung. Auf Initiative Görings veröffentlichte kurz darauf der StdF den Schnellbrief über Hitlers „Willensmeinung" für die NSDAP-Instanzen; ebenda, S. 84; vgl. IMT, Bd. XXV, S. 131-132: AO Nr. 1/39 vom 17. 1. 1939 mit Görings Schnellbrief.

65 Erwähnt in: Dienstblatt Berlin, 1939 Teil VII, S. 25, Nr. 27: Vfg. Behagel (Landeswohlfahrtsamt) vom 21.1.1939.

66 Zur Geschichte der Ende der zwanziger Jahre eingerichteten Reichsfürsorgestatistik und ihren Veränderungen bis 1939, ohne allerdings die Zählung der Juden zu erwähnen, vgl. Schoen, Armenfürsorge, S. 192-196.

67 StadtA Dresden, Fürsorgeamt, Nr. 514, Bl. 31RS: Deckblatt des Wohlfahrtsamtes vom 20.1. 1939 zum Rundschreiben vom 31.12.1938. Vgl. Dienstblatt Berlin, 1939 Teil I, S. 30, Nr. 22: Vfg. des Landeswohlfahrtsamtes vom 21. 1. 1939. 
die Juden als Sonderrubrik im Städte-, Länder- und Reichsüberblick zur Offenen Fürsorge auf. ${ }^{68}$ In Berlin notierten darüber hinaus auf Anordnung des Landeswohlfahrtsamtes die Bezirksämter Zahl und Mehrkosten derjenigen Juden, die Pflichtarbeit leisten mußten, und meldeten separat die Zahl ,arbeitseinsatzfähiger ${ }^{\text {" Juden. }}{ }^{69}$ Solche Sondererfassungen konnten Wohlfahrtsbehörden nutzen, um Juden für den neu eingeführten, von der Arbeitsverwaltung organisierten Geschlossenen Arbeitseinsatz der erwerbslosen Juden anzuzeigen. ${ }^{70}$

Gerade die lokalen Wohlfahrtsbehörden schufen sich im Zuge der radikalisierten Verfolgungspolitik eigene Instrumente, um die Bestimmungen der antijüdischen Fürsorgeverordnung vor Ort radikal umzusetzen. Immer mehr Städte richteten nun abgesonderte Amtsstuben bzw. Versorgungsstellen für die Gruppe der jüdische Armen ein. Die Verantwortlichen konnten auf diese Weise sowohl die jüdischen von den nichtjüdischen Klienten in Behördenverkehr und Versorgung strikt trennen, als auch deren Ausgrenzung effektiver organisieren. Vorbilder für separate Wohlfahrtsstellen gab es - wie gezeigt - bereits seit Mitte der dreißiger Jahre in Köln und Frankfurt am Main. Nach dem Novemberpogrom 1938 führte in Hamburg die Sozialverwaltung zunächst besondere Abfertigungszeiten für erwerbslose Fürsorgeempfänger ein, da man es den ,arischen“ Unterstützten nicht mehr zumuten wolle, mit jüdischen Armen ein Wartezimmer zu teilen. Weil man aufgrund der neuen antijüdischen Gesetzgebung mit einem Ansturm jüdischer Armer rechnete, beschloß die Sozialverwaltung Ende 1938, für diese eine separate Abteilung einzurichten. ${ }^{71}$ Im Februar 1939 eröffnete Hamburg die "Sonderdienststelle B für Juden“, eine frühere Kreisstelle auf St. Pauli. ${ }^{72}$ Eine „Sonderdienststelle A für Asoziale und Zigeuner" existierte bereits seit dem Vorjahr. Die Abteilung Arbeitsfürsorge der Hamburger Sozialbehörde, die zu den Vorreitern isolierter Arbeitsmaßnahmen für Juden in speziellen Lagern gehörte, bestimmte hingegen später spezielle Abfertigungstage, an denen Juden zu erscheinen hatten. ${ }^{73}$ In Berlin ordnete Stadtpräsident und Oberbürgermeister Lippert im Dezember 1938 persönlich an, einzelne Sprechtage und spezielle Abteilungen bzw. Sachbearbeiter in den Bezirkswohlfahrtsämtern festzulegen, um jüdische Arme zu separieren. ${ }^{74}$ Bald galt einheitlich der Donnerstag als gesonderter Sprechtag,

68 Vgl. Die offene Fürsorge im Vierteljahr Januar-März 1939 (Ergebnisse des Schnelldienstes der Reichsfürsorgestatistik), Statistisches Reichsamt, Abt. III Sozialstatistik, MS, (Berlin 1939).

69 Dienstblatt Berlin, 1939 Teil VII, S. 30-31, Nr. 22; sowie LA Berlin, Rep. 203, Acc. 867 Nr. 5100, Bl. 25: Vfg. Wohlfahrtsamt Berlin-Wedding vom 2. 2. 1939.

$70 \mathrm{Vgl}$. Gruner, Geschlossener Arbeiteinsatz, S. 71-72.

71 StA Hamburg, 351-10 Sozialbehörde, StA 26.19, Bd. 1, unfol: Niederschrift über Sitzung des Beirats der Sozialverwaltung am 22.12.1938, S. 4; vgl. ebenda: Sitzung vom 21. 11. 1938, S. 8; Teilabdruck der beiden Dokumente bei Ebbinghaus/Kaupen-Haas/ Roth, Heilen und Vernichten im Mustergau Hamburg, S. 65-67. Vgl. auch Lohalm, Fürsorge und Verfolgung, S. 51.

72 Lohalm, Fürsorge und Verfolgung, S. 52.

73 StA Hamburg, 351-10 Sozialbehörde, AW 50. 12, Bl. 105: Entwurf einer AFÜ-Vfg. vom 30. 3. 1939.

74 Dienstblatt Berlin, 1938 Teil VII, S. 342, Nr. 360: Vfg. Lippert vom 3. 12. 1938; vgl. LA Berlin, Rep. 214, Acc. 794, Nr. 13, unfol.: Vfg. Lippert vom 3.12. 1938 sowie ebenda, 
der 25. jeden Monats als spezieller Zahltag für jüdische Hilfsbedürftige. ${ }^{75}$ Einzelne Berliner Bezirksämter richteten separate Wohlfahrtsabteilungen oder -stellen für Juden ein. ${ }^{76}$ Außerdem kreierte die Stadt im Berliner Haushalt nun gesonderte Etattitel „Unterstützung für Juden" ${ }^{77}$ Das Kasseler Wohlfahrtsamt installierte sogar eine eigene Sonderverkaufsstelle für Juden, denn inzwischen weigere sich angeblich auch der "letzte Geschäftsmann “, Waren an Juden zu verkaufen. ${ }^{78}$

$\mathrm{Da}$ nach der neuen Verordnung eine weitere Versorgung der Juden durch die öffentliche Wohlfahrtspflege sowohl von der Finanzlage jüdischer Wohlfahrtsstellen als auch der Armut des Einzelnen abhängig gemacht wurde, bestimmte der Reichsfinanzminister am 9. Februar 1939, daß die Finanzämter künftig mit den Sozialversicherungsträgern eng kooperieren und auf Antrag der Wohlfahrtsämter Auskunft über jüdische Vermögen aus den Vermögensverzeichnissen erteilen sollten. ${ }^{79}$ Vorhandenes Vermögen mußte vor einer Versorgung erst aufgebraucht werden.

Obgleich die antijüdische Fürsorgeverordnung im Ausnahmefall eine Kostenübernahme durch die öffentlichen Träger, wenn auch auf niedrigstem Niveau, vorschrieb, forderte der Deutsche Gemeindetag am 24. Februar 1939 vom Reichsinnenministerium eine Beschlagnahme vom Kapital emigrationsbereiter Juden oder einen Anteil an der jüdischen „Buß-Milliarde“. Wieder war man der zentralen Ebene einen Schritt voraus und plante auf diese Weise, künftig durch jüdische Arme verursachte Kosten der öffentlichen Wohlfahrtsträger abzudecken. ${ }^{80}$ Auf der Reichsebene dachte man ähnlich, doch in anderer Richtung: Nur einen Tag später, am 25. Februar, versandte die "Reichsvereinigung der Juden in Deutschland" eine Anweisung an ihre Regionalstellen. Darin hieß es, daß "nach Genehmigung durch die zuständigen Behörden mit sofortiger Wirkung" von aus dem Altreich emigrierenden Juden „ein außerordentlicher Beitrag als Auswandererabgabe erhoben“" werden müsse. Diese Sondersteuer solle „dazu beitragen, die Mittel für die Erfüllung der Aufgaben der Reichsvereinigung der Juden in Deutschland (Auswanderungsförderung, Fürsorge, Schulen) aufzubringen ". ${ }^{81}$

Rep. 203, Acc. 867, Nr. 5100, Bl. 19: Vermerk über Besprechung am 14. 1. 1939. Vgl. Gruner, Judenverfolgung, S. 61-63.

75 LA Berlin, Rep. 211, Acc. 926, Nr. 114, Bl. 191: Vfg. Landeswohlfahrtsamt vom 17.3. 1939 .

76 In Berlin-Neukölln wurde die Wohlfahrtsstelle Neukölln-Süd allein für Juden zuständig erklärt; LA Berlin, Rep. 214 Neukölln, Acc. 794, Nr. 13, unfol.: Auszug aus Besprechung vom 7. 12. 1938. In Berlin-Wilmersdorf wurde ebenfalls eine Abteilung für Juden eingerichtet; Kommunalverwaltung unterm Hakenkreuz. Berlin-Wilmersdorf 1933-1945, hrsg. von Karl Heinz Metzger u.a., Berlin 1992, S. 161.

77 LA Berlin, Rep. 203, Acc. 867 Nr. 5100, Bl. 25 Vfg. Wohlfahrtsamt Wedding vom 2. 2. 1939.

78 Kurhessische Landeszeitung vom 26./27. 11. 1938; nach Prinz, Die Judenverfolgung in Kassel, S. 203.

79 RArbM-Runderlaß an die OFP vom 22. 2. 1939; Reichsarbeitsblatt, IV 1939, S. 109. Auch Abdruck in: Deutsche Zeitschrift für Wohlfahrtspflege, 15 (1939), H. 1, S. 28.

80 BA, R 36, Nr. 885, unfol.: DGT Berlin an RMdI am 24. 2. 1939.

81 Sauer, Verfolgung, Teil II, Nr. 366, S. 120: Rundschreiben des Israelischen Oberrats Stuttgart vom 10. 3. über RV-Rundschreiben vom 25. 2. 1939. 


\section{Die Bildung der „Reichsvereinigung “ und die Fürsorge}

Zwar existierte diese „Reichsvereinigung“ seit Anfang Februar 1939 de facto, nicht aber de jure. Ihre formelle Gründung hatte sich verzögert, denn eigentlich sollte diese Zwangsorganisation ein Grundelement des neuen Verfolgungskonzeptes von forcierter Vertreibung und forcierter Isolierung der Zurückbleibenden bilden. ${ }^{82}$ Schon fünf Tage nach dem Pogrom und drei Tage nach der Ministerkonferenz hatte am 15. November 1938 Heydrich zu einer interministeriellen Besprechung eingeladen, um die Gründung einer „Reichsvereinigung für die Betreuung jüdischer Auswanderer und fürsorgebedürftiger Juden " vorzubereiten. ${ }^{83}$ Das Vorhaben war mit Göring abgestimmt. Da man in der NS-Führung im Sommer entschieden hatte, die Last der Sozialversorgung vollständig jüdischen Einrichtungen zu übertragen, integrierte Heydrich dieses Vorhaben nun in die Bildung einer überregionalen jüdischen Zwangsorganisation. ${ }^{84} \mathrm{Am} 1$. Dezember beschlossen Vertreter von Ministerien und Sicherheitspolizei, daß der „Reichsvereinigung" neben der Fürsorge auch die Organisation eines separaten Schulsystems aufzutragen sei. ${ }^{85}$ In einem Referentenentwurf für die oben bereits zitierte Rede von Reichsinnenminister Frick auf der Berliner Tagung vom 16. Dezember 1938 hieß es dazu: Die forcierte „Auswanderung der Juden“ müsse mit Hilfe der Überwachung jüdischer Institutionen und ihrer ökonomischen Mittel sowie ihrer $\mathrm{Zu}$ sammenfassung in einer "einheitlichen Organisation" finanziell fundiert werden. In diese $\mathrm{Z}$ wangsorganisation, der späteren „Reichsvereinigung “, würden alle jüdischen Einrichtungen wie Stiftungen, Anstalten, Schulen und die jüdische Wohlfahrtspflege eingegliedert werden. Hierfür werde die alte „Reichsvertretung der Juden" restrukturiert und einer "straffen staatlichen Aufsicht" unterworfen. ${ }^{86}$

Der Aufbau der „Reichsvereinigung“ erfolgte in den nächsten Wochen und Monaten zum Teil unter Nutzung von Personal und Infrastruktur der 1933 gegrün-

82 Zum folg. vgl. Gruner, Armut und Verfolgung. Die gegenteilige These, daß die Reichsvereinigung eine Eigengründung der Vorgängerorganisation Reichsvertretung gewesen sei, findet sich zuletzt bei Hildesheimer, Esriel: Die Jüdische Selbstverwaltung unter dem NSRegime. Der Existenzkampf der Reichsvertretung und Reichsvereinigung der Juden in Deutschland, Tübingen 1994; sowie Kulka, Otto D. (Hrsg.), Deutsches Judentum unter dem Nationalsozialismus. Bd. 1: Dokumente zur Geschichte der Reichsvertretung der deutschen Juden 1933-1939, Tübingen 1997.

83 Werner Best (CdS) an Auswärtiges Amt am 15.11. 1938; zit. bei Wojak, Imtrud, Exil in Chile. Die deutsch-jüdische Emigration während des Nationalsozialismus 1933-1945, Berlin 1994, S. 46. Der Anstoß zur Bildung der Reichsvereinigung ging also von Heydrich und nicht vom Erziehungsministerium aus, wie Adam annahm; vgl. Adam Judenpolitik, S. 228.

${ }^{84}$ Adam vermutet dagegen, Heydrich hätte sich gegen die Übertragung der Fürsorge auf die Reichsvereinigung gewehrt, Adam, Judenpolitik, S. 230, Anm. 152.

85 BA, 49.01, Nr. 11787, Bl. 100-103: Vermerk über die Besprechung betr. Neuerteilung des Schulunterrichts an Juden am 1. 12. 1938 (ohne Datum); vgl. ebenda, Bl. 106-109RS: Anwesenheitsliste und Niederschrift über die Besprechung betr. Neuerteilung des Schulunterrichts an Juden am 1. 12., vom 1. 12. 1938.

86 BA, R 18, Nr. 5519, Bl. 299-305: Notiz RMdI/Adjudantur (Referentenentwurf für die Rede Fricks am 16. 12. 1938) vom 15. 12. 1938. Auszug in: Pätzold, Verfolgung, S. 202, Dok. Nr. 164. 
deten „Reichsvertretung der Juden in Deutschland“. ${ }^{87}$ Die Zwangsgründung unterschied sich aber in Struktur und Aufgaben ebenso grundsätzlich von der alten „Reichsvertretung“, dem Dachverband der Jüdischen Gemeinden bzw. der jüdischen Landes- und Provinzialverbände, wie von internen jüdischen Planungen zur Bildung eines stärker zentralisierten „Reichsverbandes“, die es innerhalb der "Reichsvertretung" wegen der radikalisierten antijüdischen Politik im Sommer 1938 gegeben hatte. ${ }^{88}$ Der „Reichsverband“ sollte nämlich alle Juden im Reich zusammenfassen und ,in ihren religiösen, kulturellen, sozialen und sonstigen Bedürfnissen [...] fördern “, nicht aber deren Emigration. Als freiwillige Mitglieder waren alle Personen jüdischen Glaubens vorgesehen, die Mitglieder von Kultusgemeinden waren. Der Zwangsgründung „Reichsvereinigung“ sollten hingegen alle laut den „Nürnberger Gesetzen“ zu Juden Erklärten angehören. Statt einer Vereinigung aller Kultusgemeinden bzw. selbständigen jüdischen Vereinigungen mit Vertretung im Rat des "Reichsverbandes" 89 sollte es in der neuen „Reichsvereinigung" nur noch von den Weisungen eines ernannten Vorstandes abhängige Zweigstellen geben. Jüdische Gemeinden blieben allein bei Kultusaufgaben noch selbständig. ${ }^{90}$ Wie die organisatorische Struktur glichen auch die Aufgaben der „Reichsvereinigung“ nur auf den ersten Blick denen der "Reichsvertretung“ bzw. des diskutierten "Reichsverbandes", nicht aber beim genauen Hinsehen: Die jüdische Fürsorge stellte künftig nicht mehr eine ergänzende Selbsthilfe zur staatlichen Wohlfahrt dar, sondern eine zwangsweise für die gesamte jüdische Bevölkerung separat zu organisierende Grundversorgung, zentral kontrolliert durch das Sicherheitshauptamt. Die Zentralwohlfahrtsstelle der Juden gliederte man zwangsweise in die Abteilung Fürsorge der Reichsvereinigung ein, welche nun auch für die Jüdische Winterhilfe verantwortlich zeichnete. Die neue Reichsvereinigung unterstand einer „Aufsichtsbehörde", der Gestapo. ${ }^{91}$ Nicht nur zentral, auch lokal konnten jetzt jüdische Organisationen durch die örtlichen Staatspolizeistellen kontrolliert werden, da alle Aktivitäten dort angemeldet und genehmigt werden mußten. ${ }^{92}$ Die Reichsvereinigung war also eine Zwangsorganisation. Auch der Aufbau einer jüdischen Wohlfahrt im Rahmen dieser Organisation darf somit nicht als Wiederbelebung traditioneller jüdischer Selbsthilfeeinrichtungen angesehen werden, wie es ab und an geschieht. Es handelte sich vielmehr um den erzwungenen und strikt überwachten Ausbau eines Fürsorgesystems, das getrennt und unter gänzlich anderen Konditionen als die öffentliche und private Wohlfahrt arbeiten mußte. Ihr - vorgegebenes

87 Zur Geschichte der Reichsvertretung vgl. Kulka, Dokumente, Bd. 1.

88 Zum Reichsverband vgl. Kulka, Dokumente, Bd. 1, S. 410-430.

${ }^{89}$ Satzungsentwurf des Reichsverbandes von 1938, in: Kulka, Dokumente, Bd. 1, S. 418 424.

90 Das waren große Kultusgemeinden und 18, die kleineren Gemeinden zusammenfassende Bezirksstellen; 10. VO zum Reichsbürgergesetz; RGBl., 1939 I, S. 1097. Satzung der Reichsvereinigung von 1939, in: JNB1., Berliner Ausgabe vom 11. 7. 1939, S. 1-2. Vgl. zum Teil ähnliche Argumente für eine Diskontinuität schon bei Plum, Günter: Deutsche Juden oder Juden in Deutschland?, in: Benz, Wolfgang (Hrsg.): Die Juden in Deutschland 1933-1945. Leben unter nationalsozialistischer Herrschaft, München 1988, S. 35-74, hier S. 70-72.

91 Vgl. dazu: Barkai, Boykott, S. 171-172.

92 BA, 15.01, Nr. 27713, Bl. 481: RFSSuChdDtPol an das RMdI vom 20. 12. 1938. 
- Ziel war, der durch die Verfolgung hervorgerufenen, strukturellen Massenverarmung in der jüdischen Bevölkerung, die die Herrschenden als größtes Hindernis für ihre Vertreibungsbemühungen sahen, zu begegnen.

Am 5. Februar 1939 unterrichtete der Chef der Sicherheitspolizei alle Staatspolizeistellen im Reich offiziell über die Zusammenfassung der in "verschiedenartigen jüdischen Organisationen verstreut liegenden Mittel in einer einzigen Organisation“. Es sei der „Reichsvertretung der Juden in Deutschland“ befohlen worden, „eine sogenannte Reichsvereinigung der Juden zu bilden und dafür zu sorgen, daß gleichzeitig alle bisher bestehenden jüdischen Organisationen verschwinden und ihre gesamten Einrichtungen der Reichsvereinigung zur Verfügung stellen". Die Gestapostellen sollten diesen Prozeß vor Ort genau observieren, aber nicht stören, denn die "notwendige Kontrolle" werde zentral in Berlin ausgeübt. ${ }^{93}$ Auf der ersten Sitzung der nach dem Vorbild der Wiener Zentralstelle kürzlich geschaffenen „Reichszentrale für die jüdische Abwanderung“, welche die forcierte Vertreibung seit dem Pogrom interministeriell koordinieren und dabei speziell für die "bevorzugte Auswanderung der ärmeren Juden sorgen“ sollte ${ }^{94}$, informierte Heydrich am 11. Februar die Ministerialbeamten über "die Heranziehung der Judenschaft selbst zu der Lösung der Auswanderungsfrage“. $\mathrm{Zu}$ diesem Zweck habe man alle "Rassejuden“ in der „Reichsvereinigung " zusammengefaßt. ${ }^{95}$ Am 17. Februar 1939 erfuhr auch die jüdische Öffentlichkeit durch das "Jüdische Nachrichtenblatt" von der Bildung der Zwangsorganisation, als deren Vorsitzender künftig Leo Baeck fungierte. ${ }^{96}$

Während der Aufbau der geplanten Organisationsstrukturen rasch vonstatten ging, verzögerte sich jedoch deren formelle Etablierung. Die Zwangsorganisation sollte eigentlich per Polizeiverordnung ins Leben gerufen werden. ${ }^{97}$ Doch das erwies sich offenbar als nicht praktikabel, und seit Ende Februar/Anfang März wurde statt dessen eine "Verordnung zum Reichsbürgergesetz" favorisiert. Man wolle alle „zu erlassenden Vorschriften in einer Verordnung zum Reichsbürgergesetz zusammenfassen", so Staatssekretär Stuckart (RMdI) am 7. März 1939 in der Einladung zu einer Ministerialbesprechung über diesen Plan. ${ }^{98}$ Offenbar sollte die

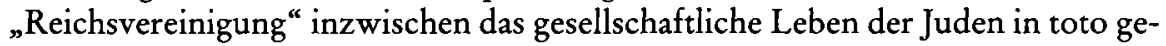
trennt von der übrigen Bevölkerung organisieren. Im März hatte man sogar schon

93 YV Jerusalem, 051/OSOBI, Nr. 8 (500-2-87), Bl. 1-2: CdS-Runderlaß (Müller) vom 5. 2. 1939. Vgl. Pätzold, Verfolgung, S. 222-223, Dok. Nr. 186: Runderlaß Stapoleitstelle Düsseldorf vom 20. 2. 1939.

94 Am 24. Januar 1939 hatte Göring die Bildung der Reichszentrale verkündet; BA, R 14, Nr. 301, Bl. 221: Göring an RMdI am 24. 1. 1939; vgl. Sauer, Verfolgung, Teil II, Nr. 365, S. $119-120$.

95 Pätzold/Runge, Pogromnacht 1938, S. 223-224, Dok. Nr. 76: Niederschrift der Besprechung am 11.2. 1939.

96 JNBl., Berliner Ausgabe, Nr. 14 vom 17. 2. 1939, S. 1.

97 Vgl. Erwähnung in: BA, R 18, Nr. 5519, Bl. 377-379: Schreiben Stuckarts (RMdI) vom 7.3. 1939.

98 Ebenda: Schreiben Stuckarts (RMdI) vom 7.3.1939 mit Anhang VO-Entwurf. Der Entwurf vom 7. 3. 1939 war mit der späteren VO zum RBG nahezu identisch; vgl. Abdruck ausgewählter Paragraphen bei Hildesheimer, Selbstverwaltung, S. 99-101 sowie Kulka, Dokumente, Bd. 1, S. 442, Anm. 5. 
im Deutschen Gemeindetag erfahren, daß ihr auch die Regelung aller „kulturellen Belange der Juden (Schule, Theater, Kultus) " übertragen werden sollte. ${ }^{99}$ Die notwendige Abstimmung zwischen den Ministerien und dem Stellvertreter des Führers über die zu erlassende Verordnung verzögerte sich jedoch, während die Zwangsorganisation bereits arbeitete. Die angeführten, eher verwaltungstechnischen Details erklären, warum die „Reichsvereinigung“ erst im Juli 1939 offiziell gegründet wurde, obwohl dies eigentlich seit dem Novemberpogrom als Teil der neuen Verfolgungskonzeption geplant war. 100

Unterdessen setzten sich die Funktionäre des Deutschen Gemeindetages bereits dafür ein, daß der neuen „Reichsvereinigung die Fürsorge für die hilfsbedürftigen Juden in vollem Umfange auferlegt" werde. ${ }^{101}$ Ministerialrat Ruppert hatte nämlich den Deutschen Gemeindetag am 1. März 1939 auf einer Sitzung informiert, „daß eine Durchführungsverordnung zum Reichsbürgergesetz bevorstände, die eine Zwangsvereinigung aller Juden, auch der christlich getauften, vorsieht, mit dem Zweck, auf Grundlage von Zwangsbeiträgen die Fragen der Auswanderung, des Schulwesens und der Offenen und Geschlossenen Wohlfahrtspflege geldlich sicherzustellen". ${ }^{102}$ Die formelle Übertragung der Fürsorgepflicht auf die Zwangsorganisation sollte also die mit der antijüdischen Verordnung vom 19. November 1938 vorgenommene Ausgrenzung der jüdischen Armen aus der öffentlichen Wohlfahrtspflege logistisch absichern. Allerdings ließ sich die Separierung der jüdischen Armen, wie zu zeigen sein wird, weder im Reich noch vor Ort so schnell wie geplant realisieren.

\section{Der chaotische Zwangstransfer der Fürsorgepflicht (Winter 1938/39 - Frühjahr 1939)}

\section{Zur Ausgrenzung vor Ort: Initiativen und Hindernisse}

Den Kommunen hatte man im Rahmen der Neuorientierung der Verfolgung die "Ghettoisierung“ der jüdischen Bevölkerung aufgetragen. Neben dieser Aufgabe enthielt das neuentwickelte Verfolgungsprogramm eine Reihe von Maßnahmen, die in den Städten und Gemeinden umzusetzen waren. Den Geschlossenen Arbeitseinsatz organisierten die lokalen Arbeitsämter ${ }^{103}$, den Zwangsankauf von Schmuck und Edelmetall die städtischen Pfandleihanstalten ${ }^{104}$, und die Übertragung der staatlichen Fürsorgepflicht auf jüdische Einrichtungen die städtischen Wohlfahrtsämter.

99 BA, R 36, Nr. 1022, Bl. 5: DGT Berlin (Geschäftsf. Präs.) an Fiehler am 4. 4. 1939 (Entwurf von Ende März). Vgl. Erwähnung bei Adam, Judenpolitik, S. 230.

100 Zur Gründung im Juli 1939 vgl. Kapitel IV. 3.

101 BA, R 36, Nr. 1022, Bl. 22: DGT Berlin (i.A. Preiser) an DGT-Provinzialdienststelle Schlesien am 8.5.1939.

102 Dokumente Frankfurter Juden, VI 44, S. 320-322: Bericht vom 3. 3. über DGT-Tagung in Berlin am 1. 3. 1939.

103 Vgl. Gruner, Geschlossener Arbeitseinsatz, S. 68-92.

104 Ausführlich dazu: Gruner, Deutscher Gemeindetag, S. 277-289. 
Obgleich die antijüdische Fürsorge-Verordnung erst ab dem 1. Januar 1939 in Kraft treten sollte, hatten einige Städte unmittelbar auf deren Bekanntgabe reagiert. In Göttingen lud das Wohlfahrtsamt bereits Anfang Dezember $1938 \mathrm{zu}$ einer Besprechung des Vorgehens ein, denn man wollte jüdische Arme ab sofort nicht mehr versorgen. Die Wohlfahrtsbeamten begründeten dies damit, daß der örtliche Jüdische Hilfsverein der Zentralwohlfahrtsstelle über genügend Mittel verfüge, um jene unterstützen zu können. Zwar sei das Vermögen des Hilfsvereins konfisziert, doch, so die Göttinger Beamten zynisch, „wenn eine Freigabe des beschlagnahmten Vermögens nicht zu erreichen sei, dann müssen die wohlhabenden Juden zu Beiträgen herangezogen werden". ${ }^{105}$ Ab Ende Dezember sperrte man dort sämtliche Sozialunterstützungen. ${ }^{106}$

In Nürnberg hatte man bereits kurz vor dem Pogrom begonnen, alle bedürftigen Juden an die dortige Jüdische Gemeinde zu verweisen. Die neue Verordnung hatte diese Praxis zwar legitimiert, aber die Fürsorgebehörden im unklaren gelassen, in welchen Ausnahmefällen die Öffentliche Wohlfahrt doch einzugreifen habe. Deshalb stellte man sich in Nürnberg auf den Standpunkt, der Notfall könne keineswegs „einfach bei der Erklärung der Juden, nicht helfen zu können, vorliegen“. Man werde deshalb davon ausgehen, daß die jüdische Wohlfahrtspflege generell alle jüdischen Armen versorgen müsse. ${ }^{107}$ Ab Januar 1939 versorgte das Fürsorgeamt Nürnberg nicht einmal mehr die nichtjüdischen Ehepartner jüdischer Hilfsbedürftiger bzw. deren Familienangehörigen. ${ }^{108}$

Nach ersten - oben beschriebenen - Ankündigungen hatte München seit dem 1. Dezember 1938 ebenfalls offiziell die Unterstützung jüdischer Armer aus kommunalen Mitteln gesperrt. ${ }^{109}$ Allerdings stellte sich in der bayerischen Landeshauptstadt schnell heraus, daß die Israelitische Kultusgemeinde München gar nicht arbeitsfähig war. Weder hatte diese so kurz nach dem Pogrom ihre Geschäfte voll aufnehmen können ${ }^{110}$, noch verfügte sie bereits wieder über alle zuvor konfiszierten Einrichtungen. Das Städtische Wohlfahrtsamt verhandelte zwar sofort mit Gestapo und NSDAP-Gauleitung, doch die Wiederaufnahme der Gemeindearbeit verzögerte sich, so daß die Stadt mit dem Transfer der jüdischen Klienten noch warten mußte. ${ }^{111}$ In der Zwischenzeit richtete sich München einerseits nach den reichsgesetzlichen Vorschriften, andererseits für die ohne zentrale Anweisungen gebliebenen Fürsorgegebiete nach den mit der Gauleitung und der Gestapo getroffenen Absprachen: Zwar sei die „Befürsorgung“ der Juden Sache der IKG

105 StadtA Göttingen, Sozialamt, Acc. Nr. 407/77, Nr.47, 1, unfol.: Aktennotiz vom 7. 12.1938.

106 Ebenda: Aktennotiz vom 28. 12. 1938.

107 Bericht des Gauamtes für Kommunalpolitik Franken, in: BA, NS 25, Nr. 86, Bl. 75 : NSDAP-Reichsleitung/HA Kommunalpolitik „Vertrauliche Berichtsauszüge“, I. Sendung vom 15.1. 1939, S. 1.

108 YV Jerusalem, M1DN, Nr. 162, Bl. 34: DGT-Dienststelle Bayern an den BFV MünchenStadt am 12.1. 1939.

109 Erwähnt in: BA, R 36, Nr. 1022, Bl. 143: OB/Wohlfahrtsamt München an Staatsministerium des Innern am 23. 10. 1940.

110 YV Jerusalem, M1DN, Nr. 168, Bl. 172: Vermerk Umhau (Persönl. Referent Fiehlers in München) für Dezernat 6 vom 30.11. 1938.

111 Hanke, Juden in München, S. 266-269. 
München, doch solle abgewartet werden, bis diese die beschlagnahmten jüdischen Altersheime wiedereröffnen könne. Die in öffentlichen Heil- und Pflegeanstalten untergebrachten jüdischen Kranken blieben zunächst dort. Obdachlose Juden würden künftig „nach einer in Aussicht stehenden Verordnung " in die Wohnungen und Hausgemeinschaften „ihrer Rassegenossen“ eingewiesen. Ausländische Juden würden wie Ausländer behandelt, in der Familienunterstützung gebe es aber keine Einschränkungen. ${ }^{112}$ Auf Vorschlag des Münchner Jugendamtes entschied Mitte Dezember 1938 dann Oberbürgermeister Fiehler in Anbetracht der „günstigen Wirtschaftslage der Juden in München“, noch vor dem Inkrafttreten der Verordnung vom 19. November aber zumindest die Versorgung jüdischer hilfsbedürftiger Minderjähriger, die meist in jüdischen Anstalten lebten, einzustellen. Zuvor schon hatte man für diese wegen der angeblich „mangelnden Bereitwilligkeit jüdischer Familien, jüdische Kinder, für die die öffentliche Fürsorge aufkommen mußte, in Familienpflege zu nehmen“, statt der realen Anstaltskosten nur geminderte Leistungen in Höhe der Familienpflege gezahlt. 113

Als die antijüdische Fürsorge-Verordnung zu Beginn des Jahres 1939 in Kraft trat, verstanden dies viele Kommunen als Startsignal, sich der jüdischen Fürsorgeklientel rasch zu entledigen. Von den Großstädten mit über 200000 Einwohnern stellten neben den schon genannten Nürnberg und München in dieser Phase auch Köln, Breslau, Dortmund, Chemnitz, Stuttgart und Düsseldorf ${ }^{114}$ ihre Zahlungen ein. Einige verweigerten die Fürsorge bei Juden vollständig, andere zumindest die Offene Fürsorge, die den Löwenanteil der Ausgaben ausmachte. ${ }^{115}$ Allein in Breslau war ab 1. Januar 1939 die Versorgung von 1400 jüdischen Armen an die Jüdische Gemeinde übergegangen. Die Stadt rechtfertigte den $Z$ wangstransfer damit, $\mathrm{daß}$ die Jüdische Gemeinde noch über beachtliche Vermögenswerte verfüge. Die Geschlossene Fürsorge mußte die Stadt ungewollt weiter ausüben, denn es gab keinerlei jüdische Anstalten vor Ort. ${ }^{116}$

Zahlten also einige Städte nur noch in der Geschlossenen Fürsorge, der Anstaltspflege, so andere hingegen nur noch in der Offenen Fürsorge. In den Städten,

112 YV Jerusalem, M1DN, Nr.168, Bl.172: Vermerk Umhau für Dezernat 6 vom 30.11. 1938.

113 Münchner Neueste Nachrichten vom 16. 12. 1938.

114 Das Wohlfahrtsamt Düsseldorf hatte vor dem 1. Januar 1939 in der Offenen Fürsorge noch 98 Juden unterstützt, wenn auch bereits nur noch mit den Sätzen der Allgemeinen Fürsorge. In der Geschlossenen Fürsorge zählte die Stadt 26 jüdische Hilfsbedürftige in Provinzialanstalten, 17 in Altersheimen und 2 in jüdischen Kinderheimen. Die Düsseldorfer Synagogengemeinde mußte also von einem Tag zum anderen über 100 Menschen mehr versorgen; OB Düsseldorf an DGT-Rheinland-Hohenzollern am 31. 5. 1939; Faksimile bei Sparing, Boykott, Enteignung, Zwangsarbeit, S.63. Vgl. dazu BA, R 36, Nr. 1022, Bl. 14-16RS: Zusammenstellung der Ergebnisse der Umfrage über Unterstützung von Juden, DGT-Rheinland-Hohenzollern in Düsseldorf vom 22. 8. 1939.

115 (Siehe Tabellen im Anhang) Die offene Fürsorge im Vierteljahr Januar-März 1939 (Ergebnisse des Schnelldienstes der Reichsfürsorgestatistik), (Berlin 1939), S. 8. Auch der BFV Magdeburg stellte für Juden sämtliche Leistungen zum 1. Januar 1939 ein; erwähnt in: BA, R 36, Nr. 1022, Bl. 65: OB Magdeburg an DGT Berlin am 16. 11. 1939.

116 Erwähnt in: Dokumente Frankfurter Juden, VI 44, S. 320-322: Bericht vom 3. 3. über Tagung des DGT in Berlin am 1. 3. 1939. Vgl. zu Breslau: BA, 75 C Re 1, Nr. 761, Bl. 138140: RV/Abt. Fürsorge (Cohn) an Oberpräsidenten/LFV in Breslau am 18. 4. 1940. 
wo die Wohlfahrtsämter weiter jüdische Arme in der Offenen Fürsorge unterstützten, taten sie dies aber unter Anlegung neuer Kriterien. Zunächst verwiesen sie alle jüdischen Armen an jüdische Stellen. Konnten jene nicht aushelfen, nahm man zwar jüdische Hilfsbedürftige in die städtische Betreuung auf, senkte aber meist die Leistungssätze. Wenn in Karlsruhe das Wohlfahrtsamt zahlte, dann nach der neuen Verordnung nur noch in der Allgemeinen Fürsorge, allerdings mit nur 80 Prozent der hier möglichen Leistungen unter Einrechnung aller bisher freigestellten Einkommen und unter Ausschluß von Zusatzhilfen wie Wochenfürsorge. Krankenpflege sollte es nur im Notfall geben. Alleinstehende Juden wollte man sogar in Heime einweisen und ihnen nur Geschlossene Fürsorge gewähren. Bei der Verteilung von Stiftungserträgen klammerte man Juden künftig aus. Diese Maximen der Stadt Karlsruhe wurden auf einer Tagung des Deutschen Gemeindetages in Baden von den lokalen Fürsorgedezernenten einhellig begrüßt.117

Von den Großstädten mit über 200000 Einwohnern zahlten laut Reichsfürsorgestatistik auch Berlin, Hamburg, Leipzig, Essen, Dresden, Frankfurt am Main, Hannover, Gelsenkirchen, Wuppertal, Bremen und Königsberg weiter in der Offenen Fürsorge an jüdische Arme. ${ }^{118}$ Doch die Ergebnisse des Schnelldienstes offenbaren nur die halbe Wahrheit, denn Leipzig taucht hier zwar auf, hatte seine Unterstützung in der Offenen Fürsorge aber teilweise eingestellt. Das dortige Fürsorgeamt hatte schon am 1. Dezember 1938 bei allen Unterstützungsstellen erfassen lassen, wieviel Juden, getrennt nach deutschen, ausländischen und staatenlosen Bedürftigen, „aus Fürsorgemitteln einschl. Kleinrentnerhilfe in offener oder Anstaltspflege zu unterstützen gewesen sind, und welcher Aufwand dadurch im angegebenen Monat entstanden ist“. ${ }^{119}$ Am 20. Dezember 1938 sperrte Leipzig die Fürsorgeunterstützung für alle Juden in der Offenen Fürsorge, ab Januar 1939 auch bei der Kleinrentnerhilfe. Anstaltspflege, also Geschlossene Fürsorge, sollte vorerst weiter bezahlt werden. ${ }^{120} \mathrm{Am} 29$. Dezember korrigierte das Fürsorgeamt seine Anweisung und klammerte polnische und tschechische Juden, die anders als in den meisten Orten hier ungefähr die Hälfte der jüdischen Unterstützten stellten, von der Sperre in der Offenen Fürsorge aus, da mit den betreffenden Staaten Abkommen bestanden.121 Das Fürsorgeamt verständigte am 2. Januar 1939 noch einmal seine Bezirksstellen, daß - außer für polnische und tschechische Juden alle Zahlungen an deutsche, staatenlose und ausländische Juden einzustellen, Behandlungs- und Kohlengutscheine nicht mehr auszugeben seien. Die Unterstüt-

117 StadtA Freiburg i. Br., C4 XVII/6, Nr. 6, unfol.: Rundschreiben DGT Baden an die Badischen BFV am 6. 1.1939 mit Anhang: Rundschreiben der Stadt Karlsruhe über die Behandlung der Juden in der Fürsorge (undat.).

118 (Siehe Tabellen im Anhang) Die offene Fürsorge im Vierteljahr Januar-März 1939 (Ergebnisse des Schnelldienstes der Reichsfürsorgestatistik), (Berlin 1939), S. 8.

119 StadtA Leipzig, AFS, Nr. 1759, Bl. 234: Rundschreiben Fürsorgeamt Leipzig vom 1. 12.1938.

120 Ebenda, Bl. 239: Dienstanweisung Fürsorgeamt Leipzig vom 20. 12. 1938.

121 Für mit Juden verheiratete „Arierinnen“ galt künftig, daß diese nicht mehr den Familienzuschlag der Gehobenen, sondern nur noch der Allgemeinen Fürsorge erhielten. Auch der Mietzuschlag für die Familie fiel weg, da die Bezahlung Sache des Familienoberhauptes sei; ebenda, Bl. 241: Dienstanweisung Fürsorgeamt Leipzig vom 29. 12. 1938. 
zung deutscher Juden werde in der Offenen Fürsorge ab sofort durch die Israelitische Religionsgemeinde (Israelitisches Wohlfahrtsamt) Leipzig übernommen. 122

In Frankfurt am Main verfuhr man genau andersherum. In der ersten Hälfte des Jahres 1939 trug das städtische Fürsorgeamt die Gesamtkosten für die Offene Fürsorge, während die Jüdische Gemeinde den Aufwand für die Geschlossene Fürsorge übernahm. Die Stadt zahlte ebenfalls lediglich 80 Prozent des Richtsatzes der Allgemeinen Fürsorge. Sonderleistungen wie Ernährungsbeihilfen, Schwangerschaftshilfen, Gesundheitsfürsorge und die Mietbeihilfe mußte bereits die Jüdische Wohlfahrtsstelle tragen. ${ }^{123}$ In einer Besprechung mit dem Oberbürgermeister rechnete die städtische Fürsorge gleichwohl bereits im Februar 1939 fest damit, daß „die Leistungskraft der Jüdischen Wohlfahrtspflege in zunehmenden Umfang sich verringere, und daß die Zahl der hilfsbedürftigen Juden, namentlich der Dauerpfleglinge (Alte, Sieche) zunehme“. Verschärfend käme hinzu, daß die Bezirksfürsorgeverbände der näheren und weiteren Umgebung sich auf Kosten der Stadt ,judenfrei“ gemacht hätten. Deshalb müsse die Stadt die sparsame Verwendung der Finanzen in der jüdischen Fürsorge überwachen. ${ }^{124}$ Die Stadt hatte zu diesem Zweck seit dem Novemberpogrom einen "Sonderbeauftragten für die jüdische Wohlfahrtspflege" ernannt.125

Die Gestapo in Frankfurt am Main wollte aber diese städtischen Pläne durchkreuzen, da sie die jüdischen Einrichtungen selbst zu kontrollieren gedachte. Sie warf der Kommune bald vor, die jüdischen Armen „schlecht behandelt" zu haben, was auf den ersten Blick paradox anmutet. ${ }^{126}$ Die Kritik entsprang jedoch der Tatsache, daß die Sicherheitspolizei jetzt im Rahmen des neuen Verfolgungskonzepts überall daran interessiert war, die Arbeitsfähigkeit jüdischer Sozialeinrichtungen zu garantieren, ja zuweilen sogar noch zu erweitern. Deshalb entstanden unerwartete Interessenkollisionen mit städtischen Behörden, wenn diese ohne Rücksicht auf die Finanzlage jüdischer Einrichtungen agierten. Wurde die jüdische Wohlfahrt in der Regel von der örtlichen Gestapo überwacht, so taten dies in einigen Orten jetzt auch die örtlichen Wohlfahrtsämter. ${ }^{127}$ Damit die staatlichen Fürsorgeverbände sich jüdischer Armer schnell entledigen konnten, überprüften je nach Organisation und Kräfteverhältnis vor Ort staatliche, kommunale oder

122 Ebenda, Nr. 1798, Bl. 198: Rundschreiben OB/Fürsorgeamt Leipzig vom 2. 1. 1939. Neben der Geschlossenen Fürsorge zahlte die Stadt noch den Tagessatz für pflegebedürftige Juden im Israelitischen Krankenhaus; Der Pflegesatz betrug 2,40 RM; ebenda, B1. 253: Dienstanweisung OB/Fürsorgeamt Leipzig vom 23. 1. 1939.

123 Dokumente Frankfurter Juden, VI 46, S. 323: Bericht des Rechnungsprüfungsamtes vom 23.6. 1939.

124 Ebenda, VI 47, S. 329-330: Besprechung Fürsorgeamt mit OB Frankfurt/M. am 26. 2. 1939.

125 Offenbar seit November 1938 handelte dieser in städtischem Auftrag. Ab 1940 unterlag er der Weisung der Gestapo; Kingreen, Raubzüge, S. 26-30, sowie Becht, Lutz: „Der Beauftragte der Geheimen Staatspolizei bei der jüdischen Wohlfahrtspflege in Frankfurt am Main", in: Frankfurt am Main, Lindenstraße. Gestapozentrale und Widerstand, Frankfurt am Main u. a. 1996, S. 87-99.

126 Dokumente Frankfurter Juden, VI 47, S. 329-330: Besprechung Fürsorgeamt mit OB Frankfurt/M. am 26. 2. 1939. Datum eigtl. 26. 6.; vgl. Kingreen, Raubzüge, S. 47, Anm. 96.

$127 \mathrm{BA}, 75 \mathrm{C}$ Re 1, Nr. 761, Bl. 94: Cohn (RV) an IKG München am 26. 8. 1940. 
polizeiliche Instanzen die finanziellen Möglichkeiten jüdischer Gemeinden zur Übernahme der Versorgung jüdischer Hilfsbedürftiger. Je nach lokaler Situation ergaben sich auf diese Weise die unterschiedlichsten Schlüssel für die zwangsweise Beteiligung jüdischer Stellen an der Finanzierung der öffentlichen Sozialunterstützung. Es kursierten sogar seit Januar 1939 von der „Reichsvereinigung“ mit Genehmigung der Gestapo aufgestellte Richtlinien, die eine Kostenteilung zwischen Fürsorgeverband und Jüdischer Gemeinde vor Ort vorschlugen. Das auf die Beispiele Frankfurt am Main und Mannheim verweisende Merkblatt gelangte über die Jüdischen Gemeinden auch in die Kommunalverwaltungen.128

In Württemberg hatte das Innenministerium hingegen eine landesweite Prüfung der Leistungsfähigkeit jüdischer Gemeinden schon Ende 1938 eingeleitet.129 Mit dem drastischen Ergebnis, daß ab 1. Januar 1939 im gesamten Land jüdische Arme von der Öffentlichen Wohlfahrt nicht mehr betreut wurden. Nur die Großstadt Stuttgart hatte sich anfänglich noch zu einem Kompromiß bereit gefunden und wollte die Hälfte der Fürsorgelasten übernehmen. Doch schon am 10. Januar 1939 kündigte man das kommunale Agreement mit der jüdischen Wohlfahrt, da der Oberfinanzpräsident deren beschlagnahmte Gelder freigegeben hatte. ${ }^{130}$

In Hamburg, wo Juden auf allen Fürsorgegebieten inzwischen geringere Unterstützungssätze erhielten ${ }^{131}$, wurden in zwei Dienstvorschriften vom 22. Dezember 1938 und 17. Januar 1939 die Einzelheiten der lokalen Praxis nach der Fürsorge-Verordnung geregelt. Die Hansestadt gehörte zu den Orten, denen es Schwierigkeiten bereitete, sich sofort der Versorgung aller jüdischen Armen zu entledigen. In der Offenen Fürsorge unterstützte die Stadt im Januar 1939 noch 608 jüdische Parteien, d. h. rund 850 Hilfsbedürftige. ${ }^{132}$ Zugleich verhandelten Sozialverwaltung und Gestapo mit den jüdischen Gemeindefunktionären über die Frage, "wieweit die Fürsorgekosten für Juden von den jüdischen Verbänden" getragen werden könnten, woraufhin letztere einen "Teil der Fürsorgeleistungen“ übernehmen mußten. ${ }^{133}$ Dem Frankfurter Vorgehen vergleichbar, wurden der Jüdischen Religionsgemeinde nun die Kosten der in Alten- und Siechenheimen, der in Wohnstiften untergebrachten Hilfsbedürftigen sowie der Waisenhauszöglinge „auferlegt“. Das Hamburger Sozialamt wollte aber darüber hinaus bereits alle städtischen Ausgaben auch in der Offenen Fürsorge ersetzt haben. Man habe festgestellt, daß das Grundvermögen der Religionsgemeinde ca. ein Jahr lang die

128 Erwähnt in: YV Jerusalem, M1DN, Nr. 162, Bl. 39-40: Vermerk des OB/Dezernat 6 München vom 19.1.1939; ebenda, B1. 194-198: Koreferat des OB/Dez. 6 München (ohne Datum) zur 6. Tagung der Süddt. ArbG für Wohlfahrtspflege am 27. 1. 1939 in Bad Dürkheim.

129 Sauer, Verfolgung, Teil II, Nr. 375, S. 134: Rundschreiben Ministerialabteilung für Bezirks- und Körperschaftsverwaltung Stuttgart vom 28. 12. 1938.

130 Ebenda, Nr. 377, S. 137: Israelitisches Fürsorgeamt an Württ. Innenministerium am 9. 3. 1939 .

131 StA Hamburg, 351-10 Sozialbehörde I, AW 40.30, unfol.: Vermerk der AFÜ vom 11. 1.1939.

132 Lohalm, Fürsorge und Verfolgung, S. 50-52.

133 StA Hamburg, 351-10 Sozialbehörde I, AW 40.30, unfol.: Vermerk der AFÜ vom 20. 1.1939. 
„Barunterstützung für die hilfsbedürftigen Juden sicherstellen“ würde. ${ }^{134}$ In einem stufenweisen Plan sollte in Hamburg demnächst der Transfer der ärztlichen Versorgung und der Krankenhilfe auf die jüdische Seite erfolgen. Erst am Schluß stand die Abgabe der Offenen Fürsorge, denn Hamburg wollte noch von der Möglichkeit profitieren, Pflichtarbeit von den Armen verlangen zu können. Als Zieltermin faßte die Sozialverwaltung den 1. April 1939 ins Auge. Wegen des zu hohen Verwaltungsaufwandes ging dann zu diesem Zeitpunkt dennoch nicht die gesamte Fürsorge auf die jüdischen Stellen über. Hamburg ließ sich aber in Absprache mit der Gestapo nun alle Ausgaben von der Jüdischen Gemeinde erstatten. Beim Ankauf von Grundstücken der Religionsgemeinde verrechnete man die städtischen Fürsorgekosten mit den Kaufpreisen. ${ }^{135}$ Das Verfahren, Mittel zur öffentlichen Versorgung jüdischer Armer über die „Arisierung“ von Immobilien zu erlangen, sollte übrigens Schule machen, selbst in den besetzten Gebieten: Im Herbst 1940 forderte z. B. die Sozialhauptkasse in Warschau die Übertragung von Grundstücken der dortigen Religionsgemeinde, um ausstehende Versicherungsbeiträge sowie getätigte Ausgaben abzudecken, bevor die geplante Bildung eines Ghettos solche Möglichkeiten künftig vereitele. ${ }^{136}$

In München dachte man über die Maximen der Fürsorge-Verordnung längst weit hinaus. Nach der Einstellung jeglicher Fürsorge für jüdische Arme plante das städtische Wohlfahrtsamt schon Mitte Dezember 1938 ein noch radikaleres Vorgehen, wovon es Oberbürgermeister Fiehler überzeugen wollte: Wenn man der neuen Verordnung folgend, die Versorgung der Münchner Juden der jüdischen Wohlfahrtspflege aufbürden könne, brauche die Behörde doch nicht zu respektieren, daß die jüdische Einrichtung es ablehne, „Rassejuden“ zu versorgen. Diese könne man doch , an die Pfarreien bzw. an die konfessionell karitativen Organisationen [...] verweisen, dies umsomehr als gerade die kirchlichen Kreise [...] auch sonst der nationalsozialistischen Rasselehre ablehnend gegenüberstehen“. Das Wohlfahrtsamt schlug vor, eine Stelle einzurichten, um die jüdische Wohlfahrtspflege und deren Leistungsfähigkeit zu kontrollieren. Für die trotz allem noch von der Öffentlichen Fürsorge zu Betreuenden, d.h. Juden in Mischehen bzw. schwerbeschädigte Juden, sollten eigene Richtsätze kreiert werden, obwohl dies nicht unbedingt erforderlich sei, da die "individuelle Handhabung der Fürsorge genug Möglichkeiten bietet, bei Juden das Unterstützungsausmaß niedriger zu halten“. Das Amt plante, für diese Gruppen die Leistungen auf folgende Sätze zu begrenzen: Für alleinstehende Juden auf $30 \mathrm{RM}$, für Ehegatten auf $15 \mathrm{RM}$, für Kinder auf $10 \mathrm{RM}$. Mietbeihilfen seien nicht zwingend vorgeschrieben und sollten nicht mehr gewährt werden, Sonderzuschläge nur noch, um der Fürsorge spätere Krankenhauskosten zu ersparen. ${ }^{137}$ Am 7. Januar 1939 vollzog das Münchner

134 BA, R 36, Nr. 899, unfol.: 8. Tagung Nordwestdt. ArbG für Wohlfahrtspflege am 13. 3.1939 in Rostock, S. 26.

135 Lohalm, Fürsorge und Verfolgung, S. 51-54.

136 BA, 39.01, Nr. 5788, Bl. 171: Bericht Sozialversicherungskasse Warschau für den Monat September 1940.

137 YV Jerusalem, M1DN, Nr. 109, Bl. 157-161: Vorlage Dezernat 6 für OB München vom 13. 12. 1938; vgl. ebenda, Nr. 168, Bl. 182-186. 
Wohlfahrtsamt den geplanten Schritt und verfügte, daß alle hilfsbedürftigen Juden, „Rassejuden“ eingeschlossen, an die Israelitische Kultusgemeinde zu verweisen seien. ${ }^{138}$ Mit ihrer Initiative übertrat die Münchner Stadtverwaltung zum wiederholten Male zentrale Verfolgungsprämissen. Denn laut der gerade erst in Kraft getretenen Fürsorge-Verordnung ging die Wohlfahrt an die Jüdischen Kultusvereinigungen über, die aber nur Mitglieder versorgten. Erst Monate später, mit der offiziellen Gründung der Reichsvereinigung, mußte die jüdische Fürsorge offiziell die Betreuung aller Juden im Sinne der „Nürnberger Rassengesetze“ übernehmen. Ob die Öffentliche Wohlfahrt noch zugunsten von bedürftigen Juden eingriff, differierte also lokal erheblich und hing wohl in besonderem Maße von den lokalen Kräfteverhältnissen zwischen Kommune und Gestapo ab.

\section{Die Fürsorgepraxis in der Reichshauptstadt Berlin}

In Berlin, der Stadt mit der größten Zahl jüdischer Einwohner im Altreich, hatte das Landeswohlfahrtsamt im Oktober 1938 noch über 7500 Juden unterstützt ${ }^{139}$ Für diese wandte es in jenem Monat 294000 RM auf. Die städtischen Kosten sanken nach dem Pogrom jedoch aus zwei Gründen schnell: In Vollzug der antijüdischen Fürsorge-Verordnung fielen nun die höheren Leistungen in privilegierten Versorgungsklassen, die vorher über 2700 jüdische Berliner bezogen, weg. Eine große Zahl Hilfsbedürftiger schied zudem zwangsweise aufgrund verschärfter Anerkennungsprüfungen aus der städtischen Obhut aus. ${ }^{140}$

Infolge der antijüdischen Fürsorge-Verordnung wollte Berlin aber sämtliche Leistungen für jüdische Berliner eingestellt wissen. Am 3. Dezember 1938 verfügte der Berliner Stadtpräsident und Oberbürgermeister Lippert persönlich, daß die Bezirkswohlfahrtsämter alle Zahlungen an Juden streng zu überprüfen hätten. Wenn überhaupt, gewährte man jetzt jüdischen Bedürftigen nur noch den lebensnotwendigen Mindestbedarf, den sie ausnahmslos durch Pflichtarbeit abzugelten hätten. ${ }^{141}$ Um die städtischen Ausgaben weiter zu senken, entschied der Chef des Berliner Landeswohlfahrtsamtes und Leiter der Ostdeutschen Arbeitsgemeinschaft für Wohlfahrtspflege des Deutschen Gemeindetages, Behagel, außerdem, ab Januar 1939 keine Kosten mehr für wohlfahrtsberechtigte jüdische Patienten in jüdischen Anstalten zu erstatten. Nicht von ungefähr plante man in der Stadtverwaltung gleichzeitig, alle Juden aus städtischen Anstalten in jüdische Heime zu verlegen..$^{142}$

138 Ebenda, Nr. 121, Bl. 30-31: Rundschreiben OB/Dezernat 6 München vom 7. 1. 1939.

139 Zum folgenden vgl. Gruner, Reichshauptstadt, S. 240; ders., Judenverfolgung in Berlin, S. 61-63.

140 BA, R 41, Nr. 155, Bl. 124: Sonderbericht (Lippert) vom 5. 1.1939 zum Wirtschaftslagebericht für Berlin, S. 13 und Tabelle im Anhang.

141 Dienstblatt Berlin, 1938 Teil VII, S. 342, Nr. 360: Vfg. OB Lippert vom 3. 12. 1938; vgl. LA Berlin, Rep. 214, Acc. 794, Nr. 13, unfol.: Vfg. OB Lippert vom 3. 12. und Besprechung vom 7. 12. 1938. Außerdem ebenda: Protokoll der Sitzung im Landeswohlfahrtsamt vom 3. 12. 1938 sowie ebenda, Rep. 203, Acc. 867, Nr. 5100, Bl. 19: Vermerk über Sitzung am 14.1. 1939.

142 Dienstblatt Berlin, 1938 Teil VII, S. 349-350, Nr. 373: Vfg. Behagel (Landeswohlfahrts- 
$\mathrm{Zu}$ diesem Zeitpunkt durften Juden in Berlin nicht mehr an der städtischen Volks- und Kinderspeisung teilnehmen. ${ }^{143}$ Das Jugendamt des Berliner Bezirks Mitte lehnte seit dem 20. Dezember 1938 die Übernahme der Unterhaltskosten von jüdischen Kindern ab, die sich in privater Pflege befanden. Als nach der Verweigerung des Jugendamtes Mitte aber auch das Jugendamt der Jüdischen Gemeinde Zahlungen ablehnte, forderte eine Pflegemutter die Stadt auf, für eine anderweitige Unterbringung ihrer sechs jüdischen Pflegekinder zu sorgen. ${ }^{144}$ Doch jüdischen Pflegekindern versagte Berlin dann ab der Jahreswende 1938/39 generell jede städtische Unterstützung, womit die Stadt das Vorpreschen einiger Bezirksämter legalisierte. ${ }^{145}$

Das städtische Vorhaben, sich der Fürsorge an Juden vollständig und schnell zu entledigen, scheiterte unterdessen an den Realitäten in Berlin. Nach dem Pogrom hatte die Kommune einen Wirtschaftsprüfer als Treuhänder für die Jüdische Gemeinde Berlin bestellt, um deren Finanzlage zu untersuchen. Erwin Köhnen klärte am 29. Dezember 1938 den Leiter des Landeswohlfahrtsamtes, Behagel, sowie den Vorstand der Jüdischen Gemeinde Berlin in einer Besprechung über die ernüchternde Bilanz seiner Recherchen auf. Die jüdische Seite sei keinesfalls in der Lage, „die Kosten für die Betreuung hilfsbedürftiger Juden, insbesondere auch nicht die Kosten für die Verpflegung der hilfsbedürftigen jüdischen Insassen jüdischer Anstalten" zu übernehmen. Die Öffentliche Fürsorge müsse deshalb weiter in vollem Umfange für die jüdischen Hilfsbedürftigen Berlins eintreten, allerdings, so schränkte der Treuhänder ein, „unter Vorbehalt der Erstattung der Ausgaben" bei einer späteren Zahlungsfähigkeit der Jüdischen Gemeinde. ${ }^{146} \mathrm{Ob}$ des finanziellen Notstandes bei der Jüdischen Gemeinde machte die Reichshauptstadt, anders als andere Städte, einen Rückzieher. Sie hob ihre eigenen Verfügungen an der Jahreswende zum großen Teil rasch wieder auf. ${ }^{147}$ Ungeachtet des in seiner Kommunalverwaltung vorhandenen Ausgrenzungswillens sollte Berlin beim Zwangstransfer der öffentlichen Fürsorgepflicht auf die jüdischen Stellen sogar später das Schlußlicht unter den deutschen Großstädten bilden. ${ }^{148}$

Wenigstens bei der Anrechnung von Leistungen wollte man in Zukunft aber rigider vorgehen. Das Berliner Landeswohlfahrtsamt begann im Januar 1939 über das bisherige Prinzip hinaus, alle von jüdischen Wohlfahrtsstellen gewährten Lei-

amt) vom 12. 12. 1938; sowie LA Berlin, Rep. 214, Acc. 794, Nr. 13, unfol.: Vfg. Kaminski (i.V. OB) vom 6. 12.1938.

143 Dienstblatt Berlin, 1938 Teil VII, S. 349-350, Nr. 373: Vfg. Behagel (Landeswohlfahrtsamt) vom 12.12. 1938.

144 CJA Berlin, 75 A Be 2, Nr. 437, Bl. 38: Clara Nathanson an Jugendamt Berlin-Mitte am 30. 12.1938.

145 Dienstblatt Berlin, 1939 Teil VII, S. 5-6, Nr. 6: Vfg. Behagel (Landeswohlfahrtsamt) vom 2. 1. 1939. Vgl. LA Berlin, Rep. 214, Acc. 794, Nr. 13, unfol.: Vfg. Behagel (Landeswohlfahrtsamt) vom 28. 12. 1938. Vgl. Kapitel III. 3.

$146 \mathrm{BA}, 75 \mathrm{C}$ Re 1, Nr. 1, Bl. 128: Auszug aus Protokoll über Rücksprache mit Treuhänder am 29. 12. 1938, vom 30. 12. 1938; LA Berlin, Rep. 214, Acc. 794, Nr. 13, unfol.: Vfg. Behagel (Landeswohlfahrtsamt) vom 29. 12. 1938.

147 Dienstblatt Berlin, 1939 Teil VII, S. 5-6, Nr. 6: Vfg. Behagel (Landeswohlfahrtsamt) vom 2. 1.1939.

148 Vgl. Kapitel V. 3. 
stungen von den städtischen Unterstützungssätzen abzuziehen, jetzt zusätzlich auch die Geld- bzw. Sachwerte der Jüdischen Winterhilfe einzukalkulieren.149 Aber den Kommunalbeamten ging es nicht um Kostenreduzierung allein, sondern auch um Separierung. Ab dem 20. Januar sollten in der Reichshauptstadt alle noch in städtischen oder privaten Alters-, Siechen-, Zufluchts- oder Sonderheimen untergebrachten jüdischen Deutschen erfaßt werden, da eine "gemeinsame Unterbringung mit arischen Insassen nicht angängig" und deren anderweitige Unterbringung einzuleiten sei. 150

Schon Ende 1938 hatte ein Berliner Kreisamt für Kommunalpolitik angeregt, überdies den Aufenthalt von „Mischlingen“ in Kindertagesstätten zu begrenzen. Das deswegen angesprochene Landeswohlfahrts- und Jugendamt Berlin teilte mit, es sei "wohl bedauernswert", daß "unter Umständen Kinder von Parteigenossen innerhalb von Kindertagesstätten mit Mischlingen zusammen sein müssen". Leider gebe es jedoch noch keine Handhabe, letztere auszuschließen. Die Jugendämter seien nach dem Reichsjugendwohlfahrtsgesetz verpflichtet, für die zeitweilige Unterbringung solcher Kinder zu sorgen. Aufgrund der Rechtslage nach den „Nürnberger Gesetzen" habe Oberbürgermeister Lippert schon 1936 angeordnet, daß Juden und „Mischlinge 1. Grades“, die dem "mosaischen Glauben“ angehören, auszuschließen sind, nicht aber die übrigen „Mischlinge“. Einen speziellen Antrag an das Reichsministerium des Innern und den Stellvertreter des Führers lehnte die Kommune ab, da im Falle einer positiven Antwort besondere „Mischlingskindergärten" eingerichtet werden müßten, was man aufgrund der geringen Zahl solcher Kinder wegen „Unwirtschaftlichkeit" vermeiden wollte. Im übrigen hätten sich in der Praxis bisher Schwierigkeiten nicht ergeben, so das Landeswohlfahrtsamt. ${ }^{151}$

Der Leiter des Landeswohlfahrtsamtes, Behagel, bat schließlich, die Leistungsunfähigkeit der Jüdischen Gemeinde anerkennend, Mitte Januar 1939 die Bezirksbürgermeister um einer einheitlichen Strategie willen von „Sondermaßnahmen auf fürsorgerischem Gebiet Abstand zu nehmen“ und „etwaige Vorschläge, die die Betreuung der Juden betreffen", der Zentrale zuzuleiten. ${ }^{152}$

\section{Das Warten auf die Ausführungsbestimmungen zur Fürsorge-Verordnung}

In den Städten und im Deutschen Gemeindetag erwartete man zu diesem Zeitpunkt Präzisierungen zur antijüdischen Fürsorge-Verordnung von zentraler Seite. Ministerialrat Ruppert (RMdI) hatte nämlich beim Deutschen Gemeindetag telefonisch "Material zur weiteren Behandlung der Judenfrage" angefordert. Am 10. Januar 1939 übermittelte Schlüter (Abt. III) dem Ministerium Memoranda der

149 Dienstblatt Berlin, 1939 Teil VII, S. 18, Nr. 19: Vfg. Behagel (Landeswohlfahrtsamt) vom 10. 1.1939.

150 LA Berlin, Rep. 203, Acc. 867, Nr. 5100, Bl. 23: Vfg. Behagel (Landeswohlfahrtsamt) vom 20. 1.1939.

151 BA, NS 25, Nr. 86, Bl. 41-42: NSDAP-Reichsleitung/HA für Kommunalpolitik, „Vertrauliche Berichtsauszüge ${ }^{\prime}, X$. Sendung vom 15. 12. 1938, S. 1-2.

152 LA Berlin, Rep. 214, Acc. 794, Nr. 13, unfol.: Vfg. Behagel (Landeswohlfahrtsamt) vom 14. 1.1939. 
Oberbürgermeister von Breslau, Frankfurt am Main und Königsberg sowie der DGT-Dienststellen Bayern und Schleswig-Holstein. ${ }^{153}$ Auf einer Sitzung der Rheinischen Arbeitsgemeinschaft für Wohlfahrtspflege kündigte am 27. Januar Zengerling den teilnehmenden Fürsorgedezernenten das baldige Erscheinen einer Ausführungsverordnung öffentlich an, in der auch das Vermögen der Synagogengemeinden eine Rolle spielen werde. 154

Trotz mehrfacher Bemühungen des Deutschen Gemeindetages ließen die versprochenen Ausführungsrichtlinien jedoch in der Folge auf sich warten. Ein Grund für die Verzögerung war offenbar die ungeklärte Frage, ob und inwieweit die ausländischen Juden in die Ausgrenzung einbezogen werden sollten. Auch die Stadt Leipzig stand - wie gezeigt - vor diesem Problem. Im Dezember 1938 hatte der Sächsische Innenminister beim Reichsminister des Innern um eine Regelung wegen der Juden polnischer Staatsangehörigkeit nachgesucht. Doch aus dem Berliner Ministerium antwortete Ruppert zunächst kategorisch, daß die Verordnung vom 19. November 1938 nicht die „Abkommen zwischen Deutschland und anderen Staaten über die fürsorgerechtliche Behandlung der Angehörigen dieser Staaten in Deutschland" brechen könne, solche ausländischen Juden also wie gewohnt zu unterstützen seien. ${ }^{155}$ Der Deutsche Gemeindetag verbreitete diesen Erlaß Ende Januar 1939 in einem Rundschreiben. ${ }^{156}$ Das NSDAP-Hauptamt für Kommunalpolitik, das ebenfalls Kenntnis von diesem Schnellbrief erhalten hatte, entwarf ein weiteres Rundschreiben. Dessen Chef Fiehler hielt das aber für überflüssig, da die Kommunen über den Gemeindetag bereits unterrichtet seien. Außerdem werde in Berlin eine Sitzung vorbereitet, die "die Neuregelung der Befürsorgung ausländischer Juden zum Gegenstand hat. Dabei wird auch über Änderungen bezüglich des Reichsbürgerrechts verhandelt werden". ${ }^{157}$ Doch auf der Sitzung am 1. März 1939, die in der Berliner Geschäftsstelle des Deutschen Gemeindetages stattfand, sprach man nicht über die Fürsorge für ausländische Juden. Die Sitzung befaßte sich ausschließlich mit den inländischen Juden. Ministerialrat Ruppert eröffnete dort - wie oben schon ausgeführt - den Anwesenden nur, daß per "Ausführungsverordnung zum Reichsbürgergesetz“ die „Bildung einer Reichsvereinigung der Juden ins Auge gefaßt sei“..158

Mehreren nach den Ausführungsbestimmungen fragenden Bezirksfürsorgeverbänden gab nur Tage später Stadtrat Fischer-Defoy auf der Sitzung der DGT-Arbeitsgemeinschaft für Wohlfahrtspflege Hessen-Nassau in Fulda die Auskunft,

153 BA, R 36, Nr. 885, unfol.: DGT/Abt. III an Ruppert am 10. 1. 1939.

154 Erwähnt in: BA, R 36, Nr. 1022, Bl. 8: DGT-Provinzialdienststelle Rheinland-Hohenzollern an DGT Berlin am 6. 4. 1939.

155 BA, NS 25, Nr. 503, Bl. 74: Schnellbrief RMdI/VW an Sächs. MdI am 2.1.1939 (Abschrift).

156 YV Jerusalem, M1DN, Nr. 162, Bl. 41: DGT/Abt. III (Schlüter) an DGT-Landes- und Provinzialdienststellen am 31.1. 1939.

157 BA, NS 25, Nr. 503, Bl. 74: Schnellbrief RMdI/VW an Sächs. MdI am 2.1.1939 (Abschrift) sowie ebenda, Nr. 137, Bl. 69: HA Kommunalpolitik an Fiehler am 6. 1. 1939; ebenda, Bl. 208: Umhau an HA Kommunalpolitik am 1.3. 1939.

158 Ebenda, Bl. 307: Umhau an HA Kommunalpolitik am 14. 4. 1939. Vgl. Dokumente Frankfurter Juden, VI 44, S. 320-322: Bericht vom 3. 3. über DGT-Besprechung in Berlin am 1. 3. 1939. 
„daß in nächster Zeit mit dem Erlaß weiterer reichsrechtlicher Vorschriften zur Ergänzung der Verordnung über die öffentliche Fürsorge für Juden zu rechnen sei. Es sei anzunehmen, daß durch diese Vorschrift alle zurzeit noch schwebenden Fragen eine Klarstellung erfahren werden ". ${ }^{159}$ Am 28. März bekräftigte Ministerialrat Ruppert gegenüber Zengerling (DGT) in Berlin, daß „demnächst die Frage der Behandlung hilfsbedürftiger Juden einschließlich ihrer Anstaltsunterbringung durch eine besondere Verordnung geregelt werde ${ }^{\alpha}{ }^{160}$ Wie die DGT-Geschäftsstelle ihrem Vorsitzenden Fiehler Anfang April 1939 kritisch mitteilte, blieb aber die Frage der Einbeziehung ausländischer Juden weiterhin offen. ${ }^{161}$ Zur gleichen Zeit unterrichtete das Badische Innenministerium alle Bürgermeister, daß „eine allgemeine Regelung [...] demnächst erfolgen" werde, bis dahin sei in Absprache mit dem Reichsinnenministerium „nichts dagegen einzuwenden, wenn die Fürsorgeverbände [...] die Hälfte der bisherigen Unterstützungen übernehmen “. ${ }^{162}$

Mit ausdrücklichem Verweis auf die antijüdische Fürsorge-Verordnung hatte unterdessen das Reichsarbeitsministerium am 1. März 1939 angewiesen, die seit Ende $1937^{163}$ unbegrenzt gewährte Arbeitslosenunterstützung bei Juden auf 20 Wochen zu befristen. Die obligate Hilfsbedürftigkeitsprüfung nach 36 Tagen Bezugsdauer, von der die Weiterzahlung der Arbeitslosenhilfe abhing, richtete man bei Juden an den verschärften Kriterien der antijüdischen Fürsorge-Verordnung aus. Nach Ablauf der 20 Wochenfrist sollten die Arbeitsämter jüdische Erwerbslose in jedem Fall an die jüdischen Wohlfahrtsstellen verweisen. ${ }^{164}$

$\mathrm{Da}$ die Befristung rückwirkend seit Januar 1939 gelten sollte, sperrten die Arbeitsämter allen erwerbslosen Juden mit über 20 Wochen Unterstützungsbezug sofort die Leistungen. Tausende, vielleicht Zehntausende verloren damit den Anspruch auf ihre Versicherungsleistungen. Schon vor dem Pogrom 1938 hatte eine immens hohe Arbeitslosigkeit unter der jüdischen Bevölkerung geherrscht, doch nach dem Pogrom verschärfte sich diese Situation durch das Gewerbeverbot noch einmal gravierend. 165 Über die neue Regelung informierte man auch die lokalen Wohlfahrtsämter, da infolge des Erlasses „ausgesteuerte“ Juden mit einer Bescheinigung über die Zahlungsunfähigkeit der örtlichen Jüdischen Gemeinde Hilfe bei der Öffentlichen Wohlfahrt beantragen konnten. ${ }^{166}$

Unterdessen, im Laufe des Monats April, hatte man in der Berliner Geschäftsstelle des Deutschen Gemeindetages aufgegeben, auf zentrale Ausführungsanweisungen zur Fürsorge-Verordnung zu warten. Inzwischen war den DGT-Beamten

159 BA, R 36, Nr. 1022, Bl. 4: Sitzung der ArbG für Wohlfahrtspflege des DGT Hessen-Nassau am 10.3. 1939.

160 Ebenda, Nr. 1842, Bl. 44: DGT-Vermerk (Zengerling) vom 28. 3. 1939.

161 Ebenda, Nr. 1022, Bl. 5: DGT Berlin an Vorsitzenden Fiehler in München am 4. 4. 1939.

162 StA Freiburg i. Br., Landeskommissär Konstanz, P. Nr. 3085, Nr. 2, unfol.: Rundschreiben MdI Karlsruhe an OB und Bgm. vom 5. 4. 1939.

163 VO über die unterstützende Arbeitslosenhilfe vom 22. 12. 1937; RGBl., 1937 I, S. 1410.

164 BA, R 41, Nr. 466, Bl. 9-10RS: Erlaß Syrup (RArbM) vom 1. 3. 1939.

165 Ausführlicher dazu vgl. Gruner, Geschlossener Arbeitseinsatz, S. 79-81.

166 LA Berlin, Rep. 214, Acc. 794, Nr. 13, unfol.: Rundschreiben OB Berlin/Hauptwohlfahrtsamt vom 19.4. 1939 mit Abschrift RArbM-Erlaß vom 1.3. 1939. Vgl. StadtA Leipzig, AFS, Nr. 1741 Bd. 4, Bl. 179RS: Dienstbesprechung im Fürsorgeamt am 5. 6. 1939. 
offensichtlich von ministerieller Seite klargemacht worden, daß die vor allem auf lokaler Ebene angesiedelten, praktischen Probleme bei der Realisierung des Zwangstransfers der öffentlichen Fürsorgepflicht in Kürze völlig ihre Bedeutung verlieren würden, wenn der zu gründenden „Reichsvereinigung“ die zentrale Organisation der Wohlfahrt für die jüdischen Armen übertragen werde. ${ }^{167}$

\section{Die Koordination städtischer Ausgrenzung im Deutschen Gemeindetag}

Als der Verordnung über die Fürsorge von Juden keine näheren Ausführungsbestimmungen folgten, herrschte in den ersten Wochen und Monaten vor Ort Unsicherheit in manchen Wohlfahrtsämtern, wie in der neuen Situation gehandelt werden solle bzw. könne. Die schon in den letzten Jahren in Ausgrenzungsfragen erprobten Gremien des Deutschen Gemeindetages bildeten wieder das Forum für die Kommunalbeamten, wo Verfahrensstandards diskutiert, koordiniert und vereinheitlicht werden konnten.

Das Thema Ausgrenzung der Juden bildete denn auch gleich nach Erlaß der Verordnung ein vieldiskutiertes Thema in den regionalen Arbeitsgemeinschaften für Wohlfahrtspflege des Deutschen Gemeindetages. So sprachen am 20. Januar 1939 auf der Tagung der Arbeitsgemeinschaft der DGT-Landesdienststelle Sachsen Bürgermeister und Landräte mit Vertretern des Sächsischen Innenministeriums und des Gemeindetages in Dresden hierüber. Lakonisch hieß es allerdings im Protokoll: „Nach Aussprache wird hierzu festgestellt, daß Schwierigkeiten insbesondere bei der Unterbringung von Juden in Anstalten usw. im allgemeinen bei den sächsischen Bezirksfürsorgeverbänden nicht entstanden sind." 168 In Essen fand am 27. Januar eine Tagung der Rheinischen Arbeitsgemeinschaft für Wohlfahrtspflege statt. Dort erfuhren die Mitglieder, daß einige Kommunen im Rheinland schon jegliche Hilfen an Juden eingestellt hätten. ${ }^{169}$

Auch auf der Sitzung der Süddeutschen Arbeitsgemeinschaft für Wohlfahrtspflege, die - ebenfalls am 27. Januar 1939 - in Bad Dürkheim abgehalten wurde, debattierten die Mitglieder über die „Fürsorge für Juden“. Sie interessierte am brennendsten, wie sich die Wohlfahrtsbehörden im Augenblick verhielten und künftig verhalten sollten, falls die lokale jüdische Fürsorge finanziell überfordert sei und die Städte um Zuschüsse oder Kostenübernahme bitte. 170 Wenn die jüdische Seite eine Kostenübernahme ablehne, so der Vertreter Münchens in seinem Koreferat, müsse deren Vermögenslage durch Offenlegen der Bücher oder ordentliche Finanzrevisionen verifiziert werden. Er verwies dann einerseits auf die eigene, äußerst rigide Praxis, andererseits aber auch auf die wachsende Zahl jüdischer Hilfsbedürftiger und die daraus sowie aus den aktuellen „Maßnahmen des

167 BA, R 36, Nr. 1022, Bl. 9: DGT. Berlin (Zengerling) an DGT-Provinzialdienststelle Rheinland am 14.4. 1939.

168 Ebenda, Nr. 912, unfol: Sitzung ArbG für Wohlfahrtsfragen Sachsen am 20.1.1939, S. 14.

169 NW-HStA Düsseldorf, RW 53, Nr. 66, unfol.: Sitzung Rhein. ArbG für Wohlfahrtspflege am 27. 1. 1939, S. 20.

170 BA, R 36, Nr. 902, unfol.: 6. Tagung der Süddt. ArbG für Wohlfahrtspflege am 27. 1. 1939, S. $1-6$. 
Reiches" resultierenden Zahlungsschwierigkeiten der jüdischen Wohlfahrtspflege. Deshalb habe die Gestapo Bestimmungen für die jüdische Seite genehmigt, die in solchen Fällen eine Kostenteilung zwischen öffentlicher Fürsorge und jüdischer Wohlfahrt vorschlügen. Im Falle einer Versorgung durch die städtische Wohlfahrt müßten natürlich - wie in München - überall niedrigere „besondere Richtsätze für Juden " aufgestellt und separate Pflichtarbeitskolonnen eingerichtet werden. ${ }^{171}$ Der Vorsitzende der Arbeitsgemeinschaft, der schon mehrfach mit antijüdischen Initiativen hervorgetretene Stadtrat Plank aus Nürnberg, verfocht zu diesem frühen Zeitpunkt bereits die radikale Auffassung, daß keinesfalls die lokale Leistungsfähigkeit jüdischer Stellen Maßstab für den Transfer sein dürfe, sondern daß ,nach überörtlichen, ja sogar, wie die Betrachtung der gesamten Judenfrage, nach internationalen Gesichtspunkten" entschieden werden müsse. Die Reichsleitung der jüdischen Wohlfahrtspflege solle durch Umverteilung oder notfalls durch Unterstützung aus dem Ausland ihre Fürsorgetätigkeit, auch lokal, sichern. Um eine solche Sicht des Problems auf der Reichsebene durchzusetzen, werde eine entsprechende Eingabe an den Deutschen Gemeindetag in Berlin vorbereitet. ${ }^{172}$

Am 1. März 1939 fand schließlich eine zentrale Sitzung zu dieser ganzen Problematik beim Deutschen Gemeindetag in Berlin statt. Ministerialrat Ruppert informierte die Anwesenden über die Gründungspläne für eine "Zwangsvereinigung aller Juden, auch der christlich getauften". Ziel sei, ihr die Finanzierung der Offenen und der Geschlossenen Fürsorge jüdischer Armer zu übertragen. Man nehme an, „daß die im Besitz der Juden befindlichen Mittel vorläufig zur Durchführung dieser Aufgaben genügen, daß allerdings infolge der Auswanderung der wohlhabenden Juden allmählich, aber sicher die Mittel verknappen werden". Ob „die Wohlfahrtspflege grundsätzlich auch in die Hände der Verwaltung der Juden gelegt werden soll“, diese Frage bleibe vorläufig unbeantwortet. Im folgenden wurden die Anwesenden über die aktuell höchst unterschiedlichen Verfahrensmuster in den einzelnen Großstädten informiert. In Frankfurt am Main trage inzwischen die jüdische Wohlfahrt den größten Teil der Kosten für die Geschlossene Fürsorge. Wie Berlin habe Frankfurt am Main die Versorgung der Juden in kommunale Verwaltung übernommen. Die Jüdische Gemeinde zahle monatlich 25000 RM an die Kommune. Dieses von Fischer-Defoy vorgestellte Frankfurter Modell zur Entlastung der städtischen Fürsorge begrüßten die Teilnehmer als nachahmenswert. Dagegen hätten die Städte Breslau und München die weitere

171 Ein ungelöstes Problem wären die jüdischen Angehörigen in der Familienunterstützung, wozu Ministerialrat Ruppert Ausführungsvorschriften in Aussicht gestellt habe; YV Jerusalem, M1DN, Nr. 162, Bl. 194-198: Koreferat des OB/Dez. 6 München (ohne Datum) zur 6. Tagung der Süddt. ArbG für Wohlfahrtspflege am 27.1. 1939; vgl. BA, R 36, Nr. 902, unfol.: 6. Tagung der Süddt. ArbG für Wohlfahrtspflege am 27. 1. 1939, S. 1-6.

172 YV Jerusalem, M1DN, Nr. 162, Bl. 107: Auszug aus der 6. Tagung der Süddt. ArbG für Wohlfahrtspflege am 27. 1. 1939 in Bad Dürkheim (Vermerk des OB/Dez. 6 München); vgl. BA, R 36, Nr. 902, unfol.: Protokoll der 6. Tagung der Süddt. ArbG. für Wohlfahrtspflege am 27. 1. 1939 in Bad Dürkheim, S. 1-6. Nürnberg und München bereiteten daraufhin gemeinsam diese Eingabe vor; YV Jerusalem, M1DN, Nr. 162, Bl. 108-109: Stadtrat Schloimann (München) an Stadtrat Plank (Nürnberg) am 19. 2. 1939. 
Durchführung der Fürsorge an Juden kategorisch abgelehnt. Die Fürsorgepolitik gegenüber weiteren Gruppen bildete zusätzlichen Stoff in der Debatte. „Mischlinge" wären nicht wie Juden zu behandeln. Bei „Mischehen“ sei nur der jüdische Partner aus der Gehobenen Fürsorge auszuschließen, nicht dagegen der „deutschblütige Gatte und die mischblütigen Kinder“. ${ }^{173}$

Ganz ähnlich wie bei den Juden entwickelten sich die Diskussion und die Praxis gegenüber den Sinti. An den Deutschen Gemeindetag hatte die Stadt Wesermünde Mitte März 1939 geschrieben: „In der Stadt [...] halten sich seit Jahren zahlreiche Zigeunerfamilien auf. [...] Ich habe es bisher möglichst abgelehnt, sie regelmäßig zu unterstützen und mich auf einmalige Unterstützungen beschränkt. "Wenn man in Wesermünde laufende Fürsorgehilfen nicht umgehen könne, bewillige man nur geringere Leistungen, da es eine allgemein bekannte Tatsache sei, daß „Zigeuner arbeitsscheu und unwirtschaftlich sind “. Der Wesermünder Beamte, Richter, betonte abschließend, „Zigeuner" seien „Schädlinge und haben der Allgemeinheit nie genützt." ${ }^{174}$ In seiner Antwort bekräftigte Zengerling (DGT-Abt. III) die Auffassung, daß „bei Zigeunern die Hilfsbedürftigkeit auf das strengste geprüft werden“ müsse, jedoch dürften mangels „besonderer Vorschriften über die Behandlung von Zigeunern in der öffentlichen Fürsorge, etwa wie sie für Juden ergangen sind“, die Richtsätze bei dieser Klientel nicht allgemein gekürzt werden. Doch auch in diesem Fall wollte der Deutsche Gemeindetag keineswegs eine Diskriminierung blockieren, es ging nur um die Verfahrensweise: Der Paragraph 13 der Reichsgrundsätze könne bei Zigeunern nicht pauschal wegen „Asozialität“ angewendet, sondern müsse in jedem Einzelfall begründet werden. ${ }^{175}$

Die Diskussion über die jüdischen Armen verlagerte sich mittlerweile von der Klärung praktischer Fragen hin zur Frage der Kosten. Am 13. März 1939 ergab die Diskussion zwischen Kommunalbeamten und Wohlfahrtsdezernenten auf einer Tagung der Nordwestdeutschen Arbeitsgemeinschaft für Wohlfahrtspflege in Rostock, daß in vielen Orten in Norddeutschland und Niedersachsen „die Fürsorge für Juden überhaupt kein Problem darstellt“. Nur der Stadtstaat Hamburg habe große Schwierigkeiten, die Fürsorge rasch dem dortigen Religionsverband zu übertragen. Martini, der Vorsitzende der Arbeitsgemeinschaft, faßte als Resultat der Tagung zusammen, „daß die Fürsorge für Juden nur für wenige, vorwiegend städtische Fürsorgeverbände noch größere Bedeutung habe, unter denen einige Großstädte besonders betroffen seien. Diesen Verbänden entsteht die Frage, wie man den Juden die Kosten der Fürsorge für ihre Rasseangehörigen soweit als möglich übertrage. Bei der nicht immer leichten Überprüfung der Leistungsfähigkeit der jüdischen Gemeinde sei eine enge Zusammenarbeit mit der Gestapo zu empfehlen".176

173 Dokumente Frankfurter Juden, VI 44, S. 320-322: Bericht vom 3.3. über DGT-Sitzung in Berlin am 1. 3. 1939. Zu Frankfurts Ausführungen vgl. Kingreen, Raubzüge, S. 27.

174 Die Eingabe richtete sich gegen eine Intervention des Regierungspräsidenten in Stade zugunsten einer „Zigeuner“-Familie; BA, R 36, Nr. 841, unfol.: OB Wesermünde an DGT am 16. 3. 1939.

175 BA, R 36, Nr. 841, unfol.: DGT/Abt. III an OB Wesermünde am 27. 3. 1939.

176 Ebenda, Nr. 899, unfol.: 8. Tagung der Nordwestdeutschen ArbG für Wohlfahrtspflege am 13.3. 1939, S. 27. 
Diverse Kommunen kritisierten jetzt, daß die lokalen Jüdischen Gemeinden zu häufig bestätigen würden, aus Mangel an Mitteln nicht alle Juden versorgen zu können. Mehrere Großstädte hatten der DGT-Provinzialdienststelle im Rheinland diese Tatsache geschildert, weshalb sich letztere Anfang April 1939 an die Zentrale in Berlin wandte. $\mathrm{Da}$ die städtischen Bezirksfürsorgeverbände unterschiedlich auf die Situation reagiert hätten, manche zahlten, andere nicht, hätten die Kommunen verlangt, das Problem zum Thema der nächsten Sitzung der Rheinischen Arbeitsgemeinschaft zu machen, um das lokale Handeln zu koordinieren. ${ }^{177}$ Die rheinische Provinzialdienststelle wollte zugleich von der DGT-Sozialabteilung generell wissen, wie auf der lokalen Ebene nach der Fürsorge-Verordnung zu verfahren sei. Zengerling bestätigte der regionalen Dienststelle des Deutschen Gemeindetages Mitte April 1939 jedoch nur, daß, obwohl zentral bereits geplant sei, die Wohlfahrtspflege allein der neu zu bildenden „eigenen Verwaltung“ der Juden zu übertragen, bis dahin sofortiger Handlungsbedarf für eine Vereinheitlichung der Fürsorgemaßnahmen bestehe. ${ }^{178}$ Das bedeutete de facto, daß von zentraler Seite keine Ausführungsbestimmungen zur Fürsorge-Verordnung mehr zu erwarten waren und somit vorerst das Handeln vor Ort entscheidend blieb.

In Frankfurt am Main plante inzwischen das Fürsorgeamt unter Fischer-Defoy, ungeachtet der Bedenken der örtlichen Gestapo, sämtliche seit Januar 1939 ausgezahlten Leistungen von der jüdischen Seite zurückzufordern, auch wenn dazu auf den "Geldstock für Auswanderbeihilfen zurückgegriffen" werden müsse, der durch eine von der Stadt eigenmächtig eingeführte Zwangsabgabe vermögender Emigranten gebildet worden war. Oberbürgermeister Krebs stimmte dem Vorschlag ohne Bedenken zu: „Es ist nicht einzusehen, daß die Stadtverwaltung als Hauptgläubiger auf ihre Forderungen verzichtet und Gefahr läuft, daß die der jüdischen Gemeinde noch zur Verfügung stehenden Mittel anderweitig Verwendung finden, insbesondere etwa vom Reich eingezogen werden." Auf die Fürsorgekosten solle die Stadt gleich noch 20 Prozent für Verwaltungsausgaben aufschlagen. ${ }^{179}$

Mit unterschiedlichen Methoden suchten sich Bezirksfürsorgeverbände im Gefolge der Fürsorge-Verordnung also bereits finanziell voll zu entlasten. Und das, obwohl noch keine Klarheit herrschte, ob die Leistungsstärke jüdischer Wohlfahrtsstellen für die Zwangsübernahme aller jüdischen Armen ausreichen würde. Die Diskussionen in den regionalen und überregionalen Gremien des Deutschen Gemeindetages dienten im ersten Quartal des Jahres 1939 sowohl der Information der Kommunen über praktikable Ausgrenzungsvarianten als auch der logistischen Absicherung des Zwangstransfers an die Jüdischen Gemeinden bzw. Wohlfahrtsstellen.

177 Ebenda, Nr. 1022, Bl. 8: DGT-Provinzialdienststelle Rheinl.-Hohenzollern an DGT Berlin am 6. 4. 1939.

178 Ebenda, Bl. 8 u. RS: DGT Düsseldorf an DGT Berlin am 6.4.1939 sowie NW-HStA Düsseldorf, RW 53, Nr. 413, unfol.: Antwort DGT Berlin an DGT Düsseldorf am 14. 4. 1939.

179 Dokumente Frankfurter Juden, VI 45, S. 322: Besprechung Fürsorgeamt mit OB vom 27. 3. 1939. Vgl. Kingreen, Raubzüge, S. 27. 


\section{Isolierung und Konzentration: Kranke in Heil-und Pflegeanstalten}

Die Frage der Kostenübernahme spielte nicht nur für die Offene Fürsorge, sondern auch für die Geschlossene Fürsorge eine zunehmende Rolle. Der Oberpräsident der preußischen Provinz Pommern fragte Ende April 1939 beim Deutschen Gemeindetag an, welche staatliche Instanz über die Vermögensverhältnisse der Jüdischen Wohlfahrtspflege in Brandenburg Auskunft geben könne. Oder könne der DGT selbst eine Nachprüfung der Vermögensverhältnisse veranlassen? Der jüdische Verband habe nämlich zur Kostenübernahme für jüdische geisteskranke Pfleglinge in öffentlichen Anstalten mitgeteilt, wegen der Emigrationsförderung nur „über sehr beschränkte Mittel für Wohlfahrtszwecke " $z u$ verfügen. ${ }^{180}$

Die Anfrage erreichte den Deutschen Gemeindetag nach einer vehementen Diskussion über die Zukunft jüdischer Kranker in öffentlichen Heil- und Pflegeanstalten, die kurz vor dem Pogrom 1938 infolge des Erlasses des Reichsinnenministeriums über die Vermeidung von "Rassenschande“ in öffentlichen Anstalten begonnen hatte. Hatten die preußischen Provinzialverbände zuerst mehrheitlich Sonderregelungen auch aus Kostengründen noch abgelehnt und nur Sachsen eine Isolation aller Juden in einer jüdischen Anstalt gefordert ${ }^{181}$, so verschärften sich seit dem Pogrom Ton und Inhalt der weiterhin beim Deutschen Gemeindetag einlaufenden Nachrichten auf dessen Umfrage. In seiner Antwort vom 16. November 1938 bat der Oberpräsident in Hannover den Deutschen Gemeindetag ohne Umschweife und ohne die Meinungen der anderen Provinzialverbände zu kennen, um die Mitteilung, „ob eine jüdische Privatanstalt bekannt ist, die zu einem annehmbaren Pflegesatz in der Lage und bereit wäre, sämtliche jüdischen Kranken aufzunehmen “. ${ }^{182}$ Beflissen erkundigte sich der Deutsche Gemeindetag dieserhalb beim Archiv für Wohlfahrtspflege. Dort konnte man allerdings nur zwei Heime, Lohr in Bayern und Bendorf-Sayn bei Koblenz, benennen. ${ }^{183}$ Auch die DGT-Provinzialdienststelle Sachsen-Anhalt hatte offenbar entsprechende Anfragen erhalten und bat deshalb Berlin um Auskunft. ${ }^{184}$ Am 21. Dezember 1938 forderte schließlich der Provinzialverband Schlesien, der die Umfrage initiiert und zuerst gegen eine Isolierung plädiert hatte, den Gemeindetag auf, den sächsischen Vorschlag zur Errichtung einer zentralen jüdischen Anstalt für sämtliche jüdische Geisteskranke zu prüfen, damit „Deutsche nicht mehr zur Betreuung von Juden herangezogen" werden müßten. Allerdings müsse ein solches Heim einigermaßen zentral gelegen sein und niedrige Pflegekosten ausweisen, damit die Provinzialverbände nicht mehr Gelder für jüdische als für „arische“ Patienten aufzuwenden hätten. 185

Wenig später, im Januar 1939, erneuerte der schlesische Provinzialverband diese Forderung: Die Situation habe sich inzwischen zugespitzt, die privaten nichtjüdi-

180 BA, R 36, Nr. 1022, Bl. 23 u. RS: OP-Zweigstelle Schneidemühl an DGT am 26. 4. 1939.

181 Vgl. Kapitel III. 3.

182 BA, R 36, Nr. 1842, Bl. 20: OP Provinz Hannover an DGT am 16. 11. 1938.

${ }^{183}$ Ebenda, Bl. 21-22: DGT (Zengerling) an Archiv für Wohlfahrtspflege am 22.11.1938 und Antwort vom 25. 11. 1938.

184 Ebenda, Bl. 17: DGT Halle an DGT Berlin am 12. 12. 1938.

185 Ebenda, Bl. 19: OP/Landeswohlfahrtsamt an den DGT Berlin am 21. 12. 1938. 
schen Anstalten in Schlesien lehnten wegen befürchteter steuerlicher Nachteile die Aufnahme jüdischer Patienten ab. Die Kranken, gerade aus den öffentlichen Heimen an die privaten Einrichtungen verwiesen, müßten von den Provinzialanstalten wieder aufgenommen werden. Die Provinzialverwaltung habe hierüber auch das Reichsfinanzministerium verständigt. ${ }^{186}$ Verschärft wurde diese Situation dadurch, daß in Schlesien die Öffentliche Fürsorge unter Berufung auf die antijüdische Fürsorge-Verordnung die Übernahme von Wohlfahrtskosten bei Juden ablehnte. ${ }^{187}$ Das hatte zur Folge, daß seit November 1938 aus Breslauer städtischen Anstalten Patienten, egal ob in der Offenen oder Geschlossenen Fürsorge Betreute, an das dortige Jüdische Krankenhaus überstellt worden waren. ${ }^{188}$ Die erzwungene Übernahme von Psychiatriekranken in einen "normalen“ Krankenhausbetrieb stellte das Jüdische Hospital vor enorme Probleme. Gerda Levine, damals Lehrschwester, erinnert sich: „Aus den städtischen Krankenhäusern hat man die psychiatrischen Patienten zu uns gebracht. Und wir waren natürlich nicht darauf eingestellt. Ich weiß z.B., daß wir bei den unruhigen Patienten einfach ein Netz über das Bett haben spannen müssen. Wir hatten ja keine anderen Vorrichtungen. "189 Am Ende des Jahres mußte die jüdische Seite sämtliche vorher in städtischen Anstalten Untergebrachten versorgen. ${ }^{190}$ Der Deutsche Gemeindetag, so der Ruf aus Schlesien, solle jetzt „mit den zuständigen Stellen Fühlung nehmen, wie die weitere Fürsorge für geisteskranke Juden beabsichtigt" sei. ${ }^{191}$

Seit dem Pogrom lehnten auch in Württemberg öffentliche Heilanstalten die Aufnahme von Juden ab bzw. verlangten die „anderweitige Unterbringung bereits eingewiesener Juden". Die DGT-Landesdienststelle Württemberg veranstaltete im Januar 1939 selbst eine Regionalumfrage, um sich ein Bild über den Umfang der „anstaltsmäßigen Betreuung von Juden“ zu machen. ${ }^{192}$ In Baden behaupteten Fürsorgedezernenten, daß eine Heimversorgung „künftig unmöglich“sei, „weil die übrigen Anstaltsinsassen eine Gemeinschaft mit Juden ablehnen“. Deshalb, so die Forderung, solle die Regionalstelle des Deutschen Gemeindetages in Kooperation mit dem Badischen Ministerium des Innern prüfen, „ob nicht die Unter-

186 Die privaten Anstalten hätten zusätzlich ca. 30 bereits aufgenommene Juden an die Öffentliche Fürsorge zurückverwiesen; ebenda, Bl. 28: OP/Landeswohlfahrtsamt Schlesien an DGT Berlin am 10. 1. 1939. Vgl. ebenda, Bl. 35: ders. an RFM am 9. 2. 1939. Vgl. Erwähnung bei Friedlander, Der Weg zum NS-Genozid, S. 424.

187 BA, R 36, Nr. 1842, Bl. 28: OP/Landeswohlfahrtsamt Schlesien an DGT Berlin am 10. 1. 1939.

188 Reinke, Andreas: Stufen der Zerstörung. Das Breslauer Jüdische Krankenhaus während des Nationalsozialismus, in: Menora. Jahrbuch für deutsch-jüdische Geschichte 1994, München-Zürich 1994, S. 411 (Anm. 42).

189 Zit. bei Reinke, Judentum, S. 270.

190 Ebenda, S. 269.

191 BA, R 36, Nr. 1842, Bl. 28: OP/Landeswohlfahrtsamt Schlesien an DGT Berlin am 10. 1. 1939. Vgl. auch ebenda, Bl.35: OP/Landeswohlfahrtsamt an den RFM am 9. 2. 1939.

192 Ebenda, Bl. 29: DGT Stuttgart an die Obmänner der DGT-Kreisabteilungen am 12. 1. 1939. Nach einer Anfrage des Israelitischen Wohlfahrtsamtes vom März 1939 verhandelte das Württembergische Innenministerium mit verschiedenen Anstalten; vgl. die Darstellung mit weiteren Einzelheiten bei Friedlander, Der Weg zum NS-Genozid, S. 426-427. 
bringung aller badischen pflegebedürftigen Juden in einer Anstalt zweckmäßiger wäre". ${ }^{193}$ Der Gemeindetag untersuchte daraufhin mit einer eigenen Umfrage ebenfalls im Januar in Baden, wieviel Juden auf Kosten der Bezirksfürsorgeverbände in öffentlichen Anstalten untergebracht seien. ${ }^{194}$

Der geschäftsführende Präsident des Deutschen Gemeindetages, Jeserich, bat schließlich bereits am 26. Januar 1939 das Reichsinnenministerium um eine zentrale Entscheidung, wie sich die Landesfürsorgeverbände in Zukunft verhalten sollten. Er schilderte anhand der Umfrageergebnisse die aktuelle Separierungspraxis durch die preußischen Provinzialverbände und verfocht jetzt die seit dem Pogrom vermehrt geäußerte Auffassung, daß sich die Forderung des Ministeriums nach vollständiger Trennung der Patienten nur durch die Konzentration der Juden in einer separaten Anstalt erfüllen lasse. ${ }^{195}$ Ähnliche Vorschläge kursierten bereits auch in der Öffentlichkeit. Der Direktor der Anstalt Hamburg-Langenhorn erörterte in der Zeitschrift "Volksgesundheit" öffentlich „die Judenfrage in den Heil- und Pflegeanstalten“. Er propagierte die Alternative, entweder "alle geisteskranken Juden" in einer von der "Judengemeinde in Deutschland" finanzierten und verwalteten separaten Anstalt zu konzentrieren oder diese Kranken in den "deutschen Heil- und Pflegeanstalten" zu belassen, aber der jüdischen Bevölkerung hierfür als Ausgleich eine Sondersteuer aufzuerlegen, die für „besondere gesundheitliche Zwecke" verwendet werden könnte. 196

Die Situation wurde immer schwieriger, da öffentliche wie private Anstalten zunehmend die Aufnahme von Juden ablehnten, jüdische Heime aber hoffnungslos überbelegt waren. Das Reichsfinanzministerium betonte zwar Anfang März 1939 in einem Erlaß ausdrücklich, daß die Aufnahme jüdischer Patienten keine Gefahr für steuerliche Begünstigungen privater Anstalten nach sich zöge. ${ }^{197}$ Doch in der Praxis änderte das sicher wenig. Da es eine zu diesem Erlaß konträre Rechtsprechung seit 1936 gab, war das Argument von Steuernachteilen bei den aktuellen Fällen wohl häufig nicht nur vorgeschoben. Ohne auf zentrale Vorgaben zu warten, beschloß in Württemberg das Innenministerium Mitte Mai 1939, alle jüdischen Patienten in der öffentlichen Heilanstalt Zwiefalten zusammenzulegen und dort geschlossene jüdische Stationen einzurichten. Doch schon am Ende des Monats war die Anstalt überfüllt. ${ }^{198}$

Der Oberpräsident des Provinzialverbandes in Merseburg versuchte so vergeblich, eine aus der Provinzialheil- und -pflegeanstalt Brieg (Schlesien) entlassene

193 StadtA Freiburg i. Br., C4 XVII/7, Nr. 6, unfol.: Niederschrift über die Ergebnisse der Fürsorgedezernenten Besprechung in Karlsruhe am 19.12. 1938.

194 Ebenda, C4 XVII/6, Nr. 6, unfol.: Rundschreiben DGT Baden vom 6. 1. 1939. In Freiburg i. Br. handelte es sich lediglich um sechs Personen; ebenda: Vermerk Wohlfahrtsamt an OB Freiburg am 6. 2. 1939.

195 BA, R 36, Nr. 1842, Bl. 32-33: DGT Berlin an RMdI am 26. 1. 1939; ebenda, Bl. 39: DGT Berlin an RMdI am 23. 2. 1939.

196 Ebenda, Bl. 37: Vermerk DGT Berlin (Zengerling) am 27. 2. 1939.

197 Friedlander, Der Weg zum NS-Genozid, S. 425.

198 Nach längeren Überlegungen entschied dann das Stuttgarter Ministerium, daß ab Oktober 1939 geisteskranke Juden in Zwiefalten, Juden mit anderen Behinderungen in der katholischen Pflegeanstalt Heggbach konzentriert werden sollten. Mit weiteren Einzelheiten vgl. ebenda, S. $427-428$. 
Jüdin in einem Heim irgendwo im Reich unterzubringen, wie er dem Deutschen Gemeindetag resigniert mitteilte. ${ }^{199}$ Daraufhin fragte der Gemeindetag noch einmal beim Archiv für Wohlfahrtspflege nach Aufnahmeplätzen an, wieder ergebnislos. Zengerling informierte den Oberpräsidenten in Merseburg, daß in Stettin die Einrichtung einer jüdischen „Irrenanstalt" geplant sei, die aber lediglich Stettiner jüdischen Geisteskranken vorbehalten bleiben sollte. Soweit dem Gemeindetag bekannt sei, seien im Reich „die bestehenden jüdischen Heime aller Art wegen Überfüllung z. Zt. nicht in der Lage, irgendwelche Personen aufzunehmen. Die Neugründung jüdischer Heime scheitert daran, daß dafür geeignete Räumlichkeiten und Häuser an Juden nicht vermietet werden oder die Gemeinden sich gegen jüdischen Zuzug sperren. [...] Im ganzen Reich besteht eine Anstalt für jüdische Geisteskranke in Sayn bei Koblenz. Die Anstalt wird von dem Hilfsverein für unbemittelte Nerven- und Geisteskranke in Köln [...] unterhalten. Der Fürsorgeverein für israelitische Nerven- und Geisteskranke in Aschaffenburg unterhält eine rituelle Abteilung in der Heil- und Pflegeanstalt in Lohr a. M. (Bayern).“200

Fürsorgeverbände und Deutscher Gemeindetag waren sich also im Frühjahr 1939 nicht nur über eine Ausgrenzung der jüdischen Armen aus der Offenen Fürsorge einig, sondern drängten darauf, noch in der Geschlossenen Fürsorge betreute jüdische Hilfsbedürftige in einzelnen öffentlichen Heil- und Pflegeanstalten zu isolieren. Pläne, sie vollständig auszuschließen, stießen jedoch an organisatorische Grenzen, da jüdische Einrichtungen zur Unterbringung jüdischer Behinderter und Alter kaum zur Verfügung standen.

\section{Isolierung und Konzentration: Alte und Obdachlose}

Offenbar ohne die DGT-Umfrage in den preußischen Provinzen zu kennen, hatte sich der für Wohlfahrt zuständige Bürgermeister von Halle/Saale, Dr. Paul May ${ }^{201}$, Mitglied im neu gegründeten Ausschuß für Wohlfahrtsrecht der Akademie für Deutsches Recht ${ }^{202}$, am 20. Dezember 1938 an den Deutschen Gemeindetag mit der Frage gewandt, wie im Falle öffentlicher Fürsorge „obdachlosen oder pflegebedürftigen bezw. gebrechlichen Juden im Rahmen des notwendigen Lebensbedarfes Unterkunft im Obdach oder Aufenthalt in einem Pflege- bezw. Siechenheim" gewährt werden solle. Da die örtliche jüdische Wohlfahrtspflege die notwendigen Mittel nicht aufbringen und auch keine überregionale Hilfe jüdischer Organisationen erwartet werden könne, müsse die Stadt eingreifen. Doch dürfe der Kommune „schwerlich zugemutet werden [...] besondere Einrichtungen für obdachlose oder pflegebedürftige Juden zu schaffen". Um eine Unterbringung dieser Obdachlosen aber in "judeneigenen Wohn- bezw. Mietshäusern“

199 BA, R 36, Nr. 1911, Bl. 7: OP in Merseburg an DGT am 27. 3. 1939.

200 Ebenda, Bl. 8: DGT an Archiv für Wohlfahrtspflege am 3. 4. 1939; ebenda, B1. 9: DGT/ Abt. III an OP in Merseburg am 11.4. 1939.

201 Geb. 1887, gest. 1974.

202 Vorsitzender des Ende April 1938 konstituierten Ausschusses war Erich Hilgenfeldt, Mitglieder u. a. OB Damrau (Görlitz), Martini, Ruppert (RMdI) und Zeitler (DGT). 
durchzusetzen, fehle eine geeignete Rechtsgrundlage. Noch problematischer sei für die Stadt die Situation der jüdischen Pflegefälle, wo nicht nur Unterbringung, sondern auch die Pflege zu organisieren sei. Im Interesse der Kommunen müßten diese Fragen vom Deutschen Gemeindetag gelöst werden. ${ }^{203}$

Diese Problematik wurde allerorten diskutiert. Die DGT-Dienststelle in Hannover bat wegen eines konkreten Falles zu Beginn des Jahres 1939 alle seine Mitglieder in der Region um Hilfe: „In einem nichtjüdischen Altersheim ist ein Jude untergebracht. Das Altersheim verlangt die anderweit[ig]e Unterbringung, weil jüdische Insassen daselbst nicht mehr verbleiben könnten. Der Bezirksfürsorgeverband, der die Kosten trägt, hat sich mit dem Israelitischen Verein für Altersversorgung und Krankenpflege, Hannover, Ellernstraße 16, wegen Aufnahme in Verbindung gesetzt. Der angezogene Verein hat jedoch mitgeteilt, daß eine Aufnahme nicht erfolgen könne, weil der Jude siech und wegen Platzmangel eine Unterbringung nicht möglich sei." Die DGT-Regionalstelle wollte von den lokalen Fürsorgeverbänden wissen, „ob, unter welchen Umständen und wo der Jude aufgenommen werden kann“. 204

Der Deutsche Gemeindetag wurde mit dem Problem Obdachlosigkeit noch von einer zweiten Seite her konfrontiert. Vor dem Hintergrund der zentralen Diskussionen über die Aufhebung des Mieterschutzes bei Juden begannen einige Städte rasch eigene Regelungen zu treffen. Obwohl sich die Herausgabe des antijüdischen Mietgesetzes verzögerte, exmittierten seit dem Pogrom bereits eine Reihe von Großstädten in größerem Umfang jüdische Mieter. ${ }^{205}$ Die Stadtverwaltung Nürnberg teilte den Mitgliedern der Süddeutschen Arbeitsgemeinschaft für Wohlfahrtspflege Ende Januar 1939 mit, daß sie seit dem 12. November 1938 die Hausbesitzer aufgefordert habe, jüdischen Mietern bis 1. Dezember zu kündigen. 250 Wohnungen mit jüdischen Mietern seien geräumt und Juden mit großen Wohnungen gezwungen worden, die exmittierten Familien aufzunehmen. Die Jüdische Kultusgemeinde mußte im Garten eines jüdischen Altersheimes für die nicht unterzubringenden Menschen Baracken aufstellen. ${ }^{206}$ In München hatte die Stadtverwaltung zwar zunächst gegen die rasche Ausführung eines Räumungsplanes der NSDAP-Gauleitung und für stufenweise Räumungen „etwa im Verlaufe eines halben Jahres“ votiert: „Wenn aus politischen Gründen ein Interesse an einer schlagartigen Aktion besteht, könnte ja die Kündigung als solche für alle Wohnungen auf einmal ausgesprochen werden, aber mit verschiedenen Terminen im Hinblick auf die vorgenannten sachlichen Gründe." Ihren Widerstand gegen die geplante Maßnahme begründete die Stadt damit, daß sie im Falle einer Totalräumung wegen der Obdachlosenfürsorge in die Pflicht gerate, die exmittierten "Judenfamilien“" unterzubringen. ${ }^{207}$ Ungeachtet dieser Einwände fanden in der

203 BA, R 36, Nr. 1842, Bl. 26: OB Halle an DGT Berlin am 20. 12. 1938.

${ }^{204}$ LA Berlin, Rep. 142/7, 1-2-6/Nr. 1, Bd. 2, unfol.: Mitteilungsdienst des DGT Hannover vom 10.1.1939.

205 Ausführlicher dazu: Gruner, NS-Judenverfolgung und die Kommunen, S. 117-118.

206 BA, R 36, Nr. 902, unfol.: 6. Tagung der Süddt. ArbG für Wohlfahrtspflege am 27. 1. 1939, S. 3.

207 YV Jerusalem, M1DN, Nr. 162, Bl. 125: Vermerk Stadt München/Dezernat 7-1 für OB vom 8. 3. 1939. 
bayerischen Landeshauptstadt im Frühjahr 1939 Kündigungen in großem Umfang statt. ${ }^{208}$ Seit dem Erlaß des „Gesetzes über Mietverhältnisse mit Juden“ vom 30. April 1939 verloren dann unzählige deutsche Juden ihre Wohnungen, durch spontane Kündigungen privater Vermieter und durch systematische „Räumungen“ der Kommunalverwaltungen. Jüdische Kultusgemeinden mußten, um die Folgen zu mildern, kurzfristig Obdachlosenheime einrichten oder bestehende Altersheime vergrößern. ${ }^{209}$ Die Jüdische Gemeinde in Leipzig baute beispielsweise eine ehemalige Privatsynagoge zu einem Obdachlosenheim um. ${ }^{210}$

\section{Die Folgen des Zwangstransfers für die jüdische Fürsorge}

Zwar waren auf Weisung Hitlers jüdische Wohlfahrtseinrichtungen (Krankenhäuser, Kinder- und Altersheime, Irren- und Blindenanstalten) von der forcierten "Arisierung" seit dem Pogrom zunächst ausgenommen geblieben ${ }^{211}$, um den systematischen Ausbau einer separaten Versorgung jüdischer Armer nicht zu gefährden. Doch die seit 1933 fortgeschrittene Deformation der sozialen und politischen Infrastruktur der Jüdischen Gemeinden und Vereine sowie die Zerstörungen während des Pogroms behinderten allerorten den im Rahmen des neuen Verfolgungsprogramms vorgesehenen Aufbau eines separaten jüdischen Wohlfahrtssystems. Aufgrund von Verfolgung, Verarmung und Emigration ihrer Mitglieder existierten von den 1933 registrierten 1610 Kultusgemeinden im Sommer 1939 nur noch 1480, von den ursprünglich 34 Landes- und Provinzialverbänden elf. ${ }^{212}$ Unzählige Vereine waren zwangsweise durch die Polizei geschlossen worden oder hatten sich selber aufgrund personeller oder finanzieller Probleme aufgelöst. Von ehemals 586 Wohlfahrtsorganisationen gab es 1939 im Reich noch 302, von 582 Begräbnisvereinen nur 80, von 43 Kindergärten noch sechs, von 113 Logen keine einzige mehr. ${ }^{213}$ Die noch verbliebenen Einrichtungen sollten entweder auch beseitigt oder in die "Reichsvereinigung" eingegliedert werden. ${ }^{214}$

Es herrschte eine angespannte Situation bei den jüdischen Wohlfahrtsstellen. Im Frühjahr 1939 waren in einigen Orten die während des Pogroms konfiszierten Fonds immer noch nicht freigegeben. Gleichzeitig drängten die Bezirksfürsorgeverbände auf die vollständige Übernahme aller Kosten. Mit der nach dem Pogrom

208 Ebenda, Nr. 114, Bl. 159-161: IKG München an OB/Gewerbeamt am 21. 4. 1939.

209 Vgl. BA, 75 C Re 1, Nr. 1, Bl. 90-106: Entwurf Eingabe RV (Dr. Arthur Lilienthal/Berthold Auerbach) an Reichsarbeitsministerium am 17.7.1939.

210 Leipziger Neueste Nachrichten vom 31. 10. 1939.

211 IMT, Bd. XXV, S. 131-132: AO des Stellvertreters des Führers Nr. 1/39 vom 17. 1. 1939. Vgl. auch zur VO über den Einsatz jüdischen Vermögens: JNBl., Berliner Ausgabe Nr. 16 vom 24. 2. 1939.

212 BA, 75 C Re 1, Nr. 31, Bl. 235: Bericht der Abwicklungsstelle für Organisationen bei der Reichsvereinigung über die Entwicklung des Vereinswesens 1933-1941, vom 7. 11. 1941.

213 In Berlin existierten von 990 Organisationen (1933) nur noch 221 (1939). In Frankfurt/ Oder gab es von den 1937 gezählten 42 jüdischen Vereinen Ende 1938 nur noch 18; ebenda; sowie YV Jerusalem, 051/OSOBI, Nr. 47 (500-3-317), unfol.: SD-OA Ost Bericht vom 13. 1. 1939.

214 BA, 75 C Re 1, Nr. 31, Bl. 235-237: Bericht der Abwicklungsstelle für Organisationen bei der Reichsvereinigung 1933-1941, vom 7. 11. 1941. Vgl. Kapitel V. 1. 
schnell wachsenden Emigration 1939 sank aufgrund der schmaler werdenden Beitrags- und Spendenbasis die Finanzkraft der Jüdischen Gemeinden rapide. Selbst die noch vermögenderen Juden konnten kaum mehr helfen, da ihr Geld mittlerweile auf Sperrkonten eingefroren war und sie mit begrenzten, monatlichen Auszahlungen auskommen mußten. In immer mehr Städten richteten die Jüdischen Gemeinden neue Kleiderkammern und Wohlfahrtsspeisungen ein. ${ }^{215}$ In Leipzig erhielten in der jüdischen Volksküche bald pro Tag 150 bis 200 Leute umsonst oder für Pfennigbeträge ein warmes Mittagessen.216 Vor allem die Alten und Pflegebedürftigen, entweder ausgestoßen aus öffentlichen Heimen oder bedürftig aufgrund der Emigration von Familienmitgliedern, mußten versorgt werden. In einem Schreiben des Israelitischen Wohltätigkeitsvereines zu Leipzig an die örtliche Gestapo hieß es im März 1939: „Die große Hilfsbedürftigkeit der von uns zu betreuenden und unterzubringenden alten und mittellosen jüdischen Personen hat die Erweiterung der Altersversorgungsanstalt von 14 auf etwa 30 Personen notwendig gemacht." Man bat um die Genehmigung, mehr Personal einstellen zu dürfen. ${ }^{217}$ Statt der früher überwiegend von privaten jüdischen Stiftungen oder Vereinen geleisteten Altenpflege mußte jetzt in der Hauptsache die Reichsvereinigung diese Versorgung garantieren. Allein in Berlin gab es 3000 Vormerkungen für Altersheim- und 300 für Siechenplätze. Zwar existierten dort 13 jüdische Altersheime mit 1683 Plätzen und zwei Siechenheime mit 265 Betten, aber alle waren voll belegt. ${ }^{218}$

Auf eine soziale Grundversorgung für Zehntausende verarmter Menschen, sowohl in der Offenen als auch in der Geschlossenen Fürsorge, waren die jüdischen Religionsgemeinden weder strukturell noch finanziell vorbereitet. Ungeachtet unzähliger kommunaler Ausgrenzungsinitiativen und trotz der Existenz der antijüdischen Fürsorge-Verordnung konnten die staatlichen Fürsorgeverbände also jüdische Arme nicht so rasch und umfassend wie gewollt von der Versorgung ausschließen. Aufgrund fehlender Gelder oder Einrichtungen mußten vor Ort die Fürsorgeverbände ganz oder teilweise die Fürsorgepflicht kurz- und mittelfristig weiter ausüben. Im Altreich versorgten die staatlichen Fürsorgeverbände in der Offenen Fürsorge im ersten Quartal 1939 noch 10357 jüdische Parteien (Einzelpersonen bzw. Familien).

Die folgende Tabelle markiert also lediglich einen Zwischenstand des Transfers der staatlichen Fürsorgepflicht in den ersten drei Monaten nach Inkrafttreten der antijüdischen Fürsorge-Verordnung, und das auch nur, was die Verwaltung betrifft, da in manchen Städten die Offene Fürsorge - wie wir gesehen haben - zwar noch von der Stadt organisiert, aber schon teilweise oder ganz von jüdischen Stellen bezahlt wurde. Das Ausmaß der Verarmung in der jüdischen Bevölkerung war

215 Arbeitsbericht der Reichsvertretung der Juden in Deutschland für das Jahr 1938 [MS], Berlin 1939, S. 35.

216 Deutschland-Berichte der Sozialdemokratischen Partei Deutschlands (Sopade), hrsg. von Klaus Behnken, 7. Aufl., Salzhausen-Frankfurt am Main 1989, 6 (1939), S. 924.

217 StA Leipzig, Polizeipräsidium Leipzig-V, Nr. 4442, Bl. 6: Israelitischer Wohltätigkeitsverein an Stapoleitstelle Leipzig am 15.3. 1939.

218 Adler-Rudel, Selbsthilfe, S. 170. 
Laufend in Offener Fürsorge bar unterstützte Parteien am 31. März 1939219

\begin{tabular}{|c|c|c|c|c|c|}
\hline Länder & $\begin{array}{l}\text { Jüdische } \\
\text { Fürsorge- } \\
\text { empfänger }\end{array}$ & $\begin{array}{l}\text { Anteil an } \\
\text { jüdischer } \\
\text { Bevöl- } \\
\text { kerung }\end{array}$ & $\begin{array}{l}\text { Anteil an } \\
\text { allen } \\
\text { Fürsorge- } \\
\text { empfängern }\end{array}$ & $\begin{array}{l}\text { Jüdische } \\
\text { Fürsorge- } \\
\text { empfänger } \\
\text { Deutsch- } \\
\text { land }\end{array}$ & $\begin{array}{l}\text { Fürsorge- } \\
\text { empfänger } \\
\text { Anteil an } \\
\text { Gesamt- } \\
\text { bevölkerung }\end{array}$ \\
\hline Preußen & 8889 & $5,12 \%$ & $1,02 \%$ & 870236 & $2,19 \%$ \\
\hline - Ostpreußen & 290 & $9,15 \%$ & $0,48 \%$ & 60759 & $2,60 \%$ \\
\hline - Berlin & 5557 & $6,74 \%$ & $3,63 \%$ & 153296 & $3,61 \%$ \\
\hline - Brandenburg & 66 & $1,64 \%$ & $0,14 \%$ & 47171 & $1,75 \%$ \\
\hline - Pommern & 154 & $4,51 \%$ & $0,31 \%$ & 49930 & $2,20 \%$ \\
\hline - Schlesien & 302 & $1,78 \%$ & $0,23 \%$ & 129798 & $2,76 \%$ \\
\hline - Sachsen & 41 & $1,51 \%$ & $0,06 \%$ & 65116 & $1,91 \%$ \\
\hline - Schleswig-Holst. & 50 & $6,62 \%$ & $0,14 \%$ & 35588 & $2,51 \%$ \\
\hline - Hannover & 250 & $4,32 \%$ & $0,45 \%$ & 55657 & $1,72 \%$ \\
\hline - Westfalen & 263 & $3,30 \%$ & $0,32 \%$ & 83442 & $1,66 \%$ \\
\hline - Hessen-Nassau & 1349 & $6,32 \%$ & $2,81 \%$ & 47922 & $1,85 \%$ \\
\hline - Rheinprovinz & 567 & $2,27 \%$ & $0,40 \%$ & 140924 & $1,83 \%$ \\
\hline - Hohenzollern & - & - & - & 633 & $0,87 \%$ \\
\hline Bayern & 82 & $0,48 \%$ & $0,06 \%$ & 142156 & $1,85 \%$ \\
\hline Sachsen & 364 & $4,75 \%$ & $0,25 \%$ & 148051 & $2,85 \%$ \\
\hline Württemberg & - & - & - & 37133 & $1,38 \%$ \\
\hline Baden & 218 & $2,34 \%$ & $0,45 \%$ & 48090 & $1,90 \%$ \\
\hline Hamburg & 450 & $4,52 \%$ & $0,90 \%$ & 49860 & $2,98 \%$ \\
\hline Thüringen & 26 & $1,34 \%$ & $0,12 \%$ & 21186 & $1,28 \%$ \\
\hline Hessen & 199 & $3,27 \%$ & $0,74 \%$ & 27034 & $1,89 \%$ \\
\hline Mecklenburg & 17 & $4,73 \%$ & $0,10 \%$ & 17450 & $2,17 \%$ \\
\hline Braunschweig & 10 & $2,31 \%$ & $0,09 \%$ & 10694 & $2,08 \%$ \\
\hline Oldenburg & 14 & $3,84 \%$ & $0,22 \%$ & 6341 & $1,28 \%$ \\
\hline Bremen & 14 & $1,93 \%$ & $0,17 \%$ & 8412 & $2,28 \%$ \\
\hline Anhalt & 18 & $4,50 \%$ & $0,26 \%$ & 6874 & $1,89 \%$ \\
\hline Lippe & 6 & $2,65 \%$ & $0,34 \%$ & 1762 & $1,00 \%$ \\
\hline Schaumburg-Lippe & 4 & $2,96 \%$ & $0,42 \%$ & 957 & $1,92 \%$ \\
\hline Saarland & 63 & $11,43 \%$ & $0,60 \%$ & 10415 & $1,28 \%$ \\
\hline Gesamt & 10374 & $3,14 \%$ & $0,74 \%$ & 1406651 & $2,13 \%$ \\
\hline
\end{tabular}

ungleich größer, als diese Angaben es widerspiegeln. Ein Gutteil der jüdischen Armen tauchte in der Reichsfürsorgestatistik gar nicht mehr auf, denn eine Reihe von Großstädten in Bayern, im Rheinland und in Sachsen hatten Juden schon gänzlich aus der Versorgung in der Offenen Fürsorge ausgeschlossen. Dann muß zu den registrierten jüdischen Wohlfahrtsempfängern noch eine erhebliche Dun-

219 Parteien hieß immer Fürsorgeempfänger plus Angehörige, damit sind die Zahlen insgesamt um ein Drittel bis die Hälfte höher als hier angegeben; Die offene Fürsorge im Vierteljahr Januar-März 1939 (Ergebnisse des Schnelldienstes der Reichsfürsorgestatistik), Statistisches Reichsamt, (Berlin 1939), S. 4 sowie Statistisches Jahrbuch für das Deutsche Reich. Hrsg. vom Statistischen Reichsamt, 58 (1939/40), Berlin 1940, S. 695. 
kelziffer hinzu addiert werden, denn gegenüber jüdischen Antragstellern herrschten in den städtischen Ämtern seit der Fürsorge-Verordnung rigide Anerkennungspraktiken. Das Mißverhältnis staatlicher Versorgung zur real vorhandenen Armut konnte bereits krasser nicht sein. Betreute die staatliche Fürsorge im Land Württemberg keinen einzigen jüdischen Hilfsbedürftigen mehr, mußte die Jüdische Winterhilfe gleichzeitig 1348 Menschen versorgen. In Berlin gewährte das Landeswohlfahrtsamt zwar noch 5557 jüdischen Parteien ständige Leistungen, doch die Jüdische Winterhilfe zählte parallel bereits 25604 von ihr unterstützte Personen.220

Reichsweit war bis zum Frühjahr 1939 der Anteil der von der Jüdischen Winterhilfe versorgten Armen an der jüdischen Bevölkerung auf 24,66 Prozent gestiegen (Winter 1937/38 noch 20,5 Prozent). In einigen Regionen zeichneten sich noch weit schärfere Notlagen ab. In der Stadt Zwickau lag der Anteil der Hilfsbedürftigen bereits bei 50,6 Prozent sowie im gesamten Saarland bei 54,42 Prozent. Jeder Zweite bekam dort also zusätzliche Hilfen. ${ }^{221}$ Im Stadtstaat Hamburg unterstützte die Winterhilfe 37 Prozent der ca. 10000 jüdischen Einwohner gegenüber 18 Prozent im Winter 1935/36. ${ }^{222}$ Nur daß Berlin mit seinen ca. 130000 von insgesamt noch 286667 jüdischen Einwohnern im Altreich eine relativ niedrige Quote von 20 Prozent wegen der Vielzahl der dort bei jüdischen Institutionen arbeitenden Menschen aufwies, senkte den Landesdurchschnitt erheblich. ${ }^{223}$ Die Bilanz der Jüdischen Winterhilfe konnte im Altreich nur unter Einbeziehung von Überschüssen aus dem Vorjahr ausgeglichen werden, da das Spendenvolumen infolge Emigration und Verarmung um über 34 Prozent gesunken war. Die betreuten Armen konnten deshalb erstmals nur reduzierte Leistungen erhalten. ${ }^{224}$

In ganz Bayern bekamen im Frühjahr 1939 nur 82 jüdische Parteien staatliche Fürsorge, 3092 Männer und Frauen hingegen jüdische Winterhilfe.225 Noch Ende Oktober 1938 hatten allein die städtischen Wohlfahrtsämter Münchens 217 Jüdinnen und Juden unterstützt ${ }^{226}$, schon im Dezember jedoch niemanden mehr. Infolge dieser Tatsache mußte die Israelitische Kultusgemeinde einen Sprung ihrer monatlichen Ausgaben von 7000 RM auf 20000 bis 25000 RM verkraften, und das bei sinkenden Einnahmen. Gegenüber der Kommune München argumentierten die jüdischen Funktionäre im Januar 1939 vergeblich mit der Erschöpfung der eigenen Reserven: „Auch würden bei einem normalen Verlauf der Dinge die Mitgliedsbeiträge selbstverständlich immer geringer werden, da man ja von einem

220 Die Offene Fürsorge im Vierteljahr Januar-März 1939, (Berlin 1939), S. 4; Gruner, Berichte, S. 322-326, Dok. Nr. 1: Bericht über die JWH 1938/1939. Sowie Statistik über die JWH 1938/39; Abdruck bei Ginzel, Günther B.: Jüdischer Alltag in Deutschland 19331945, Düsseldorf 1984, S. 223.

221 Statistik über die JWH 1938/39; Abdruck ebenda, S. 222-223.

222 Lohalm, Fürsorge und Verfolgung, S. 49.

223 Statistik über die JWH 1938/39; Abdruck bei Ginzel, Alltag, S. 222-223.

224 Gruner, Berichte, S. 322-326, Dok. Nr. 1: Bericht über die JWH 1938/1939.

225 Die offene Fürsorge im Vierteljahr Januar-März 1939, (Berlin 1939), S. 4; Gruner, Berichte, S. 331, Dok. Nr. 1: Bericht über die JWH 1938/1939.

226 YV Jerusalem, M1DN, Nr. 109, Bl. 135: Statistik München (Stand 31.10.1938) am 19. 4.1939. 
Einkommen überhaupt nicht mehr sprechen könne, denn es sei den Juden ja untersagt, irgendwie einem Erwerb nachzugehen." Man schlug Kostenteilungen wie in anderen Städten vor, ohne Erfolg. ${ }^{227}$ Im April 1939 versorgte die Israelitische Kultusgemeinde München schon 372 Parteien mit 797 Personen, denn die infolge des Erwerbs- und Gewerbeverbots grassierende Verarmung hatte die Zahl zu Versorgender drastisch erhöht. Als würden sie noch von der staatlichen Fürsorge unterstützt, mußten sich mittlerweile alle von der Jüdischen Gemeinde betreuten, arbeitsfähigen Hilfsempfänger unter 65 Jahren, außer Müttern mit Kindern und schwangeren Frauen, regelmäßig beim Arbeitsamt melden. Sie waren damit dem direkten Zugriff der Arbeitsämter für den Geschlossenen Arbeitseinsatz ausgesetzt und erhielten ab Mai 1939 die Leistungen der Kultusgemeinde nur noch gegen Vorlage dieses Kontrollstempels. ${ }^{228} \mathrm{Da}$ die Jüdische Gemeinde, von der Stadt gezwungen, auch „nichtarische Christen" und „Konfessionslose" zu unterstützen hatte, war ihr Etat zusätzlich belastet, ohne daß sie über Möglichkeiten verfügte, für diese beiden Gruppen Spendengelder zu erheben. München hatte nur zehn jüdische Ärzte als „Krankenbehandler“ für die jüdische Bevölkerung zugelassen, es fehlten vor allem Spezialärzte. Deshalb mußte die Kultusgemeinde Wohlfahrtsempfänger auch an nichtjüdische Mediziner überweisen. Das verursachte hohe Kosten, da die jüdischen Armen als „Privatpatienten“ bezahlen mußten, denn sie waren meist nicht mehr bei Krankenkassen versichert. Erschwerend kam bei der hohen Überalterung der jüdischen Bevölkerung - einem akuten Phänomen im ganzen Reich - hinzu, daß das einzige für Juden zugelassene Krankenhaus in München nur über 40 Betten verfügte. Oft konnten Kranke nur notdürftig versorgt werden. Die Israelitische Kultusgemeinde verzeichnete so hohe Ausgaben, daß sie im April 1939 noch einmal an den Oberbürgermeister appellierte, wenigstens die Kosten der medizinischen Versorgung und der Geschlossenen Fürsorge zu übernehmen. Nicht nur die Altersversorgung, auch die Emigration sah die Kultusgemeinde als gefährdet an. Die Kultusgemeinde mußte ständig Unbedenklichkeitsbescheinigungen des Stadtsteueramtes, rückständige Steuern, Führungszeugnisse und Pässe für mittellose Juden bezahlen und immense Summen für Passagen und andere Emigrationskosten aufbringen. Der Kultusgemeinde sollte die Stadt wenigstens die kommunalen Gebühren ersparen. Die IKG München argumentierte in ihrer Eingabe mit der Handhabung andernorts und verwies speziell auf die Kostenaufteilungen zwischen Jüdischen Gemeinden und Kommunen in Hamburg, Leipzig und Frankfurt am Main, außerdem auf Mannheim, wo die jüdische Seite zwar die Versorgung allein organisiere, aber von der Stadt ein Viertel der Ausgaben erstattet bekam. ${ }^{229}$

Aber nicht nur die Kostenfrage spielte eine wichtige Rolle in den Verhandlungen zwischen Jüdischen Stellen und Kommunen, sondern auch die Probleme, die bei der Installation einer laufenden Unterstützungsorganisation durch Einrich-

227 Ebenda, Nr. 162, Bl. 39-40: Vermerk OB/Dez. 6 München vom 19. 1. 1939.

228 Vgl. Gruner, Geschlossener Arbeitseinsatz, S. 68-106.

229 YV Jerusalem, M1DN, Nr. 114, Bl. 242-248: Vorstand IKG München an OB/Wohlfahrtsamt am 19.4.1939 und Anhang: Merkblatt vom 17.4. 1939. Vgl. auch Hanke, Juden in München, S. 268. 
tungen entstanden, die bisher nur ergänzende Hilfen geleistet hatten. In Hamburg protestierte der Jüdische Religionsverband energisch gegen den von der Stadt geplanten Zwangstransfer der Fürsorgepflicht, denn es fehle 1. an der Befugnis bei Behörden, Versicherungsträgern, Arbeitgebern und anderen Stellen Feststellungen zu treffen, die für die Durchführung einer ordnungsgemäßen Fürsorge unerläßlich sind, 2. an den Voraussetzungen mit dem Arbeitsamt wie ein staatlicher Fürsorgeträger zusammenzuarbeiten, 3. an den Bedingungen für die Durchführung von Zwangsmaßnahmen, 4. an Einrichtungen für Pflichtarbeiten, 5. an Möglichkeiten, Unterhaltsverpflichtete und sonstige Angehörige im In- und Ausland durch behördliche Stellen heranzuziehen, 6. an der Möglichkeit, Renten- und sonstige Bezüge bei Krankenhaus- und Anstaltspflege in Anspruch zu nehmen. Auf einer Tagung der Nordwestdeutschen Arbeitsgemeinschaft für Wohlfahrtspflege fegte im März 1939 Referent Kayser (Bremen) alle diese Einwände zynisch beiseite: „Diese vom Jüdischen Religionsverband aufgeworfenen Fragen sind bezeichnend. Sie sind nicht sonderlich ernst zu nehmen, es ist die Sorge des Religionsverbandes, die Fürsorge für seine Angehörigen selbst zu gestalten. Wenn er im Einzelfall solche Zwangsmittel nötig habe, möge er eben durch Versagung von Unterstützung einen Druck ausüben." 230

Manche Lokalbeamten argumentierten noch drastischer. Der Vorsitzende des Kreisausschusses Birkenfeld schrieb an die Bürgermeister im Kreis Idar-Oberstein Anfang April 1939: „Die bedürftigen Juden sind von der jüdischen Wohlfahrtspflege zu unterstützen und erhalten auch von da laufende monatliche Unterstützungen, die aber nach den vorgelegten Bescheinigungen so gering sind, daß sie [für den] notdürftigen Lebensunterhalt nicht ausreichen. [...] Es sind mir eine ganze Anzahl Fälle bekannt geworden, bei denen die öffentliche Fürsorge durch das Amt seit Monaten eingestellt ist. Trotzdem ist mir nicht bekannt geworden, $\mathrm{da} ß$ ein Jude verhungert ist. Aus Berichten von Ortsbürgermeistern habe ich gelesen, daß sie noch sehr gut gekleidet sind und gut genährt aussehen. Dies ist ein Beweis, daß sie von dritter Seite unterstützt werden oder noch Barmittel zur Verfügung haben.“ Er ordnete deshalb an: „Unterstützungsanträgen von Juden ist nur im äußersten Notfalle stattzugeben. [...] Ist die Gewährung von Unterstützung unter keinen Umständen mehr zu umgehen, so ist mit kleinen einmaligen Naturalunterstützungen zu helfen. [...] Grundsätzlich ist die Hergabe einer Unterstützung an Juden nur von einer entsprechenden Arbeitsleistung abhängig zu machen." 231

\section{Pflichtarbeit für Juden als städtische Norm}

Einige Wohlfahrtsverbände waren - wie beschrieben - bereits Jahre vor dem Pogrom dazu übergegangen, bei Juden die Gewährung von Fürsorgemitteln von Pflichtarbeit in isolierten Kolonnen abhängig zu machen. Nach der antijüdischen Fürsorge-Verordnung sollten Wohlfahrtsämter, die wegen der Finanzschwäche

230 BA, R 36, Nr. 899, unfol.: 8. Tagung Nordwestdt. ArbG für Wohlfahrtspflege am 13. 3. 1939 in Rostock, S. 26-27.

231 NW-HStA Düsseldorf, RW 53, Nr. 413, unfol.: Rundschreiben vom 1. 4. 1939. 
der örtlichen Jüdischen Gemeinden Juden noch unterstützten, nun gegen letztere prinzipiell unbezahlte Pflichtarbeit verhängen. Obwohl in Berlin Pflichtarbeit für jüdische Wohlfahrtsempfänger seit Mitte der dreißiger Jahre sowieso die Regel bildete, verfügte Oberbürgermeister Lippert im Anschluß an die neue Verordnung noch einmal offiziell im Dezember 1938, daß jegliche Leistungen ausnahmslos durch Pflichtarbeit abzugelten seien. Er verschärfte die zentrale Vorgabe aber sogleich im Detail: Selbst über 60 Jahre alte Juden sollten hierzu erfaßt werden. Bei Untauglichkeit wollte man deren Ehepartner zur Arbeit heranziehen. Die Ernährungszulagen für Pflichtarbeiter, die Fahrtkosten und erhöhten Nahrungsbedarf ausgleichen sollten, wurden bei Juden gekürzt. ${ }^{232}$

$\mathrm{Da}$ in Berlin der Zwangstransfer der Fürsorgepflicht zunächst als gescheitert angesehen wurde, setzte die Stadt von 1484 Ende 1938 in Berlin als arbeitsfähig Eingestuften, das war ein Viertel der jüdischen Unterstützten, $1030 \mathrm{im}$ ersten Quartal 1939 in separaten Arbeitsprogrammen ein. Im Bezirk Mitte traf die Pflichtarbeit alle in Frage kommenden 394 Juden und Jüdinnen. ${ }^{233}$ Infolge des Erlasses über die Befristung der Arbeitslosenhilfe für Juden auf 20 Wochen erwartete das Berliner Hauptwohlfahrtsamt Mitte Mai 1939 ein weiteres „Anwachsen des Zuganges“ an jüdischen Bedürftigen. Wenn diese „Ausgesteuerten“ Fürsorgeunterstützung beantragten, sollten sie "sofort" in drei separate Pflichtarbeitsprogramme für Juden (Krumme Lanke, Vandalen-Allee und Gasanstaltsgelände Schmargendorf) eingewiesen werden. ${ }^{234}$ Zwischendurch hatte die Stadt ihre Ernährungszulagen für Pflichtarbeiter erhöht, schloß davon aber am 19. Mai jüdische Pflichtarbeiter und "Asoziale“ aus. Für beide Gruppen galt als Höchstgrenze eine Zulage von täglich 0,55 RM (bei 6-8 Arbeitsstunden dreimal wöchentlich) oder 0,35 RM (bei 4 Arbeitsstunden fünfmal wöchentlich), die sie jedoch nur bei Erreichen der Arbeitsleistungen von Stammkräften erhielten. In der Praxis bekamen sie gekürzte Zulagen von täglich 0,40 RM (bei 6-8 Arbeitsstunden) oder 0,25 RM (bei 4 Arbeitsstunden). Bei schwachen Arbeitsleistungen entzog man die geringfügigen Zahlungen ganz. ${ }^{235}$ Wie Berlin führten auch andere Fürsorgebehörden, wenn sie noch Juden in der Fürsorge betreuten, ihre lokalen antijüdischen Pflichtarbeitsprogramme mit voller Kraft fort.

Unter Berufung auf die antijüdische Fürsorge-Verordnung begannen nun aber auch Wohlfahrtsverbände, die vorher keine solche „Tradition“ hatten, bei Juden die Ausgabe von Sozialhilfen prinzipiell von Arbeitsleistungen abhängig zu machen. Dresden führte Ende Dezember 1938 für zehn Unterstützte auf dem ört-

232 Dienstblatt Berlin, 1938 Teil VII, S. 342, Nr. 360: Vfg. Lippert/OB vom 3. 12. 1938; vgl. LA Berlin, Rep. 214, Acc. 794, Nr. 13, unfol.: Vfg. Lippert vom 3. 12. und Besprechung vom 7. 12. 1938. Außerdem ebenda: Protokoll der Sitzung im Landeswohlfahrtsamt vom 3. 12.1938 sowie ebenda, Rep. 203, Acc. 867, Nr. 5100, Bl. 19: Vermerk über Sitzung am 14. 1. 1939. Vgl. zum folg. Gruner, Judenverfolgung in Berlin, S. 60-67.

233 BA, R 41, Nr. 156, Bl. 66: Wirtschaftslagebericht des Stadtpräsidenten für das Gebiet Berlin, vom 24. 3. 1939, S. 55; Gruner, Berichte, S. 312.

${ }^{234}$ LA (Sta) Berlin, Rep. 03-02, Nr. 63/1, Bl. 166 u. RS: Vfg. Hauptwohlfahrtsamt vom 16. 5. 1939.

235 Dienstblatt Berlin, 1939 Teil I, S. 288-289, Nr. 175: Vfg. Behagel (Landeswohlfahrtsamt) vom 19. 5. 1939. 
lichen Heidefriedhof eine separate „Judenmaßnahme“ ein. Im Januar 1939 erweiterte das Wohlfahrtsamt dieses Programm, zusätzlich wurden nun vierzehn jüdische Unterstützte im Fichtepark mit Pflichtarbeit beschäftigt. ${ }^{236}$ In Celle richtete das Wohlfahrtsamt im März 1939 sogar für nur zwei Jüdinnen eine separate Maßnahme ein. Das Stadtgartenamt sollte sie ohne „Vergütung“ an zwei oder drei Tagen "mit Reinigen der Wege und Aufsuchen von Papier" beschäftigen.237

Pflichtarbeit wurde gegen Juden selbst bei gekürzten Unterstützungen durch die Wohlfahrtsämter verhängt. In Duisburg lebten Ende Februar 1939 noch 1103 jüdische Deutsche, von denen 95 vom Städtischen Wohlfahrtsamt unterstützt wurden. Der Bezirksfürsorgeverband gewährte ihnen seit dem 1. Februar nur noch 50 Prozent der ortsüblichen Leistungen. ${ }^{238} \mathrm{Im}$ März verfügte das Wohlfahrtsamt trotzdem für alle jüdischen Fürsorgeempfänger Pflichtarbeit und meldete sie an die zuständige Abteilung Arbeitsfürsorge. Die Parole der Kommunalbehörde lautete: „Jeder unterstützte Jude soll arbeiten.“ Frauen wie Männer unter 65 Jahren wollte man vier Tage wöchentlich jeweils acht Stunden beim Grünflächenamt nicht nur ohne Bezahlung, sondern auch ohne die sonst überall üblichen Zuschläge einsetzen. Die jüdischen Pflichtarbeiter sollten mit leichten bis mittelschweren Arbeiten in einer Baumschule oder in Gehölzpflanzungen beschäftigt werden. Bei Nichtaufnahme oder Abbruch der Arbeit werde sofort die Unterstützung gesperrt, bei Fehlschichten gekürzt. Kranke oder arbeitsunfähige Personen werde man an den Stadtarzt zur Nachprüfung überweisen, der solle dabei einen „strenge[n] Maßstab“ anlegen. Das Duisburger Wohlfahrtsamt überstellte, über die eigene Maßnahme hinausgehend, zwölf Juden dem Landesarbeitsamt Köln "zur Einweisung in eine Arbeitsmaßnahme", die ,in der Eifel lagermäßig untergebracht" wurden. Es hatte außerdem mit dem Arbeitsamt vereinbart, daß jüdische Hilfsempfängerinnen sich jeden Samstag, also am Sabbat, um 8 Uhr dort zu melden hätten. ${ }^{239}$ Ein anderes prägnantes Beispiel für eine enge Kooperation zwischen Fürsorge- und Arbeitsverwaltungen ist Hamburg, wo beide Behörden schon seit 1938 erwerbslose und fürsorgeunterstützte Juden in gemeinsam unterhaltenen Lagern beschäftigten. Arbeitsfürsorge und Arbeitsamt verhandelten in der Hansestadt seit Januar 1939 auch über die Ausweitung dieser Programme auf erwerbsbeschränkte Juden und jüdische Frauen.240

236 StadtA Dresden, Fürsorgeamt, Nr. 514, Bl. 22: Pflichtarbeiter-Statistik (Wohlfahrtsamt/ Abt. Arbeitsfürsorge Dresden), Stand 31. 12. 1938; ebenda, Bl. 49: Pflichtarbeiter-Statistik, Stand 31. 1. 1939. Im April waren es 25 Juden; ebenda, Bl. 93RS: Pflichtarbeiter-Statistik, Stand 30. 4. 1939. Im Juli arbeiteten 15 Juden nur auf dem Heidefriedhof; ebenda, Bl. 123RS: Pflichtarbeiter-Statistik, Stand 31.7. 1939.

237 StadtA Celle, Städt. Gartenamt, Akte unnumeriert, unfol.: Schreiben OB/Wohlfahrtsamt Celle vom 11.3. 1939.

238 BA, R 36, Nr. 1022, Bl. 14-16RS: Zusammenstellung der Ergebnisse der Umfrage über Unterstützung von Juden, DGT Düsseldorf vom 22.8.1939 sowie StadtA Duisburg, Best. 100 A, Nr. 106/3, unfol.: Verwaltungsberatung vom 7. 3. 1939, Bericht Stadtrat Birkenbeul.

239 Ebenda sowie ebenda, Best. 500, Nr. 905, unfol.: Vfg.-Wohlfahrtsamt vom 2.3. und 17. 3. 1939. Vgl. Zitat bei Von Roden, Duisburger Juden, S. 855.

240 StA Hamburg, 351-10 Sozialbehörde I, AW 40.30, unfol.: AFÜ-Vermerk vom 11. 1. 1939; ebenda: Auszug aus Niederschrift über die 39. Amtsleitersitzung am 26. 1. 1939. 
Andernorts ging man noch einen Schritt weiter. Nach der Reichsfürsorgeverordnung konnten Pflichtarbeitsmaßnahmen nur vom Träger der Wohlfahrtsunterstützung eingerichtet werden, also bislang immer von der Öffentlichen Wohlfahrt. Das Münchner Wohlfahrtsamt hatte deshalb im Januar 1939, vom Arbeitsamt angesprochen, die Einrichtung von Pflichtarbeitsmaßnahmen für jüdische Arme mit der Begründung abgelehnt, nach der Übertragung der Fürsorge an die Jüdische Gemeinde habe man weder Interesse hieran, noch sei man in der Lage dazu. ${ }^{241}$ Doch einige Monate später hatte man diese Auffassung wieder verworfen. Im Juni richtete die Stadt, obwohl sie selbst nicht mehr unterstützte, für Juden separate Pflichtarbeitskolonnen bei kommunalen Arbeiten ein, z.B. beim Planieren städtischer Grundstücke. Wenngleich laut Fürsorgegesetzgebung die Stadt dazu keinerlei Recht hatte, mußten auf Anordnung des schon mehrfach mit antijüdischen Initiativen hervorgetretenen Münchner Amtsdirektors Ortner ${ }^{242}$, die jetzt von der jüdischen Wohlfahrtspflege versorgten Armen Pflichtarbeit für die Kommune leisten, angeblich „zur Arbeitserziehung und zur Vermeidung einer Ausnützung der Fürsorgeeinrichtungen“. Drei Tage pro Woche sollten die Männer antreten, vorgesehen war für das Programm eine Dauer von zwei bis drei Monaten. Sie erhielten eine Tageszulage von 0,50 RM. ${ }^{243}$ Auf dieselbe ungesetzliche Weise verfuhr die Stadt Aschaffenburg. Im März 1939 mußten sechs von der „Kultusgemeinde unterstützte Leute“ getrennt von den „deutschen Volksgenossen" in der Stadtgärtnerei arbeiten. ${ }^{244}$ In Leipzig organisierte hingegen das Arbeitsamt den Einsatz jüdischer Armer, die ausschließlich von der Jüdischen $\mathrm{Ge}$ meinde Wohlfahrtsleistungen erhielten, beim Tiefbau. Wenn die Rekrutierten die Arbeitsaufnahme ablehnten, wurden sie vom Arbeitsamt als Arbeitsuchende gestrichen und die Kultusgemeinde mußte die Unterstützung sperren. ${ }^{245}$ Diese Praktiken sollten sich schnell verbreiten.

Auch in Mainz hatte die Stadt mit Wirkung vom 1. April 1939 jegliche Fürsorge für Juden aufgehoben und diese an jüdische Stellen verwiesen. Trotzdem beschäftigte man sie weiterhin - ohne rechtliche Grundlage - in unbezahlten und abgesonderten Pflichtarbeitsmaßnahmen. Das Wohlfahrtsamt Mainz verlangte von der Jüdischen Gemeinde außerdem rückwirkend für das erste Quartal 1939 einen Geldbetrag, da eine Anrechnung der Jüdischen Winterhilfe unterblieben sei, als die Stadt noch unterstützt habe. Vertrat die jüdische Seite die plausible Haltung, daß die Winterhilfe ergänzend und damit nicht anrechnungsfähig sei, definierte das städtische Wohlfahrtsamt jene als Bestandteil der „freien jüdischen Wohlfahrtspflege" und wollte die eigenen Leistungen um diese kürzen. Die Stadt Mainz intervenierte dieserhalb beim Deutschen Gemeindetag in Berlin. Man forderte eine strenge Kontrolle der Mittelverwendung in der jüdischen Fürsorge und

241 YV Jerusalem, M1DN, Nr. 162, Bl. 2: Arbeitsamt München an Hauptwohlfahrtsamt am 3. 1. 1939; ebenda, Bl. 3: Ortner (Dez. 6) an Arbeitsamt München am 16. 1. 1939.

242 Hanko meint hingegen, Ortner sei in der Stadtverwaltung kaum in Erscheinung getreten; Hanko, Kommunalpolitik in der "Hauptstadt der Bewegung“, S. 359.

243 YV Jerusalem, M1DN, Nr. 162, Bl. 54-56: Vermerke Dezernat 6/AFÜ München vom 13. und 15.6. 1939.

244 BA, R 11, Nr. 1220, Bl. 264: IHK Würzburg an RWK am 10. 3. 1939.

245 Stadt A Leipzig, AFS, Nr. 1939 Bd. 3, Bl. 260: Jahresbericht 1939 der AFÜ-Stelle. 
eine Reduzierung aller ihrer Leistungen, um eine angebliche „Besserstellung der hilfsbedürftigen Juden“ gegenüber ,arischen“ Armen zu vermeiden. 246

Den Mainzer Auffassungen wollte sich der geschäftsführende Präsident des Deutschen Gemeindetages jedoch zu diesem Zeitpunkt so nicht anschließen. Jeserich verneinte die Möglichkeit, auf die jüdische Fürsorge und deren Leistungen restriktiv einzuwirken. Auch könne die Stadt keineswegs Pflichtarbeit gegen Juden, welche sie nicht unterstütze, verhängen. Eine kommunale Kontrolle jüdischer Einrichtungen sei nach dem Zwangstransfer der Fürsorge rechtlich ebenfalls obsolet. Allerdings, so Jeserich, wären im Fall städtischer Fürsorgeunterstützung die Leistungen der Jüdischen Winterhilfe voll anzurechnen, denn sowieso sei „damit zu rechnen, daß die Sicherstellung der jüdischen Vermögenswerte zur Dekkung des Aufwandes für die hilfsbedürftigen Juden von der Reichsregierung noch gesetzlich geregelt" werde.247 Die zurückhaltende, wenn auch keineswegs gesetzeskonforme Haltung Jeserichs bildete eher eine Ausnahme im Deutschen Gemeindetag, wie die oben geschilderten Debatten in dessen Gremien gezeigt haben. Der Gemeindetag befürwortete im großen und ganzen das Streben der Kommunen nach einer Überwachung der jüdischen Fürsorge ebenso wie nach einer Ausweitung antijüdischer Regelungen auf dem sozialen Sektor.

Jeserichs Stellvertreter Zeitler hatte beispielsweise das Reichsinnenministerium ebenfalls im April 1939 aufgefordert, den Paragraphen 19 der Reichsfürsorgeverordnung über die Pflichtarbeit auch auf Familienunterhalt ${ }^{248}$ beziehende Juden anzuwenden. Die solche Leistungen beziehenden Juden sollten „auf besonderen Arbeitsplätzen als Unterstützungsarbeiter" eingesetzt werden, weil sie von den Arbeitsämtern kaum vermittelbar seien. ${ }^{249}$ Der Reichsinnenminister hatte aber schon zu Beginn des Jahres - auf Anfragen des Württembergischen Innenministeriums und des Regierungspräsidenten in Potsdam - entschieden, daß die antijüdische Fürsorge-Verordnung nicht auf die Familienunterstützung angewendet werden könne, da letztere kein Element der Öffentlichen Fürsorge sei: „Für eine sinngemäße Anwendung fehlt es an der Gleichartigkeit der zu beurteilenden Verhältnisse. Wenn die Verordnung über die öffentliche Fürsorge für Juden die Fürsorge für hilfsbedürftige Juden grundsätzlich der jüdischen freien Wohlfahrtspflege und nur hilfsweise den amtlichen Fürsorgestellen zuweist, so kommt darin zum Ausdruck, daß zur Behebung von Notständen, die innerhalb der Judenschaft auftreten, in erster Linie diese selbst berufen ist. Nachdem aber das Reich grundsätzlich die Sorge für die Angehörigen derjenigen übernommen hat, die in der deutschen Wehrmacht ihrer Dienstpflicht genügen und deshalb selbst nicht für ihre Angehörigen sorgen können, wird nicht anzunehmen sein, daß im einzelnen Fall die Sorgepflicht vom Reich deshalb abgelehnt wurde, weil der Angehörige Jude ist. Die

246 BA, R 36, Nr. 1022, Bl. 18-19RS: OB Mainz/Wohlfahrtsamt an DGT Hessen/Nassau am 6. 4. 1939.

247 Ebenda, Bl. 20 u. RS: DGT Berlin an OB Mainz am 25. 4. 1939.

248 Familienunterhalt war eine privilegierte Versorgungsform für Angehörige von zum Wehr- und Kriegsdienst eingezogenen Personen außerhalb der Offenen Fürsorge.

249 BA, R 36, Nr. 885, unfol.: DGT Berlin an RMdI am 11. 4. 1939. 
Sachlage ist [...] dieselbe wie bei jüdischen Hinterbliebenen von Gefallenen. Auch diese haben den Versorgungsanspruch behalten." 250

Isolierte Pflichtarbeit jüdischer Armer war also in dieser Phase eine auf der antijüdischen Fürsorge-Verordnung basierende generelle Zwangsmaßnahme, wenn Fürsorgeverbände Juden noch in der Offenen Wohlfahrt unterstützten, selbst bei stark gekürzten Leistungen. Immer mehr Kommunen richteten solche Arbeitsmaßnahmen inzwischen aber sogar für Juden ein, die gar nicht von ihnen, sondern von jüdischen Wohlfahrtsstellen versorgt wurden. Noch betrachtete man diese von den Städten und Gemeinden betriebenen Pflichtarbeitsprogramme dem von den Arbeitsämtern organisierten Geschlossenen Arbeitseinsatz jüdischer Arbeitsloser und Sozialunterstützter als gleichwertig. Doch als im Sommer 1939 die Arbeitsämter, bei denen ja alle arbeitsfähigen Unterstützungsempfänger gemeldet sein mußten, begannen, Juden immer massiver und repressiver zu rekrutieren, verloren diese kommunalen $Z$ wangsmaßnahmen rasch an Bedeutung. ${ }^{251}$

\section{Exkurs: Zur "Arisierung " mildtätiger Stiftungen (III)}

Bis November 1938 hatte Münchens Oberbürgermeister Fiehler wegen der auf Reichsebene andauernden Diskussion immer noch keine Genehmigungen vom Bayerischen Innenministerium erhalten, mehrere jüdische Stiftungen in seinen städtischen Fonds zu überführen. ${ }^{252}$ Offenbar unter dem Eindruck des Pogroms entschied er am 19. November einfach eigenmächtig über die geplanten „Arisierungen “. Drei Stiftungen wurden am 10. Dezember umbenannt, außerdem zwei andere Stiftungen in eine städtische Stiftung umgewandelt. 253

Seit dem Pogrom waren immer mehr Kommunen daran interessiert, jüdische Stiftungen zu „arisieren“. Die DGT-Landesdienststelle Baden teilte der Berliner Zentrale mit: „Von größeren Städten wurde mir mitgeteilt, daß jüdische Stiftungen vorhanden sind, deren Zweck an sich noch erfüllt werden kann. Es handelt sich dabei insbesondere um Wohlfahrts- und Schulstiftungen. Ich wäre dankbar, wenn zusammen mit der Regelung der gesamten Judenfrage auch dieses Problem behandelt wird."254 Der Deutsche Gemeindetag konnte am 6. Dezember nach Karlsruhe mitteilen, man habe aus dem Reichsinnenministerium erfahren, daß „in nächster Zeit mit einer generellen Regelung über die Satzungsänderungen und die sonstige Behandlung jüdischer Stiftungen zu rechnen" sei..255

$250 \mathrm{Da}$ Juden zum Wehrdienst nicht zugelassen waren, konnten somit diese Reichsversorgung „Rassejuden“ nur noch als Angehörige von wehrmachtsangehörigen „Mischlingen“ beziehen; BLHA, Pr. Br. Rep. 2 A, I SW, Nr. 1151, Bl. 12-12b: RMdI an MdI in Stuttgart vom 30. 1.1939 in Abschrift als Anlage zu RMdI an Regierungspräsidenten in Potsdam vom 6. 2. 1939.

251 Vgl. Gruner, Geschlossener Arbeitseinsatz, S. 75-78.

252 Vgl. Kapitel III. 3.

253 Hanke, Juden in München, S. 249 u. 318.

${ }^{254}$ LA Berlin, Rep. 142/7, 1-2-6/Nr. 1, Bd. 2, unfol.: DGT Baden an DGT Berlin am 23. 11.1938.

255 Intern wußte man im DGT Berlin wenig später bereits, daß noch vor Weihnachten neue Bestimmungen erscheinen würden; ebenda: DGT Berlin an DGT Baden am 6.12.1938 und Vermerk vom 20. 12. auf demselben Schreiben. 
Im Zusammenhang mit ihrer Änderung der Verfolgungsstrategie bewertete die NS-Führung nach dem Pogrom auch die Zukunft „jüdischer" Stiftungen neu. Jetzt stand nicht mehr die totale „Arisierung “ aller mildtätigen Stiftungen auf dem Plan, sondern deren ausschließliche Fixierung auf die jüdische Fürsorge. Ein entsprechender Entwurf lag im Dezember 1938 beim Stellvertreter des Führers. Nicht nur der Gemeindetag auch Frankfurt am Main zeigte sich zu diesem Zeitpunkt gut informiert. Der Beauftragte der Stadt in Berlin hatte erfahren, daß beabsichtigt sei, „rein jüdische Stiftungen als jüdisches Vermögen mit Fürsorgecharakter zu erhalten, um die öffentliche Fürsorge gemäß dem zuletzt ergangenen Erlaß zu entlasten " ${ }^{256}$ Solche Stiftungsmittel sollten also den Zwangstransfer der staatlichen Fürsorgepflicht auf ein separates jüdisches Wohlfahrtssystem finanziell absichern helfen.

Allerdings durchkreuzte dieses Vorhaben manch ältere kommunale „Arisierungspläne“. Auch die Stadt Frankfurt am Main hatte seit einigen Jahren Stiftungen jüdischer Stifter durch Umbenennungen oder Auflösungen enteignet. Oberbürgermeister Krebs reklamierte nun Anfang Dezember 1938 beim zuständigen Regierungspräsidenten, daß infolge von Verhaftung oder Emigration der Vorstandsmitglieder viele jüdische Stiftungen bzw. solche, deren Nutznießer Juden seien, nicht funktionsfähig wären. Es sei unklar, ob als „Ersatzmitglieder für jüdische Stiftungen wieder Juden zu bestellen sind. In einzelnen Fällen hat die Jüdische Gemeinde oder die Jüdische Religionsgemeinde Vorschlagsrecht". Krebs bat den Regierungspräsidenten festzustellen, ob dieses Recht „auch unter den jetzigen Umständen noch berücksichtigt werden muß", um diese jüdischen Stiftungen der Kontrolle seiner Kommune zu unterwerfen. Noch radikaler wollte Krebs bei den paritätischen Stiftungen handeln. Man könne „den arischen Mitgliedern ein $\mathrm{Zu}$ sammenarbeiten mit jüdischen Mitgliedern im Vorstand der gleichen Stiftung nicht mehr zumuten“. Was die städtischen Stiftungen betreffe, hätte der Regierungspräsident ja bereits entschieden, Juden nicht mehr heranzuziehen, weil diese keine städtischen Ehrenämter ausüben dürften. Diese Methode könne aber bei privatrechtlichen Stiftungen nicht angewendet werden. Daher schlug Krebs vor, gemischte Stiftungen entweder nur noch "deutschen Volksgenossen“ oder Juden zugute kommen zu lassen, und bat dafür um eine Generalermächtigung.257 In einigen Fällen hatte das Rechtsamt der Stadt durch Ausübung von Druck auf abwesende jüdische Vorstandsmitglieder schon entsprechende Fakten geschaffen. ${ }^{258}$ Nur das Argument, daß jüdische Stiftungen für das Funktionieren einer separaten jüdischen Fürsorge notwendig schienen und damit indirekt den Stadtsäckel entlasteten, konnte wohl Frankfurts Oberbürgermeister von einer "Generalenteignung“ abhalten. ${ }^{259}$ Allerdings gelang es der Stadt auf anderem Wege, sämtliche

256 Dokumente Frankfurter Juden, III 65, S. 118-119: Vermerk Beauftragter Stadt Frankfurt/ M. vom 12. 12. 1938; vgl. Adam, Judenpolitik, S. 193.

257 Dokumente Frankfurter Juden, III 71, S. 134-135: OB an Regierungspräsident am 6. 12. 1938. Vgl. hierzu Kingreen, Raubzüge, S. 27-28.

258 Z. B. bei der Georg-Speyer-Stiftung: Ebenda, III 74 A, S. 139-141: Rechtsamt/Stiftungsabt. an Vorstand Georg-Speyer-Stiftung am 16.11. 1938.

259 Ebenda, III 76, S. 142: OB an NSDAP-Kreisleitung/Amt für Kommunalpolitik am 17. 12. 1938 . 
Stiftungen zu kontrollieren. Krebs erreichte beim Regierungspräsidenten noch im Dezember 1938, daß alle jüdischen Fürsorge- und Ausbildungsstiftungen sämtliche Ausschüttungen dem neu ernannten städtischen Beauftragten für die jüdische Wohlfahrtspflege überlassen mußten. Der vom Regierungspräsidenten als „Stiftungskommissar" anerkannte "Juden-Beauftragte“ 260 ordnete daraufhin Ende Dezember 1938 an, daß alle jüdischen Stiftungen für mildtätige $Z$ wecke in Frankfurt am Main künftig nicht mehr selbständig ihre Mittel verteilen durften, sondern diese an die jüdische Wohlfahrt abtreten mußten.261

Auch Hamburg handelte schnell. In der Sozialbehörde trafen sich am 13. Dezember 1938 unter Leitung von Senatsrat Werner David elf Stiftvorstände und Dr. Max Plaut vom Jüdischen Religionsverband zum Thema paritätischer Stiftungen in Hamburg. Alle jüdischen Vorstandsmitglieder mußten ihr Mandat niederlegen. Die Stadt ließ infolge des Verhandlungsgeschickes der jüdischen Seite wenigstens drei der paritätischen Wohnstifte zur Einquartierung von Juden zu. Die Stifte Mendelson, Warburg und Brunn mutierten damit zwangsweise zu "jüdischen“ Heimen, der Rest galt als „arisiert“. Unter den über 1100 Bewohnern aller paritätischen Stifte gab es lediglich 91 jüdische Deutsche. Die meist älteren und alleinstehenden Frauen zwang man, in die drei genannten Stifte überzusiedeln. ${ }^{262}$ In diesen drei Wohnstiften mußte die Jüdische Religionsgemeinde künftig auf Druck der Hamburger Sozialverwaltung auch noch die Geschlossene Fürsorge jüdischer Armer organisieren und Platz für jüdische Erwachsene und Jugendliche aus den Landesanstalten sowie vom Jugendamt finden. ${ }^{263}$ Die Hamburger Regelung zur "Rassentrennung" in den paritätischen Stiftungen fand ihren schnellen Abschluß mit Satzungsänderungen im Februar 1939. Das „Entgegenkommen“ des Hamburger Senats war teuer erkauft, denn auf der Jüdischen Religionsgemeinde lasteten ab sofort alle Kosten der Geschlossenen Fürsorge, also auch für die Bewohner von Alten-, Waisen- und Siechenheimen. Die enormen Ausgaben, die auf die jüdische Seite zukamen, sollten aus Grundvermögen bzw. Stiftungserträgen finanziert werden. ${ }^{264}$

Wie schon angeführt, hatte Ende Dezember 1938 die NS-Führung verkündet, daß jüdische Stiftungen nicht mehr „arisiert“, und Mitte Februar 1939 explizit bestimmt, daß noch existierende jüdische Vereine und Stiftungen samt Vermögen in die zu bildende „Reichsvereinigung“ eingegliedert würden. Auf einer Sitzung im Reichsinnenministerium avisierte man den diese Entscheidungen ergänzenden Erlaß für Ende März. ${ }^{265}$ Doch der mehrfach angekündigte Erlaß des Reichsinnenministeriums, der eine „Rassentrennung “ bei den mildtätigen Stiftungen vorsah, erging schließlich erst am 8. Mai 1939. Dieser bestimmte, daß Juden ab sofort

260 Dazu ausführlicher Kingreen, Raubzüge, S. 27-28.

261 Dokumente Frankfurter Juden, III 77, S. 143: Rechtsamt/Stiftungsabt. an Vorstände der Jüd. Fürsorgestiftungen am 31.12.1938.

262 Schwarz, Von den Wohnstiften zu den „Judenhäusern“, S. 235-236.

263 StA Hamburg, 351-10 Sozialbehörde I, AW 26.19, unfol.: Niederschrift über Sitzung des Beirats der Sozialverwaltung am 22. 12. 1939.

264 Schwarz, Von den Wohnstiften zu den „Judenhäusern“, S. 235-236.

265 Dokumente Frankfurter Juden, III 77, S. 143: Vermerk Rechtsamt/Stiftungsabteilung vom 31. 3. 1939. 
nicht mehr in den Genuß von Stiftungsmitteln gelangen durften, die „ohne Rücksicht auf die Konfession" gestiftet worden waren. Alle jüdischen Stiftungen mußten auf ihre Ziele hin überprüft werden. Jüdische Stiftungen für die deutsche Bevölkerung seien durch Namensänderung zu „arisieren“, gemischte Stiftungen ebenso. Jüdische Stiftungen für sachliche Zwecke, z. B. für wissenschaftliche Forschungen, konnten bestehen bleiben. Der Name des jüdischen Stifters war jedoch per Satzung ebenso zu beseitigen wie jede jüdische Mitwirkung bei der Verwaltung der Stiftung. De facto sollten diese Stiftungen also auch enteignet werden. Nur jüdische Stiftungen für die jüdische Bevölkerung sollten weiter existieren. Das aber auch nur, wenn ihre Ziele mit den „Grundsätzen der Judenpolitik“ vereinbar waren. Unter strenger Kontrolle durften diese künftig ausschließlich der separaten jüdischen Emigrationsförderung, der Wohlfahrtsunterstützung oder dem Betrieb jüdischer Wohlfahrts-, Krankenhaus- bzw. Schuleinrichtungen dienen. Mit "nichtrechtsfähigen" Stiftungen, das waren oftmals Schenkungen an Kommunen, sei durch das Anwenden der Deutschen Gemeindeordnung adäquat zu verfahren. ${ }^{266}$

Der Ministerialerlaß „legalisierte“ nicht nur bisherige lokale Praktiken, sondern forderte die Kommunen zu weiterem Handeln heraus. Nun forcierte auch Breslau seine Bemühungen zur „Arisierung “ paritätischer bzw. jüdischer Stiftungen. Bis Juni 1939 tilgte man „jüdische“ Stiftungsnamen, beseitigte die Mitwirkung von Juden an deren Verwaltung und schloß jüdische Minderbemittelte als Nutznießer kategorisch aus. Die Stadt zeigte besonderes Interesse an jüdischen Altenstiften, weil deren Gebäude eine „wertvolle Ergänzung der städtischen Stiftungsaltersheime" darstellten. Sie übernahm bald die Hilleschen Altersheime. Erfolglos blieb jedoch ihr Bemühen, auch die Israelitische Krankenversorgungsanstalt in Breslau zu „arisieren“, denn diese sollte in die „Reichsvereinigung“ eingegliedert werden. Der Oberbürgermeister protestierte beim Regierungspräsidenten mit dem herbeigeholten Argument, es handle sich um eine paritätische Stiftung, da laut Statut der Krankenanstalt auch nichtjüdische Patienten in dieser behandelt werden konnten. Ungeachtet der städtischen Intervention bestätigte jedoch in diesem Fall der Breslauer Regierungspräsident den „rein jüdischen“ Charakter der Stiftung und ihre Integration in das separate jüdische Fürsorgesystem. ${ }^{267}$

Über den Ministerialerlaß hinausgehend, konnten in Bayern Stiftungen, die von der Kultusgemeinde München verwaltet wurden, durch das Staatsministerium des Innern "wegen Unmöglichkeit der Erfüllung des Stiftungszwecks“ aufgehoben werden. Dies nutzte Fiehler und gemeindete, seine Praxis von 1938 fortsetzend, bis zum Mai 1941 die restlichen jüdischen Stiftungen in extra gegründete städtische Wohlfahrtsfonds ein. ${ }^{268}$ In Berlin drängte das Stiftungsamt 1940 auf die „Ari-

266 Juden war künftig verboten, Stiftungen für deutsche bzw. für die deutsche und jüdische Bevölkerung zu errichten. „Deutsche" durften nicht mehr für "Juden" stiften, „da die Förderung von Juden durch Deutsche, insbesondere im Wege der Stiftungserrichtung, dem deutschen Volksempfinden widerspricht"; BA, 49. 01, Nr. 11787, Bl. 112-113: Erlaß vom 8. 5. 1939; Abdruck in: Dokumente Frankfurter Juden, III 81, S. 154-155.

267 Reinke, Judentum, S. 271-273.

268 Hanke, Juden in München, S. 249, 318-319. 
sierung" von vier jüdischen bzw. paritätischen Armenstiftungen mit einem Gesamtkapital von rund $200000 \mathrm{RM}$, die bereits von der Stadt verwaltet wurden, hier allerdings ohne Erfolg. ${ }^{269}$ In Frankfurt am Main unternahm man hingegen noch im Jahr 1939 alle notwendigen Schritte, um die in Frage kommenden Stiftungen $\mathrm{zu}$,arisieren". .270

Hatten einige Städte gleich nach dem Pogrom Fakten geschaffen, in dem sie paritätische und jüdische Armenstiftungen durch Namensänderungen oder Druck auf jüdische Vorstände dem Kommunalbesitz einverleibten, so legalisierte der Ministerialerlaß vom Mai 1939 ihr Vorauseilen bis auf die Frage der jüdischen Wohlfahrtsstiftungen. Ungeachtet der zentralen Pläne zur Integration solcher Stiftungen in den Apparat einer separaten jüdischen Fürsorge „arisierten“ Breslau, München und Frankfurt am Main weiterhin auch jüdische Armenstiftungen und verstießen damit sowohl gegen den zitierten Ministerialerlaß wie gegen die Verordnung über die Gründung der Reichsvereinigung vom Juli 1939, die eine Inkorporation jüdischer Stiftungen oder deren Auflösung vorschrieb.

\section{Neue Impulse für den Zwangstransfer (Sommer 1939)}

\section{Die ungeregelte städtische Praxis und der Gemeindetag}

Am 25. Mai 1939 erfolgte eine geringfügige Präzisierung der antijüdischen Fürsorge-Verordnung. Reichsarbeits- und Reichsinnenministerium verbesserten in einer Durchführungsverordnung die Versorgungsbedingungen nichtjüdischer Angehöriger von hilfsbedürftigen Juden in der Öffentlichen Wohlfahrt. Juden, welche die Kriterien für Gehobene Fürsorge und Kleinrentnerfürsorge erfüllten, erhielten ja seit der Verordnung nur noch die geringeren Sätze der Allgemeinen Fürsorge, wenn sie noch von staatlichen Fürsorgeeinrichtungen betreut wurden. Dank der Durchführungsverordnung konnten jetzt aber ihre „arischen“ Familienmitglieder die höheren Familienzuschläge der Öffentlichen Wohlfahrt erhalten, ohne selbst die Kriterien zu erfüllen, während ihren Ehepartnern diese als Juden weiterhin verweigert wurden. ${ }^{271}$

$\mathrm{Da}$ bis auf die eben geschilderte, keine weitere Ausführungsrichtlinie zur Fürsorge-Verordnung erlassen, noch die Reichsvereinigung inzwischen offiziell gegründet worden war, handelten die Städte weiter selbständig. Ob und wieweit die Öffentliche Wohlfahrt jüdische Arme noch betreute, hing in der Praxis vor allem von den Ergebnissen der Verhandlungen der Fürsorgeträger mit den lokalen Jüdischen Gemeinden ab. In Darmstadt hatte das städtische Wohlfahrtsamt im April 1939 jüdische Hilfsbedürftige noch versorgt. Letztere erhielten 80 Prozent der Sätze der Allgemeinen Fürsorge. Allerdings zog die Stadt hiervon noch die Regel-

269 BLHA Potsdam, Pr. Br. Rep. 60, Nr. 727, unfol.: OB/Stiftungsamt an Stadtpräsident Berlin am 28.11.1940 sowie ebenda: $O B /$ Stiftungsamt an Stadtpräsident Berlin am 2.10. 1942.

270 Dokumente Frankfurter Juden, III 83-86, S. 159-161.

271 LA Berlin, Rep. 214, Acc. 794, Nr. 13, unfol.: DVO vom 25. 5. 1939. 
sätze der Jüdischen Winterhilfe ab, die im April gar nicht mehr gewährt wurden. Manche jüdische Familien konnten aufgrund der deshalb zu geringen städtischen Leistungen ihre Miete nicht mehr bezahlen und wandten sich an den Armenausschuß der Jüdischen Gemeinde. Der beschloß, ihnen für den Monat April eine Sonderunterstützung zu gewähren, intervenierte aber gleichzeitig bei der Stadt gegen die Anrechnungspraxis. Das Wohlfahrtsamt Darmstadt änderte daraufhin Mitte Mai seine bisherige Haltung. Jüdische Unterstützte sollten künftig die vollen 80 Prozent des allgemeinen Richtsatzes bekommen, außerdem einen einmaligen Ausgleich für die städtischen Kürzungen des Vormonats. Die Stadt Darmstadt versprach der Jüdischen Gemeinde darüber hinaus, wenn sie Arme zusätzlich unterstütze, um die fehlenden 20 Prozent zum Richtsatz der Allgemeinen Fürsorge auszugleichen, dies nicht anzurechnen. ${ }^{272}$

Konnte in diesem Fall eine Jüdische Gemeinde also geringfügige Zugeständnisse erreichen, so mußte die jüdische Seite zur selben Zeit in der Reichshauptstadt eine herbe Niederlage einstecken. Das Berliner Landeswohlfahrtsamt vereinbarte nämlich mit dem Treuhänder der Jüdischen Gemeinde, daß letztere ab dem 1. Mai 1939 „für alle hilfsbedürftigen Juden (Rassejuden) deutscher und ausländischer Staatsangehörigkeit sowie für staat[en]lose Juden in Berlin" die Kosten und die Organisation der Geschlossenen Fürsorge (Anstaltsfürsorge) vollständig zu übernehmen habe. Nicht nur das: Die Jüdische Gemeinde mußte künftig außerdem Elemente aus der Offenen Fürsorge, nämlich die Wohlfahrtsspeisung und die Bekleidungshilfe, übernehmen und selbständig organisieren. Der stellvertretende Bürgermeister Ludwig Steeg 273 bestimmte, daß die restliche Offene Fürsorge zunächst weiterhin durch das Landeswohlfahrtsamt ausgeübt werde, allerdings mit stark gekürzten Richtsätzen. Lag der Regelsatz für Einzelpersonen in der Allgemeinen Fürsorge bei monatlich 34 RM plus Sonderleistungen und Zusatzversorgungen, so begrenzte man nun für jüdische Hilfsbedürftige die Leistungen auf $30 \mathrm{RM}$, inklusive 30 Prozent für die Mietzahlung. ${ }^{274}$ Eine ursprünglich vom Hauptwohlfahrtsamt geplante fünfzehnprozentige Reduzierung auf 28,90 RM hatte die Jüdische Gemeinde nur dadurch verhindern können, daß sie für alle künftig von städtischen Ämtern versorgten armen Juden pauschal einen

272 CAHJP Jerusalem, Darmstadt III, Nr. 145, unfol.: Armenausschuß an Vorstand IKG Darmstadt am 4. 5. 1939.

273 Geb. am 22. 12. 1894 in Ottweiler/Rheingau. Teilnahme am Ersten Weltkrieg als Freiwilliger (EK II u. a.), dann Freikorpskämpfer bei der Deutschen Schutzdivision 1918/19, danach bei der Reichswehr, u. a. Teilnehmer der konterrevolutionären Kämpfe um Berlin. Studium fünf Semester Philosophie und Staatswissenschaften, später kommunale Fachausbildung. Ab August 1919 in der Stadtverwaltung Berlin tätig. Am 15. 3.1933 übertrug man ihm die Vertretung des Staatskommissars Lippert, am 10.4. 1937 wurde er stellvertretender Bürgermeister. Er war zweimal verheiratet und hatte einen Sohn aus erster Ehe. NSDAP-Mitglied Nr. 1485884, eingetr. 1. 3. 1933. In der SS 1934 Untersturmführer, zuletzt 1943 Brigadeführer. Mitglied Lebensborn, Reichsbund der Dt. Beamten, Reichsluftschutzbund; BA, R 2 Pers., Steeg, Ludwig (Pk, SSO, Mitgliedskarte Gaukartei).

274 Dienstblatt Berlin, 1939 Teil VII, S. 146, Nr. 143: Vfg. Steeg OB/Landeswohlfahrtsamt vom 12. 5. 1939; vgl. LA Berlin, Rep. 214, Acc. 794, Nr. 13, unfol.: Vfg. Steeg OB/Landeswohlfahrtsamt 3.6. 1939. Vgl. Gruner, Judenverfolgung in Berlin, S. 66. Regelsatzhöhe erwähnt in: BA, R 36, Nr. 1023, B. 17: Vermerk DGT Berlin (Oktober 1940). 
Betrag von anderthalb Millionen RM für den Zeitraum vom 1. Mai 1939 bis zum 31. Dezember 1941 an die Reichshauptstadt überwies. 275

In der Offenen Fürsorge Berlins unterstützte jüdische Parteien ${ }^{276}$

\begin{tabular}{lll}
\hline 1939 & Parteien & Kosten im Quartal \\
\hline 31. März & 5557 & $674300 \mathrm{RM}$ \\
30. Juni & 5657 & $692400 \mathrm{RM}$ \\
30. September & 4332 & $521500 \mathrm{RM}$ \\
\hline
\end{tabular}

Nach dem eben erwähnten Abkommen sank die Zahl der von der Stadt Berlin in der Offenen Fürsorge unterstützten Juden jedoch nicht, sondern erhöhte sich zunächst, wie an der Tabelle abzulesen ist, ebenso die Kosten. Hauptgründe waren die wachsende Armut unter der Bevölkerung, die flächendeckende Erwerbslosigkeit und der gerade in Berlin anfänglich noch nicht umfassend durch die Arbeitsämter praktizierte Zwangseinsatz erwerbsloser Juden. Die Kommunalverwaltung Berlin kämpfte daher um jeden Pfennig Einsparung und stritt sich mit anderen Fürsorgeverbänden um Ausgabenerstattung. 277 Nur kurze Zeit nach dem Abkommen bürdete der Leiter des Landeswohlfahrtsamtes Behagel der Jüdischen Gemeinde weitere Elemente der Offenen Fürsorge auf. Sie mußte ab Mitte Mai 1939 auch die Kosten für Krankenhausaufenthalte von Hilfsbedürftigen, die noch in Offener Fürsorge von der Stadt unterstützt wurden, übernehmen, ebenso die Kosten für Pflegestellen von Erwachsenen. Die Pflege wurde von der Stadt gegenüber der Jüdischen Gemeinde einfach als Bestandteil der Geschlossenen Fürsorge und nicht - wie üblich - als extra Fürsorgeleistung, nämlich als Familienunterbringung, definiert. ${ }^{278}$ Nach den Knebelvereinbarungen mit der Stadt durfte die Jüdische Gemeinde Berlin auch keinen Zuschuß zu den städtischen Pflegegeldern mehr zahlen, die das städtische Jugendamt auf 27 RM monatlich begrenzt hatte. ${ }^{279}$

So unterschiedlich die Verhandlungen in Darmstadt und Berlin ausgegangen waren, so vielgestaltig zeigte sich auch die Situation in anderen Städten. Immer stärker drängten die Fürsorgeverbände darauf, den vor Ort oft willkürlich ver-

275 Erwähnt in: BA, R 36, Nr. 1023, B. 17: Vermerk DGT Berlin (Oktober 1940).

276 Die offene Fürsorge im Vierteljahr Januar/März 1939, (Berlin 1939), S. 4; Die offene Fürsorge im Vierteljahr April/Juni 1939, (Berlin 1939), S. 5; Die offene Fürsorge im Vierteljahr Juli/Sept. 1939, (Berlin 1939), S. 5.

$277 \mathrm{Zu}$ einem Kostenerstattungsstreit kam es zwischen Berlin und Zwickau für einen vom Berliner Wohlfahrtsamt unterstützten Geisteskranken. Berlin verlangte die Kostenübernahme für die ersten vier Monate des Jahres; Friedlander, Der Weg zum NS-Genozid, S. 420-421.

278 Berlin war lediglich bereit, auf die Verhängung von Pflichtarbeit bei Juden, die in Umschulungslehrgängen wohlfahrtsunterstützt wurden, zugunsten der Emigrationsvorbereitung zu verzichten; LA Berlin, Rep. 214, Acc. 794, Nr. 13, unfol.: Vfg. OB/Landeswohlfahrtsamt vom 12.5.1939 und Anhang: Niederschrift über Verhandlung mit der Jüdischen Gemeinde (o. D.).

279 CJA Berlin, 75 A Be 2, Nr. 420, Bl. 22: Lamm an Bentscher am 17. 7. 1939. 
laufenden Prozeß des Zwangstransfers der Fürsorgepflicht zu vereinheitlichen. Auf eine Initiative der Stadt Essen reagierend ${ }^{280}$, veranstaltete die DGT-Regionalstelle Rheinland im Mai 1939 eine Rundfrage zur öffentlichen Wohlfahrtspraxis gegenüber Juden. In der Berliner Geschäftsstelle des Deutschen Gemeindetages befürwortete man die geplante Umfrage der Landesdienststelle ausdrücklich, da es an zentralen Regelungen für den Zwangstransfer weiterhin mangelte. ${ }^{281}$ Die Rundfrage der DGT-Provinzialdienststelle in Düsseldorf bei den Bezirksfürsorgeverbänden im Rheinland lautete: „Um sämtlichen BFV eine einheitliche Handhabung vorzuschlagen, bitte ich um folgende Mitteilung, 1.) ob der dortige BFV den hilfsbedürftigen Juden Fürsorge gewährt, 2. ob und in welcher Höhe der dortige BFV Juden unterstützt hat. "282

Aus den auch an den Deutschen Gemeindetag in Berlin übermittelten Umfrageergebnissen 283 ergab sich für das erste Halbjahr 1939 ein höchst differenziertes Bild der örtlichen Wohlfahrtspraxis im Rheinland, allerdings mit einer klaren Tendenz zur Ausgrenzung jüdischer Armer: Von 16 rheinländischen Stadtkreisen zahlte im Sommer 1939 nur noch eine Fürsorgestelle den regulären Satz an Juden in der Offenen Fürsorge, natürlich nur, wenn die dortige Jüdische Kultusgemeinde nicht für alle Kosten aufkommen konnte. Acht Städte, unter diesen Aachen, Essen und Duisburg, bewilligten inzwischen nur noch ergänzende Hilfen neben einer Basisversorgung durch jüdische Wohlfahrtsstellen. Sieben Stadtkreise, darunter Düsseldorf und Köln, ließen in der Offenen Fürsorge überhaupt keine Leistungen an jüdische Hilfsbedürftige mehr zu. Von 25 Landkreisen gewährten vier keine Hilfen in der Offenen Fürsorge, 18 nur ergänzende Unterstützungen. Lediglich drei Landkreise zahlten noch reguläre Richtsätze. ${ }^{284}$ Wenn Bezirksfürsorgeverbände in den Landkreisen noch jüdische Arme unterstützten, bildeten auch sie separate Pflichtarbeiterkolonnen (Birkenfeld, Düren, Neuwied). ${ }^{285} \mathrm{Um}$ einige Beispiele aus der höchst unterschiedlichen städtischen Praxis im Rheinland anzuführen: Essen zahlte an Juden bis Ende Juni noch 50 Prozent, nach dem 1. Juli nur noch 25 Prozent der örtlichen Sätze. In Mülheim gab es für Juden nur noch ergänzende Hilfen in der Offenen Fürsorge, die Stadt zahlte gleichwohl noch in der Geschlossenen Fürsorge. In Mönchen-Gladbach war die jüdische Fürsorge quasi allein verantwortlich, die Stadt unterstützte lediglich zwei An-

280 BA, R 36, Nr. 1022, Bl. 8: DGT-Provinzialdienststelle Rheinland-Hohenzollern an DGT Berlin am 6. 4. 1939.

281 Ebenda, Bl. 9: DGT Berlin (Zengerling) an DGT-Provinzialdienststelle Rheinland am 14. 4. 1939; vgl. ebenda, Bl. 10RS: Handschriftl. Vermerk (20.5.1939) auf Rückseite des Briefes zum Entwurf der DGT-Rundfrage Rheinland vom 17.5.1939.

282 Ebenda, Bl. 11: Rundschreiben DGT-Provinzialdienststelle Rheinland am 17. 5. 1939.

283 Ebenda, Bl. 13: DGT Düsseldorf an DGT Berlin am 24. 8. 1939.

284 Düwell, Rheingebiete, S. 286-293, Anhang V: Zusammenstellung des DGT vom 22. 8. 1939 zum Umfrageergebnis über Unterstützungen der Juden in der Rheinprovinz.

285 BA, R 36, Nr. 1022, Bl. 14-16RS: Zusammenstellung der Ergebnisse der Umfrage über Unterstützung von Juden, DGT Düsseldorf vom 22. 8. 1939. Die in der Umfrage registrierte Pflichtarbeit jüdischer Hilfsempfänger in verschiedenen Landkreisen war nicht neue Praxis, wie Düwell annimmt, sondern - wie oben dargestellt - "traditionelle" antijüdische Maßnahme der NS-Wohlfahrt in Deutschland. Außerdem rekrutierten in diesen Fällen nicht die Arbeitsämter, wie Düwell meint; vgl. Düwell, Rheingebiete, S. 156. 
staltspfleglinge polnischer Nationalität, deren Ausweisung die Stadt aber bereits bei den zuständigen Stellen in die Wege geleitet hatte. Wuppertal leistete hingegen noch 70 Prozent der Sätze in der Offenen Fürsorge, in der Geschlossenen Fürsorge zahlte man 2,50 RM pro Tag bei einer Zuzahlung jüdischer Stellen von 0,62 RM. Einige Fürsorgeverbände bewilligten auch dann noch Leistungen in der Geschlossenen Fürsorge, wenn sie dies in der Offenen Fürsorge ablehnten. Aachen gab 1,70 RM als Pflegesatz für Juden im israelitischen Altersheim, plante aber, diese Zuschüsse zu streichen bzw. die Pflegesätze zu kürzen. Köln unterstützte nur die „Irrenpflege“, forderte aber von der örtlichen Jüdischen Gemeinde einen Tageszuschuß von 0,50 RM. ${ }^{286}$

Wenn Fürsorgestellen im Rheinland mit ergänzenden Hilfen wegen der Finanznot der lokalen Jüdischen Gemeinden eingriffen, versuchten sie mit anderen Mitteln die eigenen Ausgaben zu decken. In Neuß ging man „die noch gut bemittelten Rassegenossen " um die Gelder an, ${ }^{287}$ der Bezirksfürsorgeverband KempenKrefeld belastete Grundstücke hilfsbedürftiger Juden. ${ }^{288}$ In Viersen verrechnete man einfach Forderungen der Jüdischen Gemeinde an die Stadt mit den an jüdische Arme gezahlten Unterstützungen. ${ }^{289}$ Schon im Jahr zuvor hatte es vergleichbare Initiativen von Städten gegeben, Fürsorgemittel ersetzt zu bekommen. Im August 1938 plante die Stadt Wartenburg (Ostpreußen), den Erlös der gerade von der Jüdischen Kultusgemeinde verkauften örtlichen Synagoge zu beschlagnahmen, um damit städtische Leistungen an jüdische Bedürftige zu kompensieren. Von der Stadt um Hilfe gebeten, sandte die DGT-Provinzialdienststelle Ostpreußen - wegen der Brisanz des Anliegens - den Fall nach Berlin. Nach Abstimmung mit dem Reichskirchenministerium mußte der "Judenreferent" des Deutschen Gemeindetages, Döbereiner, damals „zu [s]einem Bedauern“ mitteilen, daß „zur Zeit noch keine Handhabe gegeben“ sei, „den Erlös aus dem Verkauf der Synagoge" sicherzustellen, „es könnte allenfalls versucht werden, die Synagogengemeinde im Wege von Vereinbarungen zur Herausgabe des Geldes für hilfsbedürftige Juden zu bewegen". ${ }^{290}$ Infolge der allgemeinen Entwicklung der Verfolgung funktionierten solche Knebelverträge einzelner Kommunen ein Jahr später offenbar reibungslos.

Ähnlich vielgestaltig wie im Rheinland zeigte sich die Situation des Zwangstransfers der Fürsorgepflicht in Sachsen und Thüringen. Chemnitz und Erfurt zahlten nicht mehr, Leipzig nur noch für polnische, tschechische und schwerkriegsbeschädigte Juden. Die Stadt Dresden unterstützte hingegen noch in der

286 BA, R 36, Nr. 1022, Bl. 14-16RS: Ergebnisse Umfrage über Unterstützung von Juden, DGT Düsseldorf vom 22. 8. 1939.

287 NW-HStA Düsseldorf, RW 53, Nr. 413, unfol.: OB Neuß-Rhein/Wohlfahrtsamt an DGT in Düsseldorf am 1.6.1939.

288 Ebenda: Landrat Kreis Kempen-Krefeld/BFV an DGT in Düsseldorf am 2. 6. 1939. Ähnlich auch in Idar-Oberstein; ebenda: Rundschreiben Kreisvorsitzender Birkenfeld an Bürgermeister am 1.4. 1939.

289 Ebenda: OB/Wohlfahrtsamt Viersen an DGT Düsseldorf am 12. 6. 1939.

290 LA Berlin, Rep. 142/7, 1-2-6/Nr. 1, Bd. 2, unfol. DGT/Abt. I (Döbereiner) an Bgm. Wartenburg am 31. 8. 1938. 
Offenen Fürsorge. ${ }^{291}$ Doch auch hier begann man, Leistungen zu beschränken. Zwar kooperierte das Städtische Wohlfahrtsamt mit der Israelitischen Wohlfahrtsstelle in Dresden und rechnete die Mietbeihilfen nicht auf die staatlichen Versorgungsleistungen an, doch ab Mai 1939 wurden die Leistungen der vom Arbeitsamt ausgesteuerten Juden reduziert, wenn die zuvor erhaltene Arbeitslosenhilfe niedriger lag als die reguläre Fürsorgeunterstützung. ${ }^{292}$

Mit dem Rückgang der Zahl der von den Wohlfahrtsbehörden noch unterstützten Juden sank auch die Zahl der jüdischen Pflichtarbeiter. Verstärkt wurde dieser Prozeß durch Veränderungen auf dem Arbeitsmarkt. In Vorbereitung des Krieges begann die Arbeitsverwaltung mehr und mehr, ihren Zugriff auf arbeitsfähige Wohlfahrtserwerbslose auszunutzen, dabei konnten sie sich der Kooperation der Wohlfahrtsämter sicher sein. ${ }^{293}$ Der Bezirksfürsorgeverband Düren (Rheinland) gewährte Juden drei Viertel der üblichen Leistungen nur, wenn diese sich beim Arbeitsamt meldeten. ${ }^{294}$ Viele jüdische Arme wurden auf diesem Weg von den Arbeitsämtern für den Geschlossenen Arbeitseinsatz rekrutiert, der mittlerweile schon fast 20000 Menschen umfaßte. ${ }^{295}$ Trotz des rasant anwachsenden Zwangseinsatzes wurden in manchen Städten, z.B. in Plauen/Vogtland, weiterhin auch wohlfahrtsunterstützte Juden in größeren Gruppen von den zuständigen Fürsorgebehörden zur Pflichtarbeit herangezogen. ${ }^{296}$ Die Hamburger Sozialbehörde setzte zusammen mit dem Arbeitsamt sogar noch bis Ende des Jahres 1939 erwerbslose und fürsorgeunterstützte Juden bei „verschärfter Unterstützungsarbeit" auf „besonderen Plätzen" und in Lagern ein. 297

\section{"Kriminelle Elemente“: Der Ministerialerlaß zur „Rassentrennung“ in der Fürsorgeerziehung}

Nach den Ministerialerlassen zur „Rassentrennung" bei Adoptionen und Vormundschaften sowie dem gesetzlich angeordneten Ausschluß der jüdischen Armen aus der Öffentlichen Fürsorge sollte im Sommer 1939 schließlich auch die Separierung der jüdischen Fürsorgezöglinge durchgesetzt werden. Gleich nach der Herausgabe der antijüdischen Fürsorgeverordnung hatten sich Wohlfahrtsbehörden nach Detailregelungen und Folgewirkungen für die staatliche Fürsorgeerziehung erkundigt. Die Stadt Breslau wollte vom Deutschen Gemeindetag wissen, ob durch den Zwangstransfer der Fürsorgepflicht auf die jüdische Wohlfahrt

291 (Vgl. Tabellen im Anhang) Die offene Fürsorge im Vierteljahr April/Juni 1939, (Berlin 1939), S. 8 sowie Sopade, 6 (1939), S. 924.

292 StadtA Dresden, Fürsorgeamt, Nr. 509, unfol.: Dienststellenleiterbesprechung vom 12. 5. 1939.

293 BA, R 36, Nr. 785, unfol.: DGT-Rundschreiben an Städte (mehr als 100000 Einwohner), vom 13. 6. 1939; vgl. ebenda: Schreiben verschiedener Städte.

294 NW-HStA Düsseldorf, RW 53, Nr. 413, unfol.: Vorsitzender Kreisausschuß/BFV Düren an DGT Düsseldorf am 7.6. 1939.

295 Vgl. dazu Gruner, Geschlossener Arbeitseinsatz, S. 68-106.

296 BA, R 36, Nr. 785, unfol.: OB/Wohlfahrtsamt Plauen an DGT Berlin am 23. 6. 1939.

297 Ebenda: Stadt Hamburg/HVA an DGT am 5. 7.1939. Vgl. ausführlicher Gruner, Geschlossener Arbeitseinsatz, S. 222. 
auch die "Tätigkeit der Amtsvormundschaft über jüdische uneheliche Kinder betroffen" sein werde. Bisher habe es keine diesbezügliche Änderung des entsprechenden Gesetzes gegeben. ${ }^{298}$ Für Schlüter, dem Leiter der DGT-Sozialabteilung, gab es darüber keine Zweifel: „Wenn auch bisher keine neuen gesetzlichen Bestimmungen über die Anwendung des Reichsjugendwohlfahrtsgesetzes auf jüdische Kinder erlassen worden sind, so wird doch zu prüfen sein, ob nach der Rechtsentwicklung und der neuesten Rechtsprechung der deutschen Gerichte ein jüdisches Kind noch als deutsches Kind im Sinne des $\$ 1$ Abs. 1 RJWG angesehen werden kann. Sollte diese Frage verneint werden, so wird man die Auffassung vertreten müssen, daß jüdische Kinder wie ausländische Minderjährige zu behandeln sind. Über diese erlangt aber das Jugendamt nicht die gesetzliche Amtsvormundschaft." Der Gemeindetag empfahl dem Breslauer Oberbürgermeister, dieses Problem auf juristischem Wege zu klären. ${ }^{299}$ In Baden waren sich die zuständigen "Sachbearbeiter" im Dezember 1938 auf einer Tagung des Deutschen Gemeindetages einig, daß jüdische Zöglinge auf jeden Fall in den Anstalten zu separieren seien. Wenn möglich, sollten sie an jüdische Heime überstellt werden. Als man erfuhr, daß die „Unterbringung und Absonderung" vom Reichsinnenministerium geprüft wurde, forderte man gleich, daß Juden generell von der staatlichen Fürsorgeerziehung ausgeschlossen werden, denn es handele sich dabei um eine "rein polizeiliche Angelegenheit ${ }^{\prime \prime} .{ }^{300}$

Die antijüdische Fürsorgeverordnung hatte nicht nur die öffentliche Diskussion um die Unterbringung jüdischer Fürsorgezöglinge neu entfacht, sondern auch die Debatte um die Behandlung anderer Gruppen. Allerdings gab es hierzu widerstreitende Meinungen: Das Land Württemberg konzentrierte seit November 1938 alle der staatlichen Fürsorgeerziehung unterliegenden „Zigeuner"-Kinder in einer nichtstaatlichen Anstalt, dem katholischen Kinderheim in Mulfingen. ${ }^{301}$ Als das Amtsgericht in Frankfurt am Main im Juni 1939 einen Jugendlichen aus dem kommunalen „Zigeunerlager“ der staatlichen Fürsorgeerziehung überwies, protestierte dagegen der Oberpräsident. Der Rechtsstreit sollte über mehrere Instanzen bis vor den Reichsjustizminister gelangen. Das Berliner Kammergericht entschied gegen den Hessischen Oberpräsidenten, denn das Ziel der Fürsorgeerziehung sei nicht, „den Zögling zu einem wertvollen deutschen Menschen heranzubilden“, sondern zuerst die Verwahrlosung zu bekämpfen, auch bei „Fremdrassigen“: „Nur wenn die Fürsorgeerziehung auch gegenüber fremdrassigen Kindern durchgeführt wird, läßt es sich verhindern, daß im deutschen Raume Angehörige fremder Rassen aufwachsen, die später als Erwachsene Schädlinge, Spaltpilze oder Parasiten im deutschen Volkskörper" sein werden. 302

298 BA, R 36, Nr. 1442, Bl. 57: OB/Fürsorgeamt Breslau (Bölsche) an DGT am 15. 12. 1938.

299 Ebenda, Bl. 58: DGT/Abt. III (Schlüter) an OB Breslau am 29. 12. 1938.

300 StadtA Freiburg i. Br., C4 VI/7, Nr. 25, unfol.: Niederschrift über Tagung des DGT Baden am 9./10. 12. 1938 in Karlsruhe und Sinsheim.

301 Friedlander, Der Weg zum NS-Genozid, S. 464.

302 BA, R 22, Nr. 1915, Bl. 315-317: Kammergerichtspräsident Berlin an RJM am 6. 12. 1939 mit Anlage: Beschluß des Kammergerichts vom 20. 11. 1939. 
Der Bezirksverband Nassau hatte zu Beginn des Jahres 1939 denselben Oberpräsidenten gebeten, beim Reichsinnenministerium eine Entscheidung herbeizuführen, ob in sinngemäßer Anwendung der Fürsorgeverordnung die Heime mit ihren Rechnungen an die jüdische Wohlfahrtspflege zu verweisen seien. Die Beamten argumentierten, daß in der Verordnung jede "Zuwendung für Zwecke der Erziehung von Juden ausgeschlossen“ werde. „Dieser Grundsatz muß auch für die Fürsorge-Erziehung von jüdischen Minderjährigen gelten. Die in früheren Entscheidungen des Kammergerichts und des Reichsgerichts vertretene Auffassung, daß die Unterbringung verwahrloster und gefährdeter jüdischer Minderjähriger in Fürsorgeerziehung im Interesse des Schutzes deutschblütiger Kinder liege und deshalb zu bejahen sei, ist heute überholt. Es läßt sich in keiner Weise und mit keinem Grund die Auszahlung von Pflege- und Erziehungskosten an jüdische Kinderheime durch die Fürsorgeerziehungsbehörden rechtfertigen." Die Verwaltung Nassau habe deshalb die Zahlung an solche Heime bereits eingestellt. 303 Auch der Deutsche Gemeindetag schaltete sich ein. Dessen Abteilung III wandte sich direkt an den Reichsinnenminister, stellte aber klar, daß man aufgrund der aktuellen gesetzlichen Bestimmungen die nassauische Auffassung nicht teile, „die Fürsorgeerziehungsheime mit ihren Rechnungen für die zurückliegende Zeit an die jüdische Wohlfahrtspflege zu verweisen". 304

Nach der Kursänderung in der Verfolgungspolitik wollte auch der Stellvertreter des Führers die Frage jüdischer Jugendlicher in den Fürsorgeanstalten im Sinne von Separierung und Isolierung regeln. In einem Schreiben vom 4. Februar 1939 an den Reichsinnenminister hieß es: „Nach den bisherigen Bestimmungen ist es möglich, über jüdische Jugendliche Fürsorgeerziehung anzuordnen. Dies ist $\mathrm{m}$. E. ein unmöglicher Zustand. Einerseits ist es ohne Sinn, jüdische Jugendliche in deutschen Fürsorgeerziehungsanstalten, die eine Besserung und Erziehung von Jugendlichen bezwecken, unterzubringen - es kann nicht unsere Aufgabe sein, [...] Juden zur leiblichen, seelischen und gesellschaftlichen Tätigkeit zu erziehen; kriminelle Elemente gehören ins Gefängnis oder ins Konzentrationslager -, zum anderen kann es auch den in den Fürsorgeanstalten untergebrachten deutschen Menschen nicht zugemutet werden, mit Juden zusammen in Gemeinschaft zu leben. Bei der destruktiven Natur des Juden wird die Erziehungsarbeit der Anstalten nur unnötigerweise gehemmt." Der Stellvertreter des Führers forderte den Reichsinnenminister auf, "das Erforderliche zu veranlassen, daß künftighin jüdische Jugendliche nicht mehr in den deutschen Fürsorgeanstalten aufgenommen werden". 305

Surén (RMdI) verlangte daraufhin vom Reichsjustizministerium, die Vormundschaftsgerichte anzuweisen, jüdische Zöglinge nur in jüdische Anstalten oder Familien einzuweisen. Gleichzeitig gab er zu bedenken, daß bei der geringen $\mathrm{Zahl}$ der Betroffenen und dem Vorhandensein von jüdischen Heimen eine Gesetzes-

303 Ebenda, Bl. 250-251: OP/Verwaltung Bezirksverband Nassau (Landrat Johlen) an OP Hessen-Nassau am 19. 1. 1939.

304 Ebenda, Bl. 251RS: DGT/Abt. III an RMdI am 1. 2. 1939.

305 Pätzold, Verfolgung, S. 218, Dok. Nr. 180: StdF an RMdI am 4. 2. 1939. Vgl. Adam, Judenpolitik, S. 223-224. 
änderung kaum notwendig erscheine. Selbst wenn die Heime nicht ausreichten, könnten sowohl die Vormundschaftsgerichte nach dem Bürgerlichen Gesetzbuch als auch die Fürsorgeerziehungsbehörden nach dem Reichsjugendwohlfahrtsgesetz die Unterbringung der Minderjährigen in eine geeignete jüdische Familie beschließen. Er forderte das Reichsjustizministerium auf, dies den Gerichten mitzuteilen. ${ }^{306}$ Das Justizministerium gab jedoch den Ball an das Reichsinnenministerium zurück: Vormundschaftsgerichte dürften nur die Anordnung zur Fürsorgeerziehung aussprechen, die Auswahl der Anstalten hätten indes die Verwaltungen zu treffen. Daher genüge es, wenn das Innenministerium seine nachgeordneten Verwaltungen entsprechend anweise. ${ }^{307}$ Die ministeriellen Verhandlungen, vor allem zwischen Reichsinnen- und -justizministerium, zogen sich zunächst weiter hin.

Nach Anfragen eines Landrates in Oschersleben und der DGT Provinzialdienststelle Sachsen hatte der Deutsche Gemeindetag sich unterdessen beim Archiv für Wohlfahrtspflege in Berlin erkundigt, „ob dort Heime bekannt sind, in denen jüdische Kinder auf Kosten der jüdischen Wohlfahrt untergebracht werden können". ${ }^{308}$ Doch nach einer erneuten negativen Auskunft wegen der Überfüllung sämtlicher jüdischer Heime mußte der Deutsche Gemeindetag - wie schon bei Heilanstalten und Altenheimen - gegenüber den Anfragenden passen. ${ }^{309}$

Ein Entwurf für einen Erlaß zur "Rassentrennung" in der Fürsorgeerziehung lag schließlich im Mai 1939 vor. ${ }^{310}$ Doch erst am 21. Juli ersuchte schließlich Staatssekretär Pfundtner (RMdI) per Runderlaß die Preußischen Fürsorgeerziehungsbehörden, die Oberpräsidenten, den Stadtpräsidenten Berlin und die Regierungspräsidenten, in den diskutierten Fällen die staatliche Fürsorgeerziehung aufzuheben. Die betreffenden Jugendlichen, und zwar Juden und „Mischlinge 1. Grades", seien in jüdische Anstalten oder Familien einzuweisen. Dies sollte aufgrund ihrer geringen Zahl, ca. 100, ohne Änderung der gesetzlichen Bestimmungen geschehen. Könne eine Aufhebung der staatlichen Fürsorgeerziehung nicht durchgesetzt werden, sollten die Minderjährigen trotzdem ausnahmslos in jüdischen Anstalten bzw. Familien untergebracht werden. Pfundtner betonte ausdrücklich, daß in solchen Fällen die Träger der Fürsorgeerziehung aber weiterhin die Pflicht hätten, die nötigen Pflegegelder aufzubringen. Den Intentionen des Stellvertreters des Führers folgend, dessen Februar-Intervention im Erlaß Pfundtners vollständig zitiert war, hieß es: Wenn als Grund für die Fürsorgeerziehung „kriminelle Veranlagung“ gegeben sei, müsse sofort der örtlichen Kriminalpolizeistelle Bescheid gegeben werden. Im Gegensatz zum Entwurf war damit jetzt nicht einmal mehr das Vorliegen einer Straftat notwendig, um die Polizei einzu-

306 BA, R 22, Nr. 1915, Bl. 244 u. RS: RMdI an RJM am 21.2. 1939.

307 Ebenda, Bl. 246: RJM/Abt. IV an RMdI am 16. 3. 1939. Erwähnt bei Adam, Judenpolitik, S. 223.

308 BA, R 36, Nr. 1911, Bl. 6: DGT/Abt. III (Zengerling) an Archiv für Wohlfahrtspflege am 30. 3.1939.

309 Ebenda, Bl. 5: DGT/Abt. III (Zengerling) an Landrat Oschersleben und abschriftl. an DGT Halle am 14. 4. 1939.

310 BA, R 22, Nr. 1915, Bl. 270-271: RMdI-Runderlaß (Entwurf) an RJM am 11. 5. 1939; ebenda, Bl. 272 u. RS: RJM an RMdI am 16. 5. 1939. 
schalten. ${ }^{311}$ Mit diesem Erlaß hatte der NS-Staat auf einem weiteren wichtigen Nebengebiet Juden in der öffentlichen Fürsorge separiert.

\section{Die Gründung der „Reichsvereinigung der Juden in Deutscbland“}

Der Deutsche Gemeindetag und das Reichsinnenministerium hatten in den ersten Monaten des Jahres 1939 wiederholt die baldige Installierung eines Zwangsverbandes, der überregional die jüdische Wohlfahrt verwalten und finanzieren sollte, angekündigt. Bislang hatte der Deutsche Gemeindetag auf ein Abwarten dieser Gründung verwiesen, insbesondere wenn Städte, die noch jüdische Arme mit Fürsorgemitteln unterstützten, einen überregionalen Finanzausgleich der Jüdischen Gemeinden forderten.

Doch bald mehrten sich solche Stimmen, unterstützt von den Regionalstellen des Deutschen Gemeindetages. Am 17. Mai 1939 intervenierte die DGT-Dienststelle Sachsen nach einer Anfrage aus Plauen bei der Berliner Zentrale. Der Spitzenverband solle durch „entsprechende Maßnahmen eine gerechte Verteilung der der jüdischen freien Wohlfahrtspflege in Deutschland zur Verfügung stehenden Mittel“ herbeiführen. ${ }^{312}$ Als auch die DGT-Landesdienststelle WestfalenLippe einen ähnlichen Antrag stellte, revidierte Anfang Juni 1939 der Deutsche Gemeindetag seine bisherige Position und instruierte die Fürsorgeverbände neu: „Wenn die örtliche jüdische Wohlfahrtspflege erklärt, daß ihre Mittel erschöpft sind, ist auf die Dachorganisation zurückzugreifen." Der Deutsche Gemeindetag bedeutete damit den örtlichen Wohlfahrtsämtern, daß sie jüdische Arme auch abweisen könnten, wenn die lokale Jüdische Gemeinde nicht zahlungsfähig war. Als Legitimation führte der Spitzenverband lediglich an, daß eine gesetzliche Regelung vorbereitet werde, „durch die eine Gesamthaftung aller Juden in Deutschland für ihre Hilfsbedürftigen festgelegt werden soll“.313

Es dauerte aber noch einen Monat, bis die seit Ende 1938 vorgenommene Transformation der alten selbständigen Dachorganisation „Reichsvertretung“ in eine zentralistische, von der Sicherheitspolizei und dem SD kontrollierte Zwangsinstitution am 4. Juli 1939 juristisch abgeschlossen war. Mit der Zehnten Verordnung zum Reichsbürgergesetz ${ }^{314}$ wurde die „Reichsvereinigung der Juden in Deutschland" offiziell zum Träger eines separaten Fürsorge- und Schulwesens erklärt. Ihr Hauptziel hieß „Förderung der Emigration“. Laut der vom Gestapochef Heinrich Müller für das Innenministerium genehmigten Satzung vom 7. Juli 1939

311 Der an die preußischen Behörden gerichtete Erlaß ging an alle Landesregierungen, damit diese für die dortigen Fürsorgeerziehungsbehörden gleiche Regelungen einführen sollten; BA, R 18, Nr. 5644, Bl. 243-244: Runderlaß RMdI/VW (Pfundtner) vom 21. 7. 1939. Bei Adam als Runderlaß vom 22. 7. 1939 erwähnt; Adam, Judenpolitik, S. 223-224. Vgl. BA, R 22, Nr. 1915, Bl. 271: Runderlaß RMdI (Entwurf) an RJM am 11. 5. 1939.

312 Der Oberbürgermeister von Plauen hatte einen solchen „Ausgleich der Mittel“ gefordert, weil die lokale jüdische Fürsorge nicht imstande war, die 22 Hilfsbedürftigen zu versorgen; BA, R 36, Nr. 1022, Bl. 26 u. RS: DGT-Landesdienststelle Dresden an DGT in Berlin am 17. 5. 1939.

313 Ebenda, Bl. 29: DGT Berlin an DGT Westfalen/Lippe am 9. 6. 1939.

314 RGBl., 1939 I, S. 1097. 
mußte die neue Zwangsorganisation „ferner alle weiteren Aufgaben [...] erfüllen, die ihr vom Reichsminister des Innern übertragen werden". ${ }^{315}$ Die Satzung durfte nur mit Zustimmung ihrer „Aufsichtsbehörde“, der Gestapo, geändert werden. ${ }^{316}$ Alle „Rassejuden“ mit Wohnsitz im Reichsgebiet zählten automatisch als Mitglieder der Reichsvereinigung. Formell unterstanden ihr damit auch die österreichischen Juden. ${ }^{317}$ Doch in der Praxis wurde für diese eine separate Organisation in Wien geschaffen. 318

Obwohl laut Satzung der Aufbau eines separaten Fürsorgewesens eine der drei Hauptaufgaben der Reichsvereinigung bildete, war im Gegensatz zu den Schulangelegenheiten merkwürdigerweise kein Vorstandsmitglied für diesen Bereich zuständig. Leiter der Abteilung Fürsorge wurde Dr. Conrad Cohn, Leiterin des Dezernats Allgemeine Fürsorge Hannah Karminski und Leiter der Gesundheitsfürsorge Dr. Walter Lustig. ${ }^{319}$ An die Stelle der bisherigen freien Provinzial- und Landesverbände für jüdische Wohlfahrtspflege traten jetzt voll verantwortlich die Bezirksstellen der Reichsvereinigung bzw. die ihr unterstellten Jüdischen Gemeinden. Neben der laufenden Fürsorge und der Jüdischen Winterhilfe organisierte die Reichsvereinigung künftig auch die Altenversorgung sowie die Gesundheits- und Kriegsbeschädigtenfürsorge. Die Abteilung Fürsorge mußte sich zudem oft auch in die Emigrationsförderung und das Schulwesen einschalten. Zwischen Januar und September 1939 emigrierte die enorme Zahl von 62000 Menschen, unter ihnen viele Mittellose. Die jüdische Fürsorge unterstützte letztere mit Passagekosten, Kleidung oder Ausrüstung, um ihnen zur Flucht aus Deutschland zu verhelfen. ${ }^{320}$ Der Emigration diente auch, daß die jüdischen Wohlfahrtsstellen Kosten für Ausbildung und „Berufsumschichtung“ übernahmen, denn qualifizierte Kräfte verfügten in vielen Ländern über bessere Einwanderungschancen. ${ }^{321}$

315 BLHA Potsdam, Pr. Br. Rep. 5 E Schwedt, VB 12, Bl. 33-38: RV-Satzung vom 7. 7. 1939. Veröffentlichung der Verordnung und der Satzung: JNBl., Berliner Ausgabe vom 11. 7. 1939, S. 1-2; Vgl. Plum, Günter: Deutsche Juden oder Juden in Deutschland, S. 7071; vgl. Barkai, Boykott, S. 171-172.

316 Erwähnt in: BA, 80 Re 1, Nr. 5019, Bl. 7: Bericht der Dt. Treuhand- und Revisionsanstalt (Stand vom 30. 6. 1940). Den Hinweis auf dieses Dokument verdanke ich Herrn Thomas Jersch, Berlin.

317 Vgl. JNBl., Berliner Ausgabe vom 11. 7. 1939, S. 1-2.

318 Vgl. den folgenden Exkurs: Fürsorge und Judenverfolgung in Wien.

319 JNBl., Berliner Ausgabe vom 21.7.1939. Erst als Cohn nach dem Ausscheiden von Heinrich Stahl im Februar 1940 mit Zustimmung der „Aufsichtsbehörde“ durch Ergänzungswahl in den Vorstand gelangte, war der Bereich Fürsorge in persona vertreten, auch wenn Cohn im Vorstand nominell die Abt. Auswanderungsvorbereitung vertrat; BA, 80 Re 1, Nr. 5019, Bl. 6-7: Bericht der Dt. Treuhand- und Revisionsanstalt (Stand vom 30. 6. 1940) sowie ebenda, $75 \mathrm{C}$ Re 1, Nr. 1, Bl. 190: Vermerk über RV-Vorstandssitzung vom 19. 2. 1940.

320 Von den nach Kriegsbeginn bis Ende 1939 ca. 5000 Emigrierten erhielten zwei Drittel RV-Mittel; Arbeitsbericht der Reichsvereinigung der Juden in Deutschland für das Jahr 1939, [MS], Berlin 1940, S. 12-14.

3211939 wurden 80 Prozent der Praktikanten in der Landwirtschaft und 70 Prozent im Handwerk unterstützt, zusammen mehr als 2000 Menschen; ebenda, S. 29. Diese Mittel waren teils von den Gemeinden zu tragen, teils von der Reichsvereinigung. Durch die 
Seit der Gründung im Juli 1939 konnte die Reichsvereinigung offiziell Beiträge von ihren $Z$ wangsmitgliedern einziehen. Mit diesen Geldern bestritt man die zentralen Aufgaben, aber auch einen Lastenausgleich zwischen den Lokalgemeinden. Aufgrund der strukturellen Verarmung der jüdischen Bevölkerung litt natürlich auch die Reichsvereinigung von Beginn an an großen Budgetproblemen. Bedeutende Hilfe kam deshalb aus dem Ausland: Organisationen wie das American Jewish Joint Distribution Committee unterstützten die jüdische Zwangsorganisation mit rasch ansteigenden Mitteln. ${ }^{322} \mathrm{Um}$ alle ihre Aufgaben, einschließlich der Wohlfahrtspflege, erfüllen zu können, wurde von der Reichsvereinigung auch die seit Frühjahr 1939 von allen jüdischen Emigranten erhobene „Auswandererabgabe" eingesetzt. ${ }^{323}$

Die Gründung der Reichsvereinigung bildete für eine Reihe von Großstädten, die noch immer jüdische Bedürftige versorgten, den willkommenen Anlaß, den Transfer auf jüdische Wohlfahrtseinrichtungen zu beschleunigen bzw. abzuschlieBen. Bremen, Essen, Frankfurt am Main und Wuppertal stellten jetzt abrupt die Offene Fürsorge für jüdische Arme ein. ${ }^{224}$ Gleichzeitig drängten die Kommunen nun auf eine Übertragung der gesamten Geschlossenen Fürsorge an die Reichsvereinigung und auf eine strikte Kontrolle ihrer Finanzen, wobei sich besonders Fischer-Defoy (Frankfurt am Main) hervortat. Er schlug dem Deutschen Gemeindetag Ende Juli vor, die staatlichen Fürsorgeverbände mit der Überwachung der jüdischen Wohlfahrt zu beauftragen, außerdem deren Fürsorgeleistungen strikt zu begrenzen, damit sich die Mittel der Reichsvereinigung nicht zu rasch erschöpften. Hinter die Forderung seines Frankfurter Stadtrates, schnell eine entsprechende Anordnung durch das Reichsinnenministerium zu erlassen, stellte sich auch Oberbürgermeister Krebs. ${ }^{325}$

Am 14. August 1939 informierte die DGT-Landesdienststelle Sachsen den Gemeindetag in Berlin über eine weitere kommunale Intervention. Der Oberbürgermeister von Leipzig habe angefragt, wann denn die Durchführungsvorschriften zur Zehnten Verordnung zum Reichsbürgergesetz zu erwarten seien und ob diese „auf die Übernahme der Kosten für die Anstaltsfürsorge (einschließlich Krankenhauskosten) für hilfsbedürftige Juden durch die Reichsvereinigung der Juden besonders eingehen werden". Anlaß war ein Rundschreiben der Reichsvereinigung vom 27. Juli, dessen Inhalt der Oberbürgermeister über die Israelitische Religi-

Auflösung von Kleingemeinden kam die RV bald ganz für die Kosten auf. Insgesamt gab es im Juli 19393425 Ausbildungsplätze; Adler-Rudel, Selbsthilfe, S. 157 und Anhang, S. 204.

322 Allein die Ausgaben des Joint für Deutschland wuchsen von 686000 Dollar 1938 auf 978102 Dollar im Jahr 1939; Bauer, My Brothers Keeper, S. 258.

323 Arbeitsbericht der Reichsvereinigung der Juden in Deutschland für das Jahr 1939 [MS], Berlin 1940, S. 8.

324 (Vgl. Tabellen im Anhang) Die offene Fürsorge im Vierteljahr April/Juni 1939, (Berlin 1939), S. 8; Die offene Fürsorge im Vierteljahr Juli/Sept. 1939, (Berlin 1939), S. 8. Ende August 1939 gab auch in Bonn das städtische Wohlfahrtsamt jegliche Unterstützung an Juden auf; StadtA Bonn, Pr. 14/1, unfol: Vermerk Amt 70 vom 17. 2. 1940.

325 BA, R 36, Nr. 1022, Bl. 39-40: Fürsorgeamt Frankfurt/Main an DGT am 21. 7. 1939 und am 22. 8. 1939 sowie ebenda, Bl.51: OB Frankfurt/Main an RMdI sowie DGT am 31. 8.1939. 
onsgemeinde in Leipzig erfahren hatte. Das Rundschreiben betonte, daß die Mittel der Reichsvereinigung begrenzt seien: „Wir [die RV, W.G.] haben gebeten, bis zu einer weiteren Regelung, die erst nach Prüfung unserer finanziellen Leistungsfähigkeit wird erfolgen können, einstweilen zu veranlassen, daß die Träger der öffentlichen Fürsorge hinsichtlich der Unterstützung jüdischer Hilfsbedürftiger keine Veränderung gegenüber dem Zustande vor dem Erlaß der Zehnten Verordnung zum Reichsbürgergesetz vornehmen." Die Jüdische Gemeinde Leipzig strebte unter Berufung auf das Rundschreiben an, daß „die Kosten der Anstaltsfürsorge für Juden weiterhin vom Bezirksfürsorgeverband (Fürsorgeamt der Stadt) “ getragen werden sollten. ${ }^{326}$

Nach Rücksprache mit Ministerialrat Ruppert (RMdI) gab am 25. August 1939 jedoch Preiser aus der Sozialabteilung des Deutschen Gemeindetages folgende Weisung aus: Obwohl noch keine letzte Klarheit über die reale Finanzkraft der Reichsvereinigung bestehe, solle die Öffentliche Fürsorge sich jetzt „ohne weitere Verzögerung möglichst ganz von der Unterstützung der Juden freimachen“. Der Gemeindetag empfehle, nicht nach dem Rundschreiben der Reichsvereinigung vorzugehen, ,jedenfalls bräuchten sich die Fürsorgeverbände daran keineswegs gebunden zu fühlen". Preiser bemerkte aber, daß Ministerialrat Ruppert der Auffassung sei, daß noch nicht zu scharf vorgegangen werden solle: „Falls die Zweigstelle der Reichsvereinigung in Leipzig die Unterstützung der Juden in offener Fürsorge restlos übernommen hat, wäre gegen ein Entgegenkommen bei den Kosten der Anstaltsfürsorge keine Bedenken zu erheben. ${ }^{\text {"327 }}$

Das Feilschen der Städte und Gemeinden um Kostenentlastung resultierte aus ihren lokalen finanziellen Interessen. Im Reichsmaßstab bedeutete eine totale Kostenübernahme durch die Reichsvereinigung in dieser Phase allenfalls den sprichwörtlichen Tropfen auf den heißen Stein der Gesamtfürsorgekosten, denn die Öffentliche Fürsorge sah sich in dieser Phase per se durch den allgemeinen wirtschaftlichen Aufschwung finanziell stark entlastet. Im Altreich waren die Bargeldausgaben städtischer und ländlicher Fürsorgeverbände von Ende März 1939 bis Ende September um mehr als zwanzig Millionen Reichsmark auf rund 103,5 Millionen Reichsmark gesunken. Die Ausgaben an Juden nahmen leicht überproportional um $370000 \mathrm{RM}$ ab. Den Löwenanteil dieses Gewinns verzeichneten jene Städte, die nach der Installierung der Reichsvereinigung die Fürsorge an Juden eingestellt hatten.

Unter finanziellen Gesichtspunkten konnte eine Ausgrenzung der Juden deshalb allenfalls auf der lokalen Ebene interessant werden, wenngleich das Einsparungspotential im Verhältnis zu den Gesamtlasten wohl oft nur gering war, wie ein Beispiel aus Berlin zeigt. Hier betreute die städtische Wohlfahrt ja noch Juden in der Offenen Fürsorge. In einem Berliner Bezirk mit geringer jüdischer Bevölkerung hatte sich die Zahl der Armen aller Kategorien von Januar 1939 bis August von knapp 5000 auf rund 3900 vermindert, für die man zwischen April und August noch 600000 RM ausgegeben hatte. Dagegen war die Zahl der jüdischen

326 Ebenda, Bl. 49 u. RS: Geschäftsführ. Direktor DGT Sachsen an DGT Berlin am 14. 8. 1939.

327 Ebenda, BI. 50: DGT Berlin (i. A. Preiser) an DGT Sachsen vom 25. 8. 1939. 
Die Offene Fürsorge im Jahr 1939328

\begin{tabular}{lll}
\hline Städtische BFV & Lauf. Barleistungen in RM & Davon für Juden \\
\hline Am 31. März & 78739000 & 1180000 \\
Am 30. Juni & 71947000 & 1157000 \\
Am 30. September & 67313000 & 798000 \\
\hline
\end{tabular}

Die Offene Fürsorge im Jahr 1939329

\begin{tabular}{lll}
\hline Ländliche BFV & Lauf. Barleistungen in RM & Davon für Juden \\
\hline Am 31. März & 41019000 & 69000 \\
Am 30. Juni & 36768000 & 66000 \\
Am 30. September & 36297000 & 47000 \\
\hline
\end{tabular}

Betreuten annähernd konstant geblieben. Insgesamt hatte das Wohlfahrtsamt für letztere gerade $9445 \mathrm{RM}$ aufgewendet. ${ }^{330}$

Nüchtern analysiert, scheinen die Motive von Stadtverwaltungen und Fürsorgebehörden, jüdische Arme als Gruppe vollständig auszugrenzen und um eine totale Kostenübernahme durch jüdische Stellen zu kämpfen, also immer teils ideologischer, teils finanzieller Natur gewesen zu sein. Das beweist auch ein Vorgang in München. Das dortige Wohlfahrtsdezernat übte im August 1939 Druck auf die Kultusgemeinde aus, ein jüdisches Altersheim einzurichten. Amtsdirektor Ortner argumentierte, dies sei dringend notwendig, ,weil keine Aussicht besteht, daß die alten versorgungsbedürftigen Juden von anderen Ländern aufgenommen werden“. Das von der Kultusgemeinde zu unterhaltende Heim sollte nach dem Willen Ortners "nicht nur möglichst außerhalb des Stadtbereichs, sondern in einer möglichst abgelegenen, vom Fremdenverkehr nicht berührten Gegend“ errichtet werden. „Damit würde erreicht, daß die Juden vollkommen aus der Stadt verschwinden und daß überdies die bisher von den Juden zur Versorgung verwendeten Objekte, nämlich das isr[aelitische] Altersheim an der Klenzestraße, die Lipschütz'sche Versorgungsanstalt und das israelische Pensionat an der Kaulbachstraße anderweitigen Zwecken zugeführt werden könnten." Diese Einrichtungen sollten künftig als Altersheime für "deutsche Volksgenossen“ dienen. Da die Stadt aber der Jüdischen Gemeinde kein Gebäude zur Verfügung stellen wollte, hatte man bereits mit dem Bayerischen Staatsministerium des Innern diskutiert, even-

328 Die offene Fürsorge im Vierteljahr Januar/März 1939, (Berlin 1939), S. 3; Die offene Fürsorge im Vierteljahr April/Juni 1939, (Berlin 1939), S. 3; Die offene Fürsorge im Vierteljahr Juli/Sept. 1939, (Berlin 1939), S. 3.

329 Die offene Fürsorge im Vierteljahr Januar/März 1939, (Berlin 1939), S. 3; Die offene Fürsorge im Vierteljahr April/Juni 1939, (Berlin 1939), S. 3; Die offene Fürsorge im Vierteljahr Juli/Sept. 1939, (Berlin 1939), S. 3.

330 LA (Sta) Berlin, Rep. 47-08, Nr. 113, Bl. 29RS. 
tuell Einrichtungen der katholischen Kirche zu enteignen, um diese als jüdisches Altersheim zu verwenden. ${ }^{331}$

Die Stadt München zielte also einerseits auf strikte Isolierung der jüdischen Alten, wollte sich andererseits gleichzeitig die Altersheime der Jüdischen Gemeinde aneignen. Mit der Gründung der Reichsvereinigung, die eine separate Fürsorge für die jüdische Bevölkerung organisieren und finanzieren sollte, erhielt der Zwangstransfer der Fürsorgepflicht im Sommer 1939 zwar neuen Schub, konnte jedoch trotzdem nicht in allen Städten und Gemeinden abgeschlossen werden.

\section{Exkurs: Fürsorge und Judenverfolgung in Wien Ende 1938 - Ende 1939}

Die Zahl jüdischer Einwohner hatte sich in Wien bis zum Ende des Jahres 1938 auf rund 120000 vermindert. Das war nicht zuletzt eine Folge des Novemberpogroms, der in Wien als einer der gewalttätigsten im NS-Staat angesehen werden muß. Nach dem Ende des Pogroms registrierte man mehr als 27 Tote, 42 gebrandschatzte Bethäuser, viele zerstörte Bet- bzw. Lernstuben, 4000 gesperrte Geschäfte, geplünderte Ausspeisungsstellen und Wohlfahrtseinrichtungen, außerdem mehrere Tausend Verhaftete. Die Armut in der jüdischen Bevölkerung wuchs jetzt noch einmal rapide. Haushaltsvorstände waren geflüchtet oder verhaftet. Wohnungen mußten aufgegeben werden. ${ }^{332}$

Die Wiener Kultusgemeinde verfügte kaum noch über Einnahmen. Insgesamt verzeichnete die Fürsorge der Kultusgemeinde am Ende des Jahres 1938 ein Defizit von 2 Millionen RM. Die Ausgaben für Ausspeisung betrugen 745000 RM, für Geschlossene Fürsorge 1,1 Millionen RM und für die Offene Fürsorge 1,6 Millionen RM. Dem standen aber nur Einnahmen in Höhe von 1,4 Millionen RM aus der Geschlossenen Fürsorge und aus Spenden gegenüber. ${ }^{333}$ Der Sicherheitsdienst der SS verpflichtete die Kultusgemeinde, die „zur Erhaltung der mittellosen Juden und der Förderung der Auswanderung notwendigen Devisenbeträge von ausländischen jüdischen Organisationen" zu beschaffen. ${ }^{334}$ Doch die Israelitische Kultusgemeinde sah sich vor ständig neue Herausforderungen gestellt. Der Leiter der Judenabteilung bei der Wiener Gestapo, der nicht wie die Mitarbeiter der Zentralstelle strategisch auf die Funktionsfähigkeit der jüdischen Einrichtungen achtete, hatte ihr im Herbst 1938 im Beisein eines Beamten des Wiener Magistrats mitgeteilt, daß alle jüdischen Patienten in öffentlichen Spitälern von den „arischen“ Kranken abgesondert werden müßten. Er verlangte, daß die Kultusgemeinde künftig diese Patienten allein versorgen solle. Die Jüdische Gemeinde verfügte zwar über die organisatorischen Voraussetzungen, nicht aber über die notwendigen Finanzen. Der Leiter der Kultusgemeinde, Löwenherz, machte die Gestapo

331 YV Jerusalem, M1DN, Nr. 109, Bl. 20-21: Stadt München/Dez. 6 an Dez. 7 am 14. 8. 1939.

332 Ausführlicher dazu Gruner, Zwangsarbeit und Verfolgung, S. 67-72.

333 CAHJP Jerusalem, A/W, Nr. 165/1, Bl. 262-265: Bericht der IKG Wien an die Gestapo Wien vom 27.1.1939.

334 Die Judenpolitik des SD, S. 196, Dok. Nr. 32: Lagebericht des SD-II 112 für das Jahr 1938. 
darauf aufmerksam, daß selbst das Problem fehlender Altenheime noch ungelöst sei. ${ }^{335}$ Die Stadt Wien legte zusätzlich noch die Vormundschaften über 200 uneheliche jüdische Kinder nieder. Viele Kinder mußten deshalb die städtischen Heime verlassen. Die jüdischen Heime waren überfüllt. 336

Die Stadt Wien hatte inzwischen ihre Fürsorge bei Juden in weiten Bereichen eingestellt. Sie zahlte in der Offenen Fürsorge offenbar lediglich noch für wenige Gruppen, außerdem für die Geschlossene Fürsorge. ${ }^{337}$ Unter Berufung auf die neu erschienene Fürsorgeverordnung kämpfte die Kultusgemeinde seit Ende des Jahres 1938 darum, daß die Stadt Wien - in Angleichung an die Verhältnisse im Altreich - wenigstens die „Vergütung der Kurkosten“ für wohlfahrtsbedürftige jüdische Kranke im jüdischen Spital übernehme. Man bat Eichmanns Zentralstelle, den Magistrat zu überzeugen, der Kultusgemeinde auch für ihre Winterhilfsaktion sowie für die laufende Fürsorge Zuschüsse zu geben. Ohne kommunale Mittel seien eine Fortsetzung der Tätigkeit und ein Ausbau der Fürsorge im Sinne der behördlichen Weisungen nicht realisierbar. ${ }^{338}$

Vom 1. bis 22. Januar 1939 gab die Kultusgemeinde Wien 152000 RM in ihrer Offenen Fürsorge aus, entweder als periodische Leistungen, als Pflegegelder oder als Mieten. Bis Ende Januar sollte dieser Betrag auf rund 200000 RM steigen. Hauptgründe für das Anwachsen der Ausgaben waren die Verarmung durch das Erwerbsverbot, die Emigration von Familienvorständen, die erzwungene Räumung von Wohnungen, die Verhaftung von Angehörigen und die zwangsweise Ansiedlung Tausender Familien aus der Provinz in der österreichischen Hauptstadt. ${ }^{339}$ Die Hauptaufgaben der Kultusgemeinde hießen zu Beginn des Jahres 1939: 1. Förderung der Emigration, 2. Fürsorge für die auf ihre Auswanderung wartenden Familien und 3. die Sorge um die zurückbleibenden Alten und Siechen. Immer mehr Arme mußten mit Lebensmitteln unterstützt werden. Erich Feier beschreibt diese Entwicklung in seiner Familie: „Wir hatten zwar immer in sehr bescheidenen Verhältnissen gelebt, waren aber nie auf Wohltätigkeit angewiesen.

335 CZA Jerusalem, S 26, Nr. 1191g, unfol.: Bericht IKG Wien 1938- 1944/45 (LöwenherzBericht), S. 4.

336 Bericht Franzi Löw, seit 1937 Fürsorgerin der IKG Wien, in: Jüdische Schicksale. Berichte von Verfolgten, hrsg. vom Dokumentationsarchiv des österreichischen Widerstandes, Wien 1992, S. 187. In der Geschlossenen Fürsorge unterhielt die IKG Wien ein Altersheim, ein Krankenhaus, vier Waisenhäuser, ein Kinderambulatorium, fünf Kindergärten, zwei Mädchenheime, ein Blindeninstitut, einen Kinderhort, eine Tagesheimstätte und ein Lehrlingsheim; CAHJP Jerusalem, A/W, Nr. 165/1, Bl. 262-265: Bericht IKG Wien an die Gestapo Wien vom 27.1.1939.

337 Für den Zwangstransfer in Wien konnte kein konkretes Datum ermittelt werden. Ein weitgehender Ausschluß der österrreichischen Juden aus der Offenen Fürsorge zum 1. 1. 1939 mit dem Inkrafttreten der Fürsorge-Verordnung ergibt sich aus diversen Dokumenten und den im folg. geschilderten Petitionen der Kultusgemeinde an die Stadtverwaltung.

338 CAHJP Jerusalem, A/W, Nr. 165/1, Bl. 80: IKG Wien-Wochenbericht vom 3.1.1939, S. 30.

339 Allein im Dezember 1938 kamen fast 6000 Familien aus der Provinz. In diesen Wochen gewährte die IKG auch vielen Armen eine Zusatzunterstützung für die Bezahlung der Gebühren zur Ausfertigung der Kennkarten; ebenda, Bl. 259-261: Bericht IKG Wien an die Gestapo Wien vom 27. 1. 1939. 
Jetzt waren wir es: Gegenüber unserer Wohnung befand sich eine jüdische Ausspeisung. Eine Zeitlang zögerten wir, als das Geld immer knapper wurde, haben wir uns dort eintragen lassen und uns täglich das Mittagessen abgeholt, die einzige warme Mahlzeit am Tag. Aus schaffenden Menschen waren wir zu Bettlern geworden. “ ${ }^{340}$ In 16 Wiener Ausspeisungsstellen erhielten im Januar 1939 inzwischen täglich rund 20000 Menschen eine warme Mahlzeit. ${ }^{341}$

Entwicklung der Ausspeisungen bei der IKG Wien W42 $^{32}$

\begin{tabular}{lrll}
\hline & Personen & & Personen \\
\hline 1938 & & & \\
März & 3789 & September & 13323 \\
April & 8274 & Oktober & 14217 \\
Mai & 9951 & November & 16067 \\
Juni & 10995 & Dezember & 18274 \\
Juli & 11259 & 1939 & \\
August & 11488 & Januar & 20730 \\
\hline
\end{tabular}

Zusätzlich zu den Ausspeisungen versorgte die Kultusgemeinde weit über 1500 Juden im jüdischen Spital, in den Waisenhäusern sowie in ihren Alten- und Blindenheimen mit Essen. War der Umfang dieser Versorgungsleistungen extrem angestiegen, so wuchsen gleichzeitig auch die Schwierigkeiten beim Kauf der hierfür benötigten Lebensmittel. Der Reichsnährstand hatte nämlich die „Lieferung bestimmter Artikel in größeren Mengen an jüdische Abnehmer" verboten. Daher mußte die Kultusgemeinde bei Zucker und Gemüse Einzelhandels- statt Großhandelspreise bezahlen. ${ }^{343}$

Von jüdischen Woblfabrtsküchen täglich versorgte Personen ${ }^{344}$

\begin{tabular}{lllll}
\hline 1939 & Januar & Mai & Juli & September \\
\hline Österreich & 22227 & 36207 & 34206 & 34195 \\
Deutschland & 23308 & 32000 & - & \\
\hline
\end{tabular}

340 Bericht Erich Feier, in: Jüdische Schicksale, S. 122.

341 Die Zahl der ausgegebenen Portionen war von 28111 im März 1938 auf 533176 im Januar 1939 gestiegen; CAHJP Jerusalem, A/W, Nr. 165/1, Bl. 256-258: Bericht der IKG Wien an die Gestapo Wien vom 27. 1. 1939.

342 Ebenda, Bl. 258.

343 Ebenda, Bl. 258-259.

344 Angaben nach Bauer, My Brothers Keeper, S. 257; sowie CAHJP Jerusalem, A/W, Nr. 129, unfol.: Undat. Bericht der IKG Wien für den Joint (in engl., Nov. 1939). 
Im Januar 1939 unterstützte die IKG Wien über 21000 Personen mit Fürsorgemitteln. ${ }^{345}$ Nur die rasche Auswanderung verhinderte vorerst ein weiteres Ansteigen der Bedürftigen. Aufgrund der pressierenden Finanzlage richtete am 24. Januar die Kultusgemeinde Wien schließlich an die Leitung der Magistratsgruppe I noch einmal eine ausführliche Petition: $D a$ die Jüdische Gemeinde zu einer Unterstützung der Masse der jüdischen Armen nicht mehr in der Lage sei, möge die Stadt Wien, im Sinne der vom Reichsstatthalter am 19. Dezember 1938 für Österreich bekanntgemachten Verordnung über die öffentliche Fürsorge der Juden, für „jüdische Fürsorgezwecke aus öffentlichen Mitteln einen entsprechenden Beitrag" bewilligen. Nach Paragraph 35 der Reichsfürsorgeverordnung wäre dieser vorrangig für Unterkunft, Kleidung und Krankenpflege zu verwenden. Es ging hier also um die Offene Fürsorge. Da die finanzielle Basis des jüdischen Spitals infolge der Ablehnung einer direkten Verrechnung durch mehrere Krankenkassen ebenfalls gefährdet sei, schlug die Jüdische Gemeinde zusätzlich vor, die „krankenanstaltsmäßige Versorgung der Juden" nach dem Berliner Modell zu regeln. ${ }^{346}$ Die Berliner Regelung beinhaltete, alle hilfsbedürftigen jüdischen Patienten nur noch in jüdischen Krankenhäusern zu behandeln, die Kosten aber von der Stadt begleichen zu lassen. ${ }^{347}$ Löwenherz verhandelte am 28 . Februar 1939 sogar persönlich noch einmal mit Bürgermeister Neubacher über einen städtischen Kostenbeitrag für die im jüdischen Spital behandelten unbemittelten Personen, außerdem über die Vergütung der „Aufenthaltskosten für Pfleglinge des Altersheimes der Israelit[itischen] Kultusgemeinde“, für welche die städtische Fürsorge zuständig sei. $^{348}$

Gerade die Versorgung der Alten und Siechen erforderte umfangreiche Mittel, die unter den aktuellen Bedingungen unmöglich aufgebracht werden konnten. ${ }^{349}$ Die 485 Plätze im Altersheim Seegasse galten als belegt, doch 2000 Menschen bewarben sich bereits um weitere Plätze. Die Jüdische Gemeinde schlug der Gestapo vor, eine „Versorgungsanlage“ für 3000 bis 4000 Alte zu errichten, um die Emigration jüngerer Familienmitglieder nicht durch das „ungewisse Schicksal ihrer greisen Eltern" zu hemmen. Diese Anlage solle die Stadt bauen und die Kultusgemeinde verwalten. Als Gegenleistung könne die Kommune doch Stiftungsgelder erhalten, die zum Teil der Jüdischen Gemeinde gehörten, zum Teil vom Stillhaltekommissar beschlagnahmt worden waren. Die Alternative einer Privatunterbringung der jüdischen Alten und Siechen schied für die Jüdische Gemeinde angesichts von der Stadt radikal betriebener Wohnungskündigungen aus. 350

345 Ebenda, Nr. 106, unfol.: Tätigkeitsbericht IKG Wien 13. 3. - 31. 12. 1938, S. 18.

346 Ebenda, Nr. 165/1, Bl. 264-267: Bericht IKG Wien an die Gestapo Wien vom 27. 1. 1939 sowie ebenda, Nr. 165/3, Bl. 100: Bericht IKG Wien über Tätigkeit in den ersten drei Monaten des Jahres 1939 (undat.).

347 Dienstblatt der Stadt Berlin, 1938 Teil VII, S. 121, Nr. 111: Vfg. Plath (i.V. OB) vom 8. 4. 1938; vgl. Gruner, Judenverfolgung in Berlin, S. 48.

348 CAHJP Jerusalem, A/W, Nr. 165/3, Bl. 100: Bericht IKG Wien über Tätigkeit in den ersten drei Monaten des Jahres 1939 (undat.).

349 Ebenda, Nr. 165/3, Bl. 68: Bericht IKG Wien an Zentralstelle vom 20. 3. 1939, S. 2.

350 Ebenda, Nr. 165/1, Bl. 262-265: Bericht der IKG Wien an die Gestapo Wien vom 27. 1. 1939. Für die Unterbringung hatte die IKG bisher das ehemalige Waisenhaus Gold- 
Im Monat März 1939 versorgte die jüdische Fürsorge trotz einer anhaltenden Emigrationswelle immer noch rund 20000 Personen. Die Kultusgemeinde Wien verhandelte deshalb mit der Stadt Wien weiter über die Kostenübernahme bei den Altenheimen und in der Offenen Fürsorge. ${ }^{351}$ Die Stadt versorgte in der Offenen Fürsorge nur einen Bruchteil der tatsächlich jüdischen Bedürftigen, nicht einmal mehr 3000 Parteien. ${ }^{352}$ (Vgl. folg. Tabelle) Diese Bedürftigen rekrutierten sich möglicherweise aus den noch geschützten Gruppen, den Schwerkriegsbeschädigten Juden, den Juden in „Mischehen“ und den ausländischen Juden. Gleichzeitig wurden die noch aus öffentlichen Mitteln unterstützten Juden in den kommunalen Wohlfahrtsanstalten separiert. Das ordnete am 22. Juni 1939 der Leiter des Städtischen Hauptverwaltungs- und Organisationsamtes an. Anlaß war eine Beschwerde beim Gauleiter, daß im Obdachlosenasyl Auslandsdeutsche in den gleichen Räumen mit Juden und „Asozialen“ untergebracht seien und gemeinsam mit diesen zu Arbeiten herangezogen werden würden. 353

Die Diskrepanz zwischen der Zahl der von der Öffentlichen Fürsorge und der von der jüdischen Wohlfahrt versorgten Juden gestaltete sich immer krasser. Die monatlichen Kosten der Jüdischen Gemeinde beliefen sich mittlerweile auf das doppelte der Ausgaben der städtischen Fürsorge an jüdische Bedürftige im ganzen Quartal. Allein im Juli 1939 betrugen die Gesamtausgaben der Kultusgemeinde für Wohlfahrt, für Alte und Kranke sowie für die Suppenküchen 720000 RM. ${ }^{354}$

Von der Öffentlichen Fürsorge unterstützte Parteien in Wien ${ }^{355}$

\begin{tabular}{lll}
\hline 1939 & Zahl & Kosten im Quartal \\
\hline 31. März & 2790 & $138800 \mathrm{RM}$ \\
30. Juni & 2731 & $131300 \mathrm{RM}$ \\
30. September & 2826 & $139800 \mathrm{RM}$ \\
\hline
\end{tabular}

schlagstraße, ein Gebäude des Talmud-Thoravereins in der Malzgasse 16, das Hotel Barschak und das Schulgebäude Wasnerstraße zugeteilt erhalten; ebenda, Nr. 165/3, Bl. 101: Bericht IKG Wien über Tätigkeit in den ersten drei Monaten des Jahres 1939 (undat.).

351 Ebenda, Bl. 67-68: Bericht IKG Wien an Zentralstelle vom 20. 3. 1939, S. 1-2.

352 Die offene Fürsorge im Vierteljahr Januar-März 1939, (Berlin 1939), S. 4; Die offene Fürsorge im Vierteljahr April-Juni 1939, (Berlin 1939), S. 4

353 Wiener StadtA und LA, MD (HVO), Nr. 946/1939, unfol.: Vfg. Leiter HVO am 22. 6.1939.

354 Ohne Unterstützung von Emigranten; ebenda.

355 Die offene Fürsorge im Vierteljahr Januar/März 1939 (Ergebnisse des Schnelldienstes der Reichsfürsorgestatistik), (Berlin 1939), S. 5; Die offene Fürsorge im Vierteljahr April/Juni 1939, (Berlin 1939), S. 5; Die offene Fürsorge im Vierteljahr Juli/Sept. 1939, (Berlin 1939), S. 5 . 
Von jüdischen Fürsorgestellen in bar unterstützte Juden in Wien 356

\begin{tabular}{lll}
\hline 1939 & Zahl & Kosten im Monat \\
\hline Juli & 20489 & 263799 RM \\
August & 22961 & 286267 RM \\
September & 31364 & 167077 RM \\
\hline
\end{tabular}

Nur aufgrund dieser extrem angespannten finanziellen Situation behielten in Österreich die Jüdischen Gemeinden die Eigenschaft, Körperschaften des öffentlichen Rechts zu sein, und damit alle Steuervorteile, während im Altreich alle Gemeinden seit März 1938 per Gesetz zu Vereinen degradiert worden waren. Am 1. November 1938 hatte das Reichsfinanzministerium den Reichskirchenminister gemahnt, für die Einführung des entsprechenden Gesetzes in Österreich zu sorgen, damit die jüdischen Gemeinden auch hier alle Steuervorteile verlören. ${ }^{357}$ Der SD konnte dies jedoch aufgrund seiner starken Stellung in Wien blockieren. Die Gründe lieferte der RFSS und Chef der Deutschen Polizei dem Reichskirchenminister, als er diesen am 25. Mai 1939 bat, die Einführung des Gesetzes etwa noch anderthalb bis zwei Jahre aufzuschieben: Die „fürsorgerische Tätigkeit“ der Wiener Kultusgemeinde wäre durch diese einschneidende Steuerbelastung gefährdet und „ein Großteil der Juden in der Ostmark würde der öffentlichen Fürsorge zur Last fallen“. Nach Mitteilung der Zentralstelle Wien würden außerdem - im Falle der Einführung des Gesetzes - die ausländischen Organisationen ihre Devisenzahlungen einstellen, damit käme die Auswanderung praktisch zum Erliegen. Da offenbar auch der Stellvertreter des Führers zustimmte, der bereits am 14. April 1939 über die außerordentlichen Widerstände gegen das geplante antijüdische Gesetz informiert worden war, konnte man den Aufschub durchsetzen. 358

$\mathrm{Da}$ dies allein die akuten Probleme nicht löste, hatte man unterdessen im Mai 1939 innerhalb des Berliner SD-Judenreferats aber auch diskutiert, die der Wiener Zentralstelle zur Verfügung stehenden Gelder, insgesamt 2,75 Millionen RM, zur Finanzierung der Auswanderung und der jüdischen Altershilfe zu verwenden. Das nur für den Inspektor der Sicherheitspolizei und für Eichmann zugängliche Konto mit den den Juden abgepreßten Geldern war ein Geheimfonds, denn Abgaben erfolgten weder an das Reichsfinanzministerium noch an andere Reichsstellen. ${ }^{359}$ Eichmann selbst wandte sich in Wien Anfang August mit Geldforderungen auch an Reichskommissar Bürckel: „Durch die Auswanderung der jungen und noch arbeitsfähigen Juden, die vielfach alte unbemittelte Angehörige zurücklassen müssen, fallen letztere der Israelitischen Kultusgemeinde zwecks Betreuung zur Last. Die Zahl dieser mittellosen, auf Aussterbe-Etat gesetzten Juden wird in kür-

356 CAHJP Jerusalem, A/W, Nr. 129, unfol.: Bericht IKG Wien für Joint (engl., Nov. 1939).

357 ÖStA/AdR Wien, Bürckel-Mat., Nr. 1762/1, unfol.: RFM (Hedding) an RKM am 1. 11.1938.

358 Ebenda: RFSSuCdS (S-PP II B) an RKM am 25. 5. 1939.

359 YV Jerusalem, 051/OSOBI, Nr. 35 (Moskau 500.1.625), Bl. 133: Vermerk SD II 112 (Hagen) vom 16. 5. 1939; auch in: BA, R 58, Nr. 486, Bl. 53. 
zester Zeit schätzungsweise 5000 betragen." Eichmann betonte, daß die Kultusgemeinde Wien nur über 826 Betten in vier Heimen verfüge. Die Stadt Wien habe zusätzlich 370 Betten in kommunalen Altersheimen bereitgestellt. Notwendig für eine "geschlossene Befürsorgung" seien größere Heimobjekte und für deren $\mathrm{Be}-$ trieb ausreichende Geldmittel. Eichmann schlug dem Reichskommissar vor, aus dem vom Stillhaltekommissar beschlagnahmten Vermögen jüdischer Stiftungen und Institutionen in Höhe von über 10 Millionen RM jetzt Mittel zur „Sicherung der unumgänglich notwendigen jüdischen Alters- und Siechenfürsorge" freizugeben. Von den 10 Millionen hatte die Kultusgemeinde nur knapp zwei Millionen erhalten und zwei Millionen seien für die Einrichtung einer Stiftung für jüdische Fürsorge verwendet worden. Über 1,8 Millionen RM waren aber als Aufbau-Umlagen an die NSDAP geflossen, $690000 \mathrm{RM}$ an die Aufbaufonds-Vermögensverwaltungs $\mathrm{GmbH}$ Wien sowie 5,7 Millionen an nichtjüdische Körperschaften und Gemeinden. Die Aufbau-Umlagen, die Gelder des Aufbaufonds sowie die Mittel der Stiftung für jüdische Fürsorge sollten nun zweckgebunden der Zentralstelle zur Verfügung gestellt werden. ${ }^{360} \mathrm{Als}$ Bürckel das Dokument gesehen hatte ${ }^{361}$, erhielt Eichmann jedoch eine gerade zu empörte Antwort aus dem Reichskommissariat. Dort sah man überhaupt nicht ein, "warum ausgerechnet Vermögenswerte der Partei und ihrer Gliederungen für jüdische Auswanderung eingesetzt werden sollen“. Besser bestreite die Zentralstelle die Unkosten „aus dem Erlös der seinerzeit von den geflüchteten Juden beschlagnahmten Vermögenswerte“ “. ${ }^{362} \mathrm{Da}$ weder die Verhandlungen mit dem Reichskommissar noch die Unterredungen mit der Stadtverwaltung ein Ergebnis zeitigten, sahen sich Eichmann und seine Wiener Zentralstelle schließlich bei Kriegsbeginn genötigt, $380000 \mathrm{RM}$ aus den von emigrierten Juden bezahlten „Paßumlagen“ freizugeben, um die Arbeit der jüdischen Fürsorge abzusichern. ${ }^{363}$ Nach der zentralen Entscheidung, deutsche und österreichische Juden künftig nach Polen zu deportieren, änderte der Stellvertreter des Führers nun auch seine Haltung zum Gesetz über die jüdischen Gemeinden in Österreich. Denn das bisherige Gegenargument einer Förderung der Zwangsemigration war damit entfallen. ${ }^{664}$

Obwohl der neugegründeten Reichsvereinigung auf dem Papier auch die österreichischen Juden als $Z$ wangsmitglieder angehörten, war dies in der Praxis nicht der Fall und offenbar auch nicht notwendig. Die Zentralstelle Eichmanns überwachte seit langem die Wiener Kultusgemeinde und ihre Fürsorgemaßnahmen weit strikter, als dies bei den Jüdischen Gemeinden im Reich durch die Gestapo der Fall war. Gelang es der Zentralstelle auf Reichsebene den drohenden Verlust von Steuervorteilen aufzuhalten, um die soziale Versorgung der jüdischen Bevöl-

360 ÖStA/AdR Wien, Bürckel-Mat., Nr. 1762/2, Bl. 6-8: Eichmann an RK Bürckel am 4. 8. 1939. Abdruck bei Rosenkranz, Verfolgung, S. 196-197.

361 Vgl. Paraphe Bürckels auf dem Dokument; ÖStA/AdR Wien, Bürckel-Mat., Nr. 1762/2, Bl. 6-8: Eichmann an RK Bürckel am 4. 8. 1939.

362 Ebenda, Bl. 9 u. RS: Reichsamtsleiter Hoffmann an Zentralstelle am 21. 8. 1939.

363 CZA Jerusalem, S 26, Nr. 1191g, unfol.: Bericht IKG Wien 1938- 1944/45 (LöwenherzBericht), S. 15.

364 ÖStA/AdR Wien, Bürckel-Mat., Nr. 1762/1, unfol.: Reichsstatthalterei Wien an Zentralstelle am 25. 11. 1939. 
kerung nicht zu gefährden, so war sie in den Verhandlungen mit dem Reichskommissar und der Kommune Wien weit weniger erfolgreich. Die Stadt ließ sich offenbar bis auf einige kleinere Kompromisse nicht davon abhalten, jüdische $\mathrm{Be}-$ dürftige aus der Öffentlichen Fürsorge auszuschließen. Hatte bis zum Kriegsbeginn die Zentralstelle vor allem die Vertreibung forciert, so diskutierte man beim Reichskommissar wie auch in der Stadtverwaltung schon vor Kriegsbeginn Pläne, alle jüdischen Männer und Frauen in Barackenlager „umzusiedeln“ und sie ausnahmslos Zwangsarbeit verrichten zu lassen. Nach Kriegsbeginn betrieben alle österreichischen Instanzen die Verfolgung der Juden immer stärker gemeinsam mit dem Ziel, diese rasch aus Wien nach Polen entfernen zu können. ${ }^{365}$

$* * *$

Wie eingangs in diesem Kapitel geschildert, wurde während des Pogroms im November 1938 die Infrastruktur vieler jüdischer Wohlfahrtseinrichtungen zerstört. Kurz nach dem Pogrom stoppten die Fürsorgeämter in Nürnberg und München bereits die Versorgung jüdischen Armer, ohne daß eine gesetzliche Regelung vorlag. In den Diskussionen nach dem Pogrom entschied dann die NS-Führung, die seit dem Sommer 1938 vorbereitete Verordnung über den Ausschluß der jüdischen Armen von der Öffentlichen Fürsorge als ein Grundelement ihrer neuen Verfolgungspolitik zu erlassen, die eine vollkommene Isolierung der jüdischen Bevölkerung vorsah. Die Verordnung des Reichsinnenministeriums erschien am 19. November 1938 und bestimmte, alle jüdischen Armen seien künftig an die jüdischen Wohlfahrtsstellen zu verweisen. Nur wenn deren Mittel nicht ausreichten, sollte die Öffentliche Wohlfahrt helfen. Führte schon die Verkündigung der Verordnung dazu, daß Wohlfahrtsämter in einigen Städten Juden nicht mehr betreuten, so kam es seit ihrem Inkrafttreten am 1. Januar 1939 zu einer ganzen Welle lokaler Ausschlußmaßnahmen.

Jüdische Wohlfahrtsempfänger wurden ab 1939 von den Fürsorgeverbänden für die Reichsfürsorgestatistik landesweit erfaßt. In den Großstädten richtete man Sonderdienststellen für ihre separate Betreuung ein. Der geplante Zwangstransfer der staatlichen Fürsorgepflicht an die Jüdischen Gemeinden stieß jedoch in vielen Orten auf Hindernisse. Die jüdischen Einrichtungen verfügten oft weder über die organisatorischen noch die finanziellen Voraussetzungen, eine separate Grundversorgung für alle jüdischen Armen zu gewährleisten. Einige Städte "arisierten“ zudem noch ohne Skrupel mildtätige ,jüdische "Stiftungen, die für ein Funktionieren einer separaten Fürsorge unabdingbar waren. Die Gestapo, die im Rahmen des neuen Verfolgungsprogramms die jüdischen Einrichtungen kontrollierte, blockierte deshalb in einer Reihe von Städten den Totalausschluß der jüdischen Bedürftigen aus der Fürsorge. In Verhandlungen mit den Kommunen und den Jüdischen Gemeinden wurden unterschiedlichste Modi der Organisation und Finanzierung der Versorgung bedürftiger Juden vereinbart. Ob Übernahme der Offenen oder der Geschlossenen Fürsorge durch jüdische Stellen, ob Zahlung

365 Ausführlich dazu: Gruner, Zwangsarbeit und Verfolgung, S. 93-141. 
eines monatlichen Beitrages durch die Stadt oder die Jüdische Gemeinde, die Absprachen waren vielgestaltig, denn die von den Städten erwarteten zentralen Ausführungsbestimmungen zur Fürsorge-Verordnung erschienen nicht. Die konkreten Details des Umfangs und des Zeitpunktes des Zwangstransfers hingen vom Engagement der Kommunen und Fürsorgeträger ebenso ab, wie von den lokalen Kräfteverhältnissen zwischen Stadt und Gestapo. Die uneinheitlich organisierte lokale Praxis wurde in den regionalen Arbeitsgemeinschaften für Wohlfahrtspflege und im Wohlfahrtsausschuß des Deutschen Gemeindetages von Bürgermeistern und Fürsorgedezernenten diskutiert und koordiniert. Einig war man sich unter den Fürsorgebeamten über die grundsätzliche Separierung der jüdischen Bevölkerung. Das Reichsinnenministerium bestimmte im Juli 1939, daß alle jüdischen Fürsorgezöglinge nur noch in jüdischen Anstalten unterkommen sollten, wie zuvor von lokaler Seite gefordert. Bei Insassen von öffentlichen Heil- und Pflegeanstalten drängten Fürsorgeverbände sogar auf die Konzentration in einer separaten jüdischen Anstalt. Da den Jüdischen Gemeinden Gelder und Gebäude für solche Heime fehlten, unternahmen Stettin und Württemberg eigene Schritte zur Separierung jüdischer Patienten in öffentlichen Anstalten.

Wenn die Öffentliche Wohlfahrt in der Offenen Fürsorge noch unterstützte, dann nur gegen die Ableistung von unbezahlter Pflichtarbeit, meist ohne die üblichen Zulagen. Sogar nach dem lokalen Übergang der Fürsorgepflicht auf Jüdische Gemeinden rekrutierten Städte wie Leipzig, Mainz und München Juden illegalerweise weiter für unbezahlte kommunale Pflichtarbeiten. Mit der formellen Gründung der Reichsvereinigung im Juli 1939, die hierdurch zum offiziellen Träger eines separaten jüdischen Fürsorgewesens wurde, erreichte der lokale Ausschlußprozeß, vor allem in der Offenen Fürsorge, einen neuen Höhepunkt. Bisherige lokale Kompromisse wurden von städtischer Seite aufgekündigt und Juden an die jüdische Wohlfahrt verwiesen. Unter Berufung auf die Zuständigkeit der Reichsvereinigung für die jüdische Wohlfahrt drängte der Deutsche Gemeindetag nun erstmals die Städte, sich umgehend von der jüdischen Armenklientel zu befreien. Infolge dieser neuen Konstellation forderten immer mehr Kommunen sogar bereits eine vollständige Erstattung ihrer Kosten. Bis Ende August 1939 hatten im Altreich von 20 Großstädten zwölf jede Leistung der Offenen Fürsorge an jüdische Arme eingestellt, die restlichen oft in anderen Wohlfahrtsbereichen, wie Berlin in der Geschlossenen Fürsorge. Ähnlich sah die Situation in Österreich aus. Während die jüdische Wohlfahrt trotz akuter Finanznot inzwischen rund 30000 Arme versorgte, betreute das Wohlfahrtsamt der Stadt Wien nur noch knapp 3000 jüdische Parteien, offenbar lediglich kriegsbeschädigte und ausländische Juden sowie Juden in Geschlossener Fürsorge. Obwohl die Zentralstelle Eichmanns über eine starke Stellung im lokalen Behördensystem verfügte, gelang es ihr für eine Finanzierung der Offenen jüdischen Fürsorge weder bei der Stadtverwaltung noch beim Reichskommissar Zugeständnisse zu erreichen. 